\title{
Development of Thermal Management Strategies Using Cylinder Deactivation for Low-Load Operation in Heavy-Duty Diesel Trucks
}

Christian M. Hushion

West Virginia University, ch0036@mix.wvu.edu

Follow this and additional works at: https://researchrepository.wvu.edu/etd

Part of the Automotive Engineering Commons, and the Heat Transfer, Combustion Commons

\section{Recommended Citation}

Hushion, Christian M., "Development of Thermal Management Strategies Using Cylinder Deactivation for Low-Load Operation in Heavy-Duty Diesel Trucks" (2021). Graduate Theses, Dissertations, and Problem Reports. 8228.

https://researchrepository.wvu.edu/etd/8228

This Thesis is protected by copyright and/or related rights. It has been brought to you by the The Research Repository @ WVU with permission from the rights-holder(s). You are free to use this Thesis in any way that is permitted by the copyright and related rights legislation that applies to your use. For other uses you must obtain permission from the rights-holder(s) directly, unless additional rights are indicated by a Creative Commons license in the record and/ or on the work itself. This Thesis has been accepted for inclusion in WVU Graduate Theses, Dissertations, and Problem Reports collection by an authorized administrator of The Research Repository @ WVU. For more information, please contact researchrepository@mail.wvu.edu. 


\title{
Development of Thermal Management Strategies Using Cylinder Deactivation for Low-Load Operation in Heavy-Duty Diesel Trucks
}

\section{Christian Hushion}

\author{
Thesis Submitted to the Benjamin M. Statler College of Engineering \\ and Mineral Resources at West Virginia University
}

in partial fulfillment of the requirements for the degree of

\author{
Master of Science \\ in \\ Mechanical Engineering \\ Arvind Thiruvengadam, Ph.D., Chair \\ Marc Besch, Ph.D. \\ Derek Johnson, Ph.D., PE \\ Gregory Thompson, Ph.D. \\ Department of Mechanical and Aerospace Engineering \\ Morgantown, West Virginia \\ 2021
}

Keywords: Diesel Engine, Cylinder Deactivation, Low-Load Emissions Control, Engine Calibration, Exhaust Thermal Management

Copyright 2021 Christian Hushion 


\section{Abstract}

\section{Development of Thermal Management Strategies Using Cylinder Deactivation for Low-Load Operation in Heavy-Duty Diesel Trucks}

\section{Christian Hushion}

Cylinder deactivation (CDA) has been used in gasoline engines, for decades, as a strategy for fuel consumption reduction. The idea of CDA in the heavy-duty diesel (HDD) engine sector has gained traction as a pathway to fuel efficient thermal management strategy. Oxides of nitrogen (NOx) control has been a major focus over the last decade and maintaining conducive aftertreatment temperatures is a major design aspect. HDD original equipment manufacturers (OEM) have developed a variety of thermal management strategies which almost all revolve around large fuel penalties. The goal of all of these strategies is for thermal management of the diesel particulate filter (DPF) and the selective catalytic reduction (SCR) systems.

Low-load duty cycles are a target area of thermal management due to insufficient SCR temperatures for NOx conversion after extended time in these operating regions. Operation inside of this low temperature window include: stop and go, creep mode, downhill coasting and extended idle. In these load scenarios, typical operation is below $30 \%$ rated torque of the engines. Studies have shown that reduction in brake-specific fuel consumption (BSFC) results in small exhaust temperature increase. Significant turbine outlet temperature (TOT) increases have been demonstrated with little to no BSFC penalty.

Implementation of a cost-effective CDA system, developed by Jacobs Vehicle Systems, has been implemented onto a 6-cylinder 15 L HDD engine platform. Each cylinder has individual control capabilities.

The project is focused on reducing fuel penalties associated with thermal management strategies while improving SCR activity. Low-load operation, below 30\% power curve, was targeted due to significant SCR substrate cooling when exhaust gases are below the SCR temperature. By increasing the TOT temperature with CDA, the cooling rate of the SCR will reduce, and in some operating conditions, will add heat to the SCR.

Steady-state testing observed an increase for all turbine outlet and SCR inlet temperatures using CDA. Each $10 \%$ load point resulted in a $1 \%-14 \%$ increase in brake thermal efficiency. Additionally, the fuel benefit varied from a reduction of $8.5 \%$ to an increase of $0.9 \%$ for operating points tested in the CDA window. While cooling effects of motoring were analyzed, total time to cool the SCR increased by $99 \%$ with three cylinders deactivated while motoring the engine 


\section{Acknowledgement}

As a student who transferred to West Virginia University as a sophomore, I never dreamed it would evolve into what occurred. I cannot thank my family enough for always supporting me and pushing me to purse my dreams. I want to specifically thank my mom and dad for their love and sacrifices to help me reach my academic achievements. I also want to thank all my grandparents because without them pursing my academic goals would have never been possible. I cannot thank them all enough for their love and support.

I would like to recognize and thank Dr. Arvind for being an incredible research advisor. Not only has he been a great mentor but he has been even better friend. I cannot thank him enough for his support along the way. Arvind, without you none of this would have been possible. I know I would not have been able to have an experience like this anywhere else. I cannot thank you enough for always pushing me to be the best I could be. You have helped me greatly throughout our time working together, I will carry many things learned from you with me the rest of my life. I would also like to thank Mona for her support alongside Arvind.

As an undergraduate and graduate researcher, I cannot thank enough the people in CAFEE who have helped me along the way. Dr. Marc Besch has been another great mentor for me and I cannot thank him enough for all he did to help me throughout the years. I have enjoyed all of our time working together and am glad Arvind and I were able to keep you safe in South Africa. Dan Carder, without you many of the things I was able to do and experience are not possible. Andrew Melcher specifically I would like to thank. I would still be in the ERC trying to figure out which mysterious wire become unplugged which made the whole lab shut down. 
You have been great to work with and an even better friend. Allen Duffy, you have also been a great friend and coworker, I always enjoyed working with you. Stephen, Dylan and Jason thank you for always supporting me and providing a helping hand. To the rest of the people at CAFEE I have enjoyed our time together and all the memories we share. I cannot thank you all enough for the help and support. Dr. Rasik Pondicherry and Filiz Kazan, thank you both for your help conducting my research. Much of my work could not have been accomplished without you. Both of you have been great friends throughout our time together.

I also would like to thank Dr. Thompson and Dr. Johnson for being members of my committee. The amount of time that you both put into vetting this document is greatly appreciated.

West Virginia University has brought me many groups of friends that I am very thankful for. First, I would like to thank Meredith for her love and support. Jake, Meg, Noah, Jen, and Connor you all are a part of so many great memories from 1231. Luke, Justin, and the "WVU Guests" I cannot thank you all enough for the great times together. Jordan and Hunter, thank you for being two of my best friends who pushed me in our academic ventures together. 


\section{Table of Contents}

Acknowledgement .............................................................................................................

List of Figures ................................................................................................................ vii

List of Tables ...................................................................................................................

Chapter 1: Introduction and Objectives ………............................................................... 1

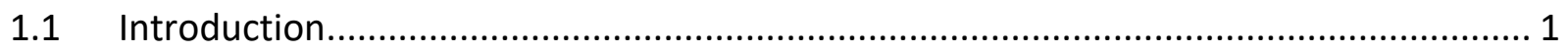

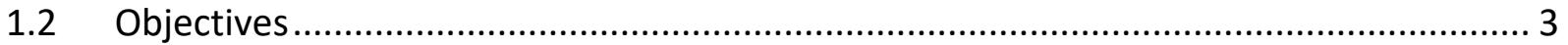

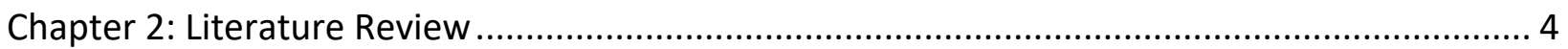

2.1 CDA Literature Review ......................................................................................... 4

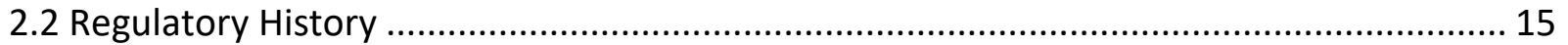

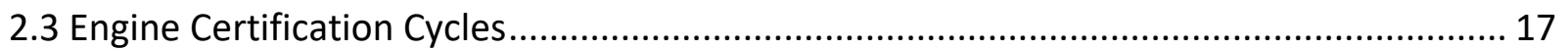

2.3.1 Federal Test Procedure ....................................................................................... 17

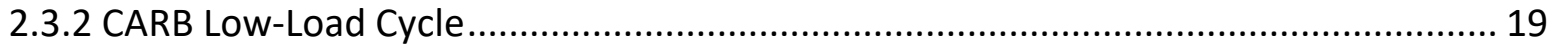

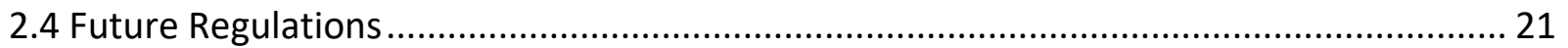

Chapter 3: Experimental Setup and Methodology .................................................................... 23

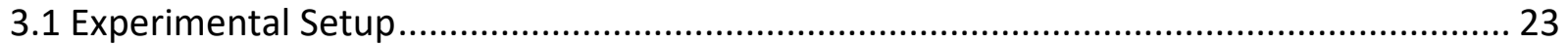

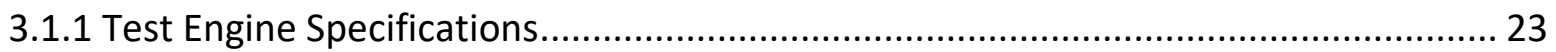

3.1.2 Engine Dynamometer and Test Cell.......................................................................... 26

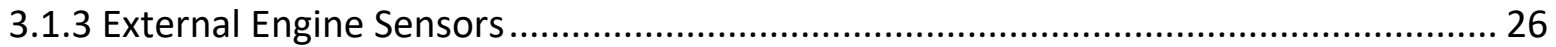

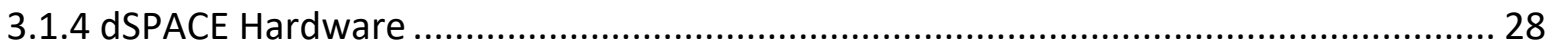

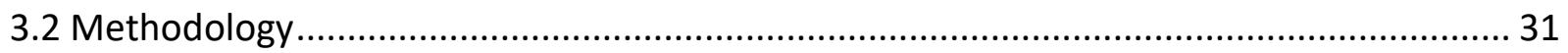

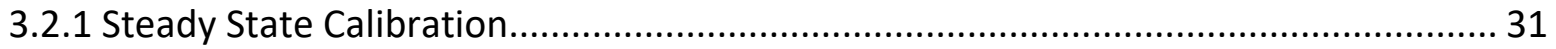

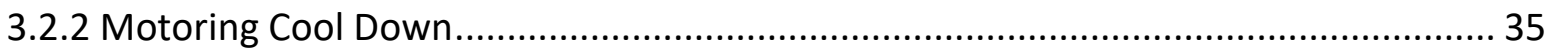

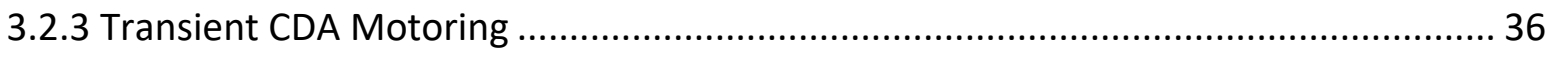

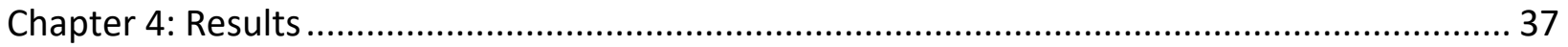

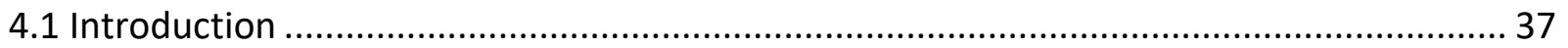

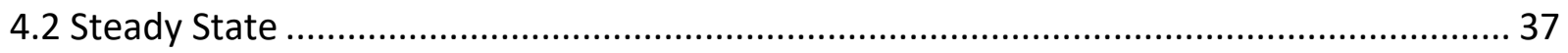

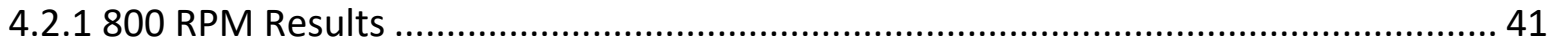

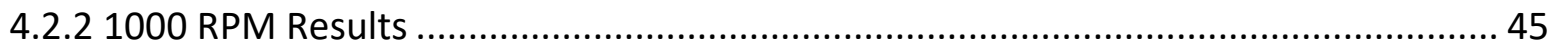

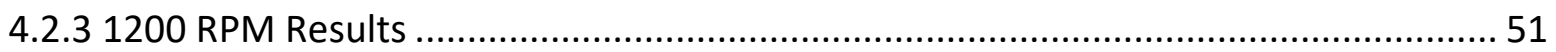

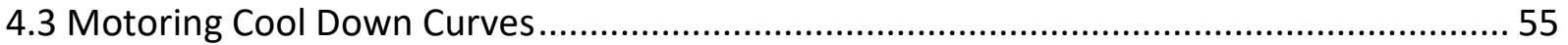




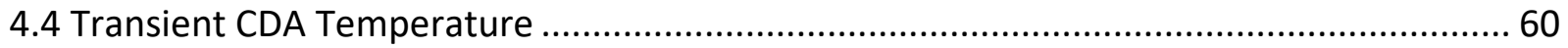

Chapter 5: Conclusions and Recommendations for Future Work.......................................69

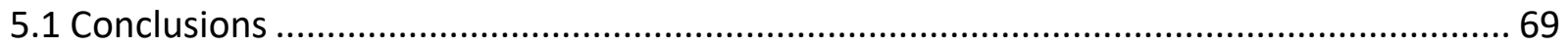

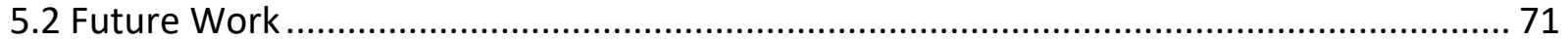

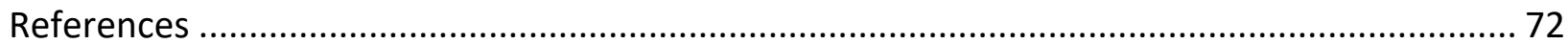

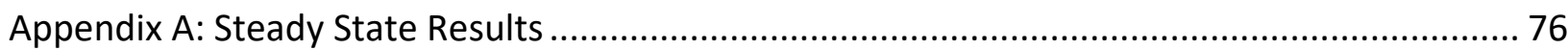

Appendix B: Motoring Occurrences During Transient Cycles.............................................. 78 


\section{List of Figures}

Figure 1: NOx Conversion Efficiency (Cavataio et al., 2007) ..................................................... 5

Figure 2: DSF in Transient Operation (Farrell et al., 2020) ...................................................... 10

Figure 3: V11660 C5 (left) and V11806 C5 (right) SCR Temperatures (Matheaus et al., 2020) . 12

Figure 4: U.S. EPA Emission Standard Evolution (Thiruvengadam, 2018) ................................ 17

Figure 5: Normalized FTP Speed and Torque Points (Emission Test Cycles; Heavy-Duty FTP

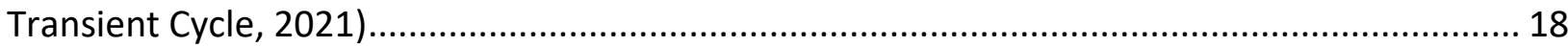

Figure 6: Normalized LLC Speed and Torque Points (Emission Test Cycle; Low Laod Cycle (LLC), 2021)

Figure 7: 2024-26 MY Feasible Standards and Requirements (California Air Resources Board, 2019) 21

Figure 8: Engine Instrumentation Schematic................................................................... 24

Figure 9: CDA Valve Bridge Cross Section Drawing (Baltrucki et al., 2017) .............................. 25

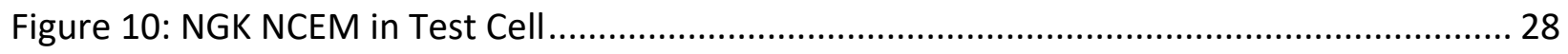

Figure 11: dSPACE External Signals and Logic Model ........................................................... 29

Figure 12: dSPACE Low Side Driver Triggers Model............................................................... 30

Figure 13: Torque Curve with LLC Points and CDA Test Points .............................................. 31

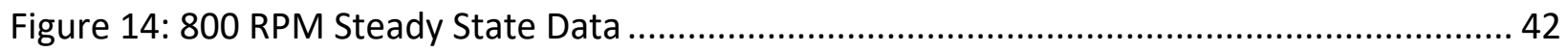

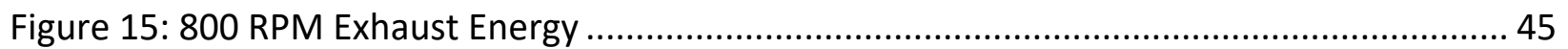

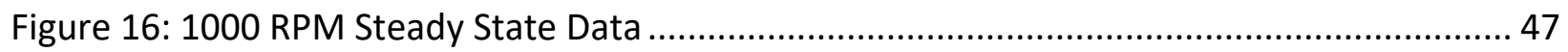

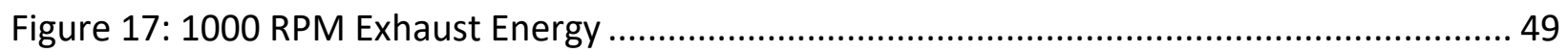

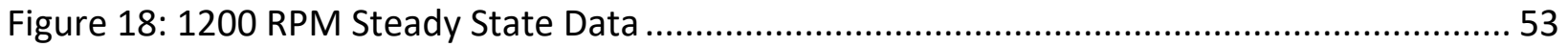

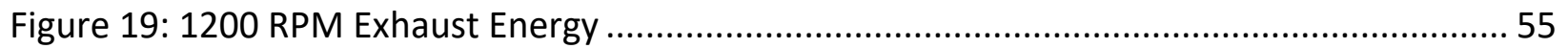

Figure 20: 800 RPM SCR Inlet Motoring Cool Down.............................................................. 57

Figure 21: 1200 RPM SCR Inlet Motoring Cool Down .............................................................. 58

Figure 22: 1500 RPM SCR Inlet Motoring Cool Down ........................................................... 59

Figure 23: Cold Start FTP CDA While Motoring .............................................................. 61

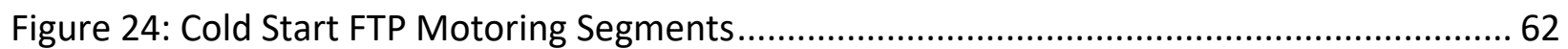

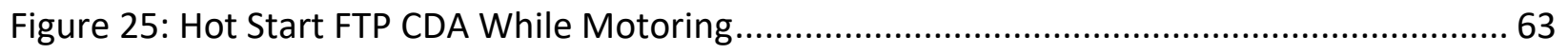

Figure 26: Hot Start FTP Motoring Segments ........................................................................ 65

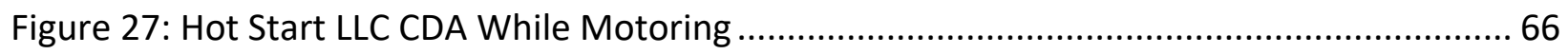

Figure 28: Hot Start LLC Motoring Segments ...................................................................... 68

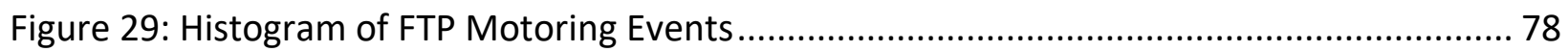

Figure 30: Histogram of LLC Motoring Events ................................................................... 79 


\section{List of Tables}

Table 1: 800 RPM Steady State Data ...................................................................................... 76

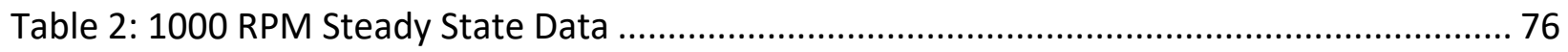

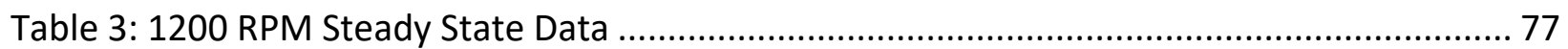




\section{Chapter 1: Introduction and Objectives}

\subsection{Introduction}

Exhaust thermal management is critical for the future of engine certification to meet reduced emissions standards. Heavy-duty diesel (HDD) engines produce harmful exhaust emissions for the environment and human health. Pollutants from engines are controlled by certification limits to reduce the impact on human health and the environment. More stringent emissions regulations are pushing engine manufactures to turn to nontraditional technologies to conform to new regulations. The concept of cylinder deactivation (CDA) has gained traction in the HDD market as a fuel-efficient thermal management strategy. For the HDD market, thermal management strategies cause fuel penalties resulting in elevated aftertreatment temperatures (Körfer et al., 2012). Originally used in gasoline engines as a fuel efficiency technology, CDA on HDD engines have shown a pathway to a reduction in the fueling penalties associated with exhaust thermal management. There is also potential for improvements of brake thermal efficiency (BTE) in some loading conditions (Roberts, 2014).

The United State Environmental Protection Agency (USEPA) has set Greenhouse Gas (GHG) standards to regulate and reduce fuel consumption, control oxides of nitrogen (NOx) production and limit particulate matter (PM) emissions (Emission Standards; GHG Emissions \& Fuel Economy, 2021). Emissions of PM are health hazards which affect respiratory system function and is a carcinogen (United States Environmental Protection Agency, 1979). A highly critical pollutant is NOx and more strict regulations will push manufactures to turn toward alternative technologies to meet future certification values. California Air Resources Board 
(CARB) is proposing new regulations that will focus on certifying HDD engines on a low-load cycle (LLC) (Heroy-Rogalski et al., 2019). The LLC will be used in addition to the Federal Test Procedure (FTP) for engine emissions certification. The shift to focus on a LLC is to provide sufficient exhaust energy to the NOx aftertreatment system under low-load and thus low temperature operations. The LLC highlights extended low-load segments and idling which is not captured in the FTP cycle (Southwest Research Institute, 2019). CDA is a promising pathway to compensate for lower temperatures which are associated with low-load operation. Exhaust thermal management is critical for low-load operation to maintain or increase temperatures, such that the aftertreatment system is more efficient in reducing NOx emissions.

Current technologies that original equipment manufacturers (OEM) use cause fuel penalties to provide thermal management. Fuel injection by a seventh injector located at the inlet of the diesel oxidation catalyst (DOC), late exhaust stroke fuel injection, exhaust throttling, and variable-geometry turbocharging (VGT) optimization are a few of the technologies used to meet USEPA 2010 regulations (Körfer et al., 2012). Many vocation duty-cycles are characterized by creep mode, extended idle, and stop and go operation. These operations account for higher NOx emissions due to low aftertreatment system temperatures, specifically the selective catalytic reduction (SCR) system (Harris, 2020). Operations below 30\% of the full power curve account for a major fraction of engine operations in high traffic density operating regions. CDA is focused on low-load operation where cooling of the aftertreatment is attributed to the mass of air moving through the engine as well as reduced exhaust temperatures. CDA is advantageous because it reduces the displacement of the engine while active, thus decreasing the mass flowrate of exhaust through the aftertreatment. Along with the mass flow rate 
reduction, increased fueling in active cylinders leads to elevated exhaust temperatures for firing cylinders. The combination of higher relative temperatures and reduced mass flow rate for identical loading conditions allows for CDA to potentially be an effective low-load thermal management strategy (Jäs̈seläinen, 2020).

\subsection{Objectives}

The global objective of this study is to investigate the exhaust thermal management performance of a CDA hardware on a HDD engine platform. This study primarily examines ways to maintain and promote conducive temperatures in the SCR catalyst.

Steady state analysis will be performed to optimize the engine calibration for maximizing turbine outlet temperatures (TOT) while having zero or a negative fuel penalty. The steady state calibration will alter engine control parameters to develop new calibration tables while operating under CDA.

Analysis of cooling effects on the aftertreatment will provide useful information on how to mitigate these unwanted characteristics. Aftertreatment cooling occurs during low-load operation, an increase in fueling would be necessary to keep exhaust temperatures hot enough for the SCR to stay functional. Understanding of how to reduce cooling effects will prove useful in developing a robust calibration for thermal management using CDA.

Once a new calibration is developed, transient cycles will be used to validate the performance of the CDA hardware. The FTP and LLC will be used to determine the fuel and temperature benefits of CDA during transient operation. 


\section{Chapter 2: Literature Review}

\subsection{CDA Literature Review}

Cylinder deactivation has been utilized for gasoline engines since the 1980's. It has been proven that it is able to reduce fuel consumption as well as increase thermal efficiency of the engine. Due to the throttle valve being partially closed at low-load, a spark ignition engine has major pumping losses, thus requiring more fuel to compensate (Leone \& Pozar, 2001). One issue that needs investigation is how cooled cylinder walls alter combustion when reactivated. Noise vibration and harness (NVH) also needs to be researched since the engine will become unbalanced due combustion not occurring in all cylinders. Diesel development, especially heavy-duty, has been limited due to the current cost of producing an engine. With emissions restrictions, which generally affect diesels the most, their aftertreatment systems are more rigorous. This results in raised hardware costs to begin with while an engine is developed. The other hurdle to address is how the vibrations will affect the engine since heavy-duty engines are larger and more sensitive to vibration changes.

Cylinder deactivation for diesel engines is used for thermal management at low operating loads as well as potential for cold starting. Exhaust temperatures can be increased with deactivation with minimal fueling penalties. This strategy is enticing due to forecasted future emissions standards. CARB is proposing a standard of $0.02 \mathrm{~g} / \mathrm{bhp}-\mathrm{hr}$ of NOx emissions (California Air Resources Board, 2019). The SCR is typically not active until it is above $200^{\circ} \mathrm{C}$. When the SCR is at $200^{\circ} \mathrm{C}$, the conversion efficiency exceeds $90 \%$ for $\mathrm{Cu} /$ Zeolite SCR (Boriboonsomsin et al., 2018). Figure 1 shows SCR NOx conversion efficiency based on temperature and SCR material. Using current methods, exhaust temperatures are unable to 
reach that temperature for extended low-load operation. An important step for manufacturers is to consider technologies available to ensure that aftertreatment systems warms quickly and stays warm. Manufacturers focus on minimizing the cost of technology applications while being able to achieve regulation standards. Increased complexity of engine and aftertreatment design is also not wanted since these systems are already highly complex.

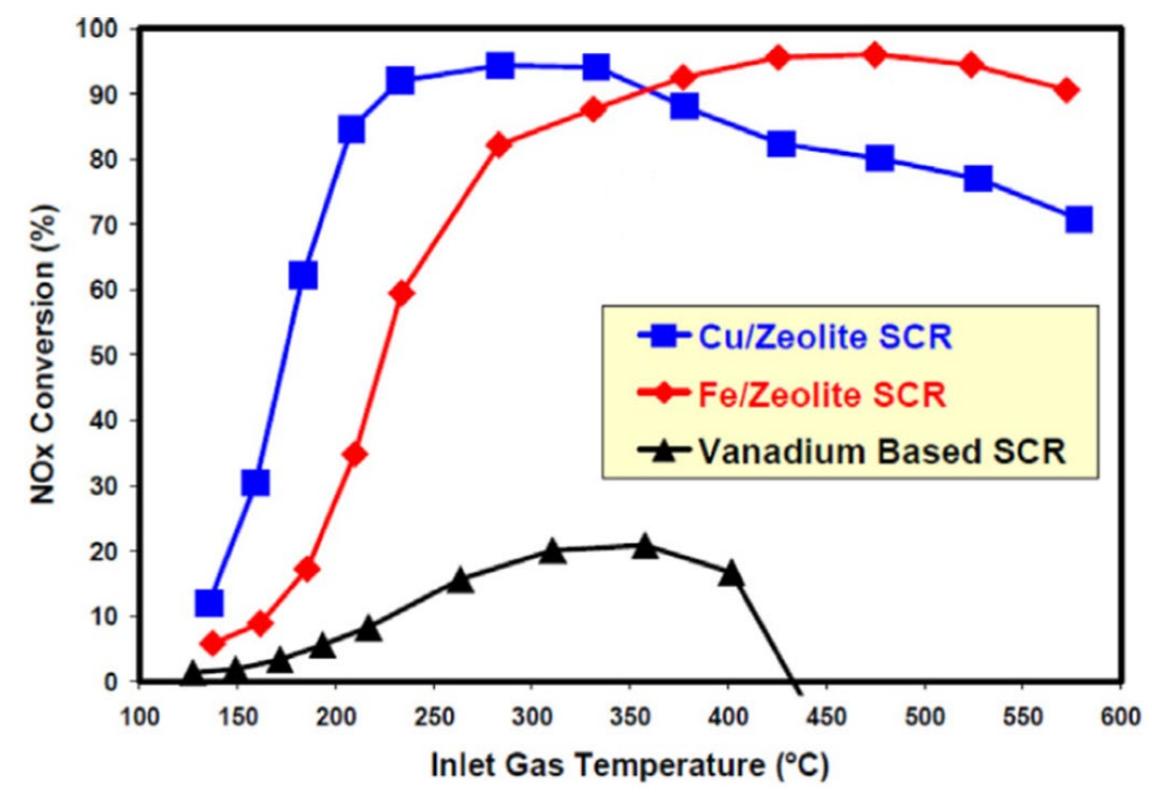

Figure 1: NOx Conversion Efficiency (Cavataio et al., 2007)

One of the main concerns is to characterize how the vibrations of the engine will change during deactivation. Comfort of the driver is paramount due to the nature of heavy-duty applications. There is limited research on how firing order changes for deactivated cylinders would affect heavy-duty diesel engine vibration. Both engine vibration and flywheel torque pulsation changes are critical to incorporating CDA into the HDD market.

Magee's master's thesis work was performed on a 2010 inline 6, 6.7L ISB diesel engine. The engine had a variable geometry turbo and a high-pressure exhaust gas recirculation (EGR) 
cooled system. The engine was equipped with variable valve actuation; thus, each valve was controlled individually with complex hardware which required significant modifications to the engine. The motivations for the project were to investigate efficiency improvements and exhaust thermal management (Magee, 2014).

For thermal management, CDA will function as a mechanism to change the air to fuel ratio (AFR) of diesels at low-load as well as mass flow of through the engine. At low-load, the AFR of diesels can be greater than 80 to 1 , thus exhaust temperature will never exceed $250{ }^{\circ} \mathrm{C}$. Cylinder deactivation allows for the AFR to be closer to stoichiometric at low-load, resulting in elevated exhaust temperatures. With deactivation, less fresh air is in the system which allows for higher temperatures (Magee, 2014).

Testing to validate the theory, EGR was not used during a load sweep at $1200 \mathrm{rpm}$. At $50 \mathrm{ft}$-lbs. of torque, the smallest difference in outlet turbine temperature was observed. This was due to being the lowest load tested, thus the least amount of total fuel was used. The difference was approximately $100{ }^{\circ} \mathrm{C}$ high and the actual temperature was about $260{ }^{\circ} \mathrm{C}$ (Magee, 2014). Even at the low-load with deactivation the outlet temperatures would be hot enough for high conversion of NOx. Over the entire range of testing, the temperatures of the exhaust were higher for deactivation than they were when all six cylinders were used. It was also concluded that the VGT needed to be manipulated to ensure that the AFR would not become too rich (Magee, 2014). When a diesel engine becomes too rich, soot production is increased and the extra fuel injected does not equate to a gain in power. Effectively the fuel is wasted and becomes soot as the AFR approaches stoichiometric. 
While examining the brake thermal efficiency of the engine, it was observed that the engine was more efficient at low-loads compared to all cylinders active. The opposite was seen at high load, showing that there is a threshold for which operation is optimal from an efficiency standpoint (Magee, 2014). It is important to note that deactivation is not typically used higher than $30 \%$ maximum load. This is due to concerns of vibration as well as smooth power delivery. Even in spark ignition vehicles, deactivation will not be seen at mid to high load without complex control algorithms. Since efficiency decreased at medium and high loads, deactivation will not be used in these regions.

The final part of the study was to look at NOx emissions during deactivation while using EGR, which was disabled for the initial phase of the study. During this phase of testing, very little difference in outlet temperatures for deactivation were measured when different amounts of EGR were commanded. The AFR dropped as EGR increased but that is expected (Magee, 2014). NOx was observed to be lowest when the largest fraction of EGR was allowed in, as expected but PM would increase due to a such a high EGR fraction.

Another research group, led by Lu, tested at the possibility of active diesel particulate filter (DPF) regeneration while using cylinder deactivation. For certain applications, such as long-haul trucking, this technology could reduce cost of aftertreatment systems. The majority of DPF's are catalyzed and will passively regenerate, mostly on highway operation. Catalyzed DPF's are more expensive than the non-catalyzed DPF. If catalyzed DPF's are not needed, trucks equipped with this technology would be less expensive to purchase and maintain. This technology would allow for a reduction in fuel penalties to actively regenerate a DPF. Cylinder 
deactivation could be an alternative method from fuel dosing to raise exhaust temperatures to regenerate the DPF (Lu et al., 2015).

The group saw that during deactivation, turbine outlet temperatures were $520-550{ }^{\circ} \mathrm{C}$ which are hot enough for active regeneration. The largest temperature seen with all six cylinders firing was $420^{\circ} \mathrm{C}$ (Lu et al., 2015). While during highway operation, the brake specific fuel consumption (BSFC) was lower when all cylinders were firing. This is because the longer injection process and heat release when more fuel is injected into the cylinder. They noted that this is not a surprise since the engines are normally optimized for highway cruising (Lu et al., 2015). The start of injection was delayed during testing to understand how 3-, 4- and 6-cylinder firing would affect temperatures. They observed no benefit for delaying injection during normal operations. Above $400{ }^{\circ} \mathrm{C}$, to raise the temperature a further $20^{\circ} \mathrm{C}$ there is a $20 \%$ increase in fuel consumption (Lu et al., 2015).

While examining how emissions were affected during the highway operation, PM saw an increase due to the reduced AFR (Lu et al., 2015). They stated that this may not be a significant impact due to active regeneration but no tests were conducted to confirm their statement. The final part of the study was to determine the effect of heat transfer due to deactivation. The mass flow and temperature of the exhaust are the factors which cause the DPF to heat up. It was determined that for a similar BSFC cylinder deactivation resulted in an increased rate of the DPF heating up (Lu et al., 2015).

Roberts' thesis topic was studying how cylinder deactivation could be used at idle. Two idle loadings were selected to compare the performance at. A "loaded" idle, simulated the 
engine giving auxiliary power and a "lightly loaded" idle representing a pure idle of a truck in operation. The motivation of the study was to determine the effects of thermal management at idle conditions (Roberts, 2014). This is an area of concern for NOx conversion since low-load results in aftertreatment temperatures below the threshold needed for NOx conversion to occur.

While at the "lightly loaded" idle, the temperature of the exhaust during deactivation was elevated. During normal idle, the exhaust temperature were $120^{\circ} \mathrm{C}$. Over closing the variable geometry turbo and ignition delay resulted in the outlet temperature of $183^{\circ} \mathrm{C}$. The fuel penalty for those operating conditions increased $3 \%$. At a $14 \%$ fueling penalty, the turbine outlet temperature was observed to be $207^{\circ} \mathrm{C}$ (Roberts, 2014). The impact of CDA on SCR temperatures were not discussed, $200^{\circ} \mathrm{C}$ is the temperature threshold of SCR operation.

During the loaded idle, the baseline temperature was $190^{\circ} \mathrm{C}$. Using only CDA, not adjusting injection or VGT position, the exhaust temperatures increased to $310{ }^{\circ} \mathrm{C}$. At this condition, a $2 \%$ fueling penalty occurred (Roberts, 2014). The data collected shows a viable method of increasing exhaust temperatures at a loaded ideal using CDA. These temperatures would be sufficient enough to ensure the SCR is at operational temperatures.

Tula and Cummins demonstrated a CDA system using Tula's Diesel Dynamic Skip Fire (dDSF) technology. The engine tested was the Cummins $15 \mathrm{~L} X-15$ efficiency series engine. The controls strategy was complex algorithm which evaluated event to event combinations to optimize exhaust temperatures, fuel consumption, transient performance, and NVH (Farrell et al., 2020). Tula used their proven dDSF system, which is used in gasoline engines for smooth 
torque delivery and a reduction in vibrations due to specific firing orders throughout operation of the engine. Tula's dDSF allows for dynamic CDA, thus allowing for as many as five cylinders to be active and as low as one active cylinder. This increases the possible range of operating conditions while considering BTE, fuel consumption, and exhaust temperatures (Farrell et al., 2020).

Torque thresholds were established based on firing density. Firing density is a combination of firing patterns which range from 0.25 up to 0.9 . A firing density of 0.5 means three of the six cylinders are firing. Under 0.5 firing density, the maximum torque at $1000 \mathrm{rpm}$ observed was $280 \mathrm{ft}-\mathrm{lb}$. No CDA was used once the torque demand exceeded $370 \mathrm{ft}-\mathrm{lb}$ for 1000 rpm. Figure 2 demonstrates how firing density changed with torque demand while using dDSF with CDA (Farrell et al., 2020).

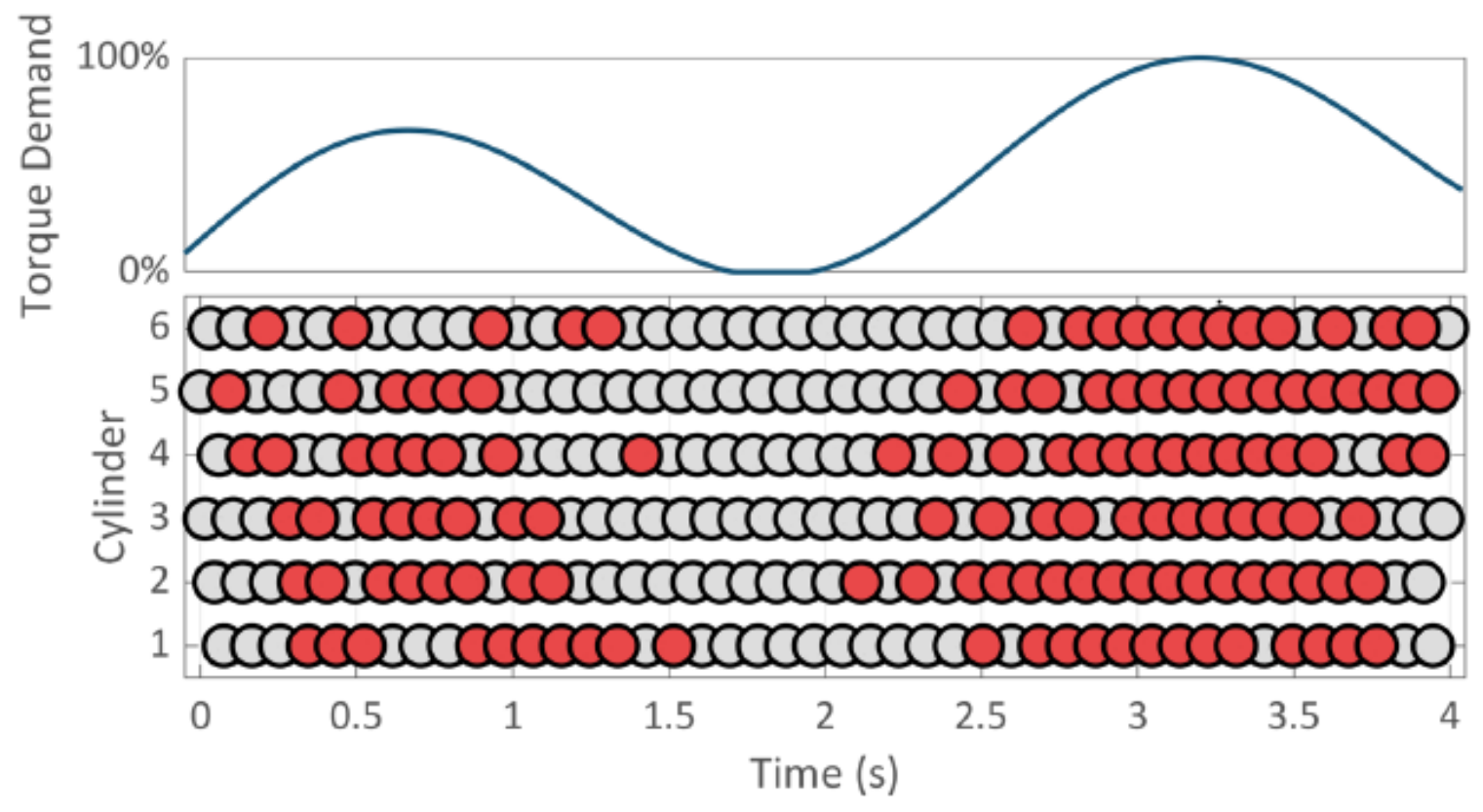

Figure 2: DSF in Transient Operation (Farrell et al., 2020) 
At $1000 \mathrm{rpm}$ and no torque demand, turbine outlet temperatures increased by nearly 50 ${ }^{\circ} \mathrm{C}$. For $148 \mathrm{ft}-\mathrm{lb}$ of torque and $295 \mathrm{ft}-\mathrm{lb}$, TOT increased nearly $90^{\circ} \mathrm{C}$ and $100{ }^{\circ} \mathrm{C}$, respectively. Simulations were performed to evaluate an FTP and LLC cycle using the initial dDSF calibration. In the FTP, tailpipe out NOx was reduced $45 \%$ and $\mathrm{CO}_{2}$ was reduced $1.5 \%$. In the LLC cycle, there was a $66 \%$ reduction in NOx and a $3.7 \%$ reduction in $\mathrm{CO}_{2}$. The reduction in NOx was due to elevated exhaust temperatures and the fuel benefit was due to the fuel savings in low-load areas where the engine is inefficient (Farrell et al., 2020).

The U.S. Department of Energy sponsored a SuperTruck II program for Navistar to develop a CDA engine. The engine tested was a 13L 6-cylinder engine rated for 450 horsepower. The engine was equipped with a VGT, common rail fuel system, and cooled EGR. The aftertreatment consisted of a DOC, DPF, SCR, and an ammonia clean-up catalyst. The aftertreatment was specific to the engine model. The CDA system was provided by Jacobs Vehicle System (Matheaus et al., 2020). The heavy-duty FTP and CARB's low-load cycle were used along with other established test cycles to evaluate CDA over multiple vocation applications. The CDA calibration that was developed had limitations for cold start conditions, as the calibration was optimized for operation when the engine was warm. The CDA calibration was not certified to meet current emissions standards and was optimized for fuel efficiency. When running in CDA, only three cylinders were actively firing. CDA was active at idle and up to 6 bar brake mean effective pressure (BMEP) (Matheaus et al., 2020).

The first cycle discussed is the V11660 cluster 5 which was the lightest loaded cycle that was tested. The work over the cycle was $1.27 \mathrm{~kW}$-hr for the engine. The cycle was created 
from drayage applications transporting goods over short distances. The cycle was conducted multiple times until the aftertreatment reached a stable temperature profile. Of the cycle runs that were used for analysis, tail pipe $\mathrm{NOx}$ and $\mathrm{CO}_{2}$ were reduced with $\mathrm{CDA}$ by $16 \%$ and $15 \%$ respectively. Additionally, the average SCR inlet temperature increased from $150^{\circ} \mathrm{C}$ to $187^{\circ} \mathrm{C}$. Another test cycle was the V11806 cluster 5 which was a transfer truck cycle and has an extended idle section. The cycle brake work for the cycle was $5.81 \mathrm{~kW}$-hr. The average SCR temperature increased with $\mathrm{CDA}$ from $166^{\circ} \mathrm{C}$ to $195^{\circ} \mathrm{C}$. Tail pipe NOx was reduced by $30 \%$ with CDA while $\mathrm{CO}_{2}$ was decreased by $10 \%$ (Matheaus et al., 2020). Figure 3 below shows SCR inlet temperature plots for both of the cycle clusters.
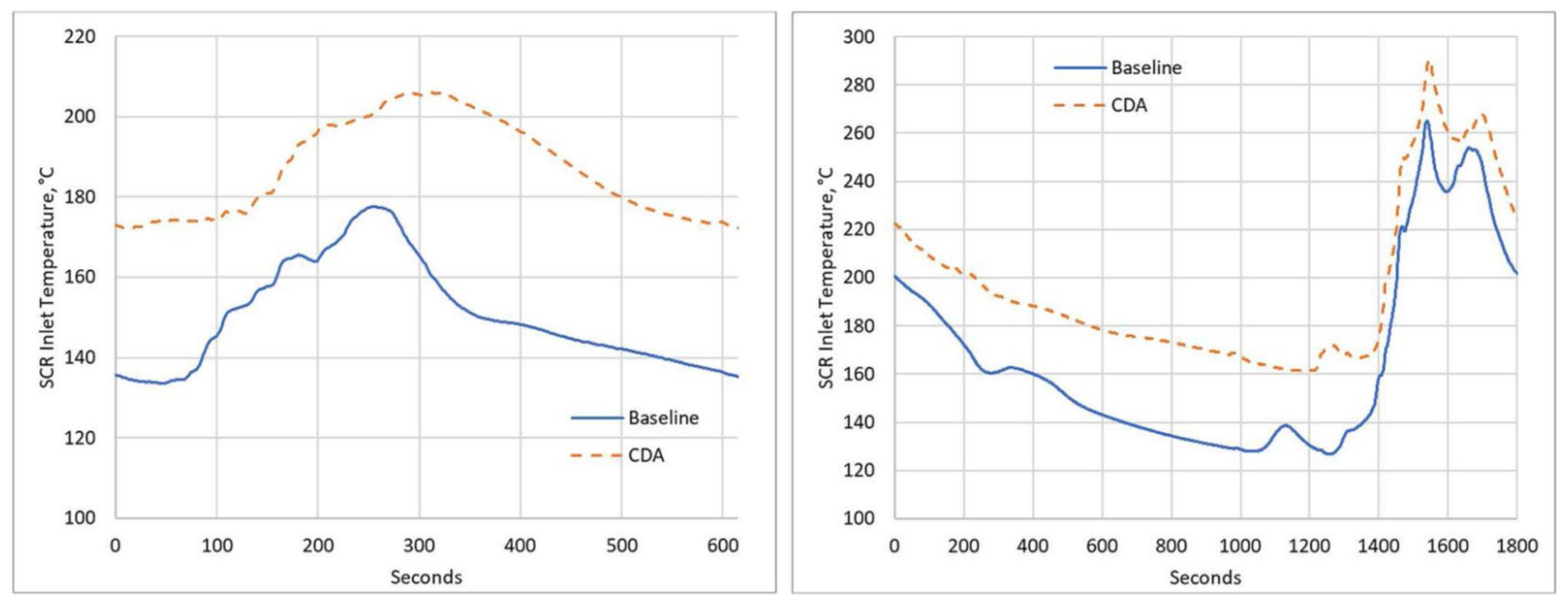

Figure 3: V11660 C5 (left) and V11806 C5 (right) SCR Temperatures (Matheaus et al., 2020)

The two cycles discussed were combined with other clusters into the low-load cycle. The cycle brake work for the LLC is $28.99 \mathrm{~kW}$-hr for the tested engine. During the LLC, $92 \%$ of operation fell below 5 bar BMEP, where CDA was operational. Over the $\mathrm{LLC}, \mathrm{CO}_{2}$ was reduced by $12 \%$ when CDA was used during the cycle. Additionally, the average SCR inlet temperature was increased from $183^{\circ} \mathrm{C}$ to $222^{\circ} \mathrm{C}$. With the increased aftertreatment temperature, tailpipe 
NOx was reduced by $77 \%$. The SCR NOx conversion efficiency was $74 \%$ for the baseline and $95 \%$ for CDA (Matheaus et al., 2020). During FTP testing, no cold starts were discussed. The cycle work over the FTP was $21.69 \mathrm{~kW}$-hr. The SCR NOx conversion efficiency was $97 \%$ for both the baseline and CDA test. Although conversion efficiency did not change, NOx was reduced by $8 \%$ and $\mathrm{CO}_{2}$ by $6 \%$ during the $\mathrm{CDA}$ test cycle. The average SCR inlet temperature increased from $244^{\circ} \mathrm{C}$ to $268^{\circ} \mathrm{C}$. Decrease in NOx and $\mathrm{CO}_{2}$ are attributed to less fuel used during the test cycle and higher average aftertreatment temperatures. With the reduction of exhaust flow, the authors discussed the difficulty to reach a fast warm up during cold start. It was noted that they believe additional strategies might be needed such as elevated idle, post injection or early exhaust valve opening (Matheaus et al., 2020).

Southwest Research Institute conducted a study to evaluate the performance of the OEM turbocharger on CDA diesel engines. The engine used was a 2017 Cummins X15 rated for 500 horsepower and 1,844 ft lbf of torque at $1000 \mathrm{rpm}$. The engine was equipped with a highpressure common rail fuel system, VGT, and high pressure EGR. The turbocharger was optimized for peak power and thus is not as efficient as it could be for low-load applications, like CDA (Morris and McCarthy, 2020). The VGT allows for a wider power band as well as a larger range of being efficient at producing boost. Baseline boost was able to achieve $35 \mathrm{kPa}$ at 0 BMEP and $1200 \mathrm{rpm}$. During CDA, $35 \mathrm{kPa}$ was achieved at $2.5 \mathrm{BMEP}$ for $1200 \mathrm{rpm}$. At 1700 rpm, $50 \mathrm{kPa}$ boost pressure was seen at 0 BMEP. While operating in CDA mode, $50 \mathrm{kPa}$ of boost was measured till 2.25 BMEP. The difference in boost pressure is due to the reduced air flow while CDA was active. The VGT was held at a constant position to determine the boost for CDA operation to provide a fair comparison of the two modes. Two calibrations were developed, 
"stay hot" and "get hot". Each were evaluated at warmed up engine temperatures only, no cold start validations were performed. The stay hot strategy was focused on reducing fuel consumption and engine out NOx while still providing increased exhaust temperatures (Morris and McCarthy, 2020).

During testing of the stay hot calibration, at $600 \mathrm{rpm}$ and 0 to $1 \mathrm{BMEP}, \mathrm{CDA}$ resulted in a $10-15{ }^{\circ} \mathrm{C}$ increase and a fuel reduction of $45 \%$ and $20 \%$ respectively. Due to the small temperature gains, exhaust energy was decreased because of the flow rate reduction. The turbocharger efficiency also decreased during these CDA loading points. There was sufficient airflow during CDA and allowed for acceptable AFR, concluding the stock turbocharger was sufficient for CDA in these ranges. Engine speeds of 800 rpm from 0 to 2 bar BMEP and 1000 rpm from 0 to 3 bar BMEP had similar results to the $600 \mathrm{rpm}$ operating condition. Exhaust temperatures increased with a decrease in fueling. Exhaust energy was reduced because of the reduction in flow rate during CDA. The turbocharger was adequate for both speeds but 1000 rpm had a 10\% reduction in flow per cylinder during CDA (Morris and McCarthy, 2020).

During 1200 rpm testing, cylinder firing number was changed throughout the load sweep. Across the whole sweep, fueling decreased, exhaust temperatures increased and engine out NOx decreased. During mode changes exhaust temperatures decreased but overall were still higher than the baseline exhaust temperature. The mode change was necessary to ensure an appropriate AFR and air flow into each cylinder. The turbocharger was again adequate at these test points but there was a larger flow loss per cylinder compared to the other operating points. The authors note that turbocharger efficiency is not a good measure of 
whether or not an alternative turbocharger should be used. Efficiency is inherently low at lowloads which is the targeted area of CDA. Rather, they suggest using AFR and air flow rate into each cylinder as a better metric to determine if the turbocharger is sufficient (Morris and McCarthy, 2020).

Using the get hot strategy, idle speed was raised from $600 \mathrm{rpm}$ to 800 and $1000 \mathrm{rpm}$. The elevated idle speed is to promote an increase in exhaust enthalpy due to the increased flow rate at higher engine speeds. The engine load remained the same for each respective speed. Exhaust temperature increased over all CDA applications with the largest increase of $200^{\circ} \mathrm{C}$ at $1000 \mathrm{rpm}$ and 3 bar BMEP. Exhaust enthalpy increased over the whole load sweep for both 800 and $1000 \mathrm{rpm}$ idles. At $800 \mathrm{rpm}$, a $2-3 \mathrm{~kW}$ increase in exhaust energy required a 3-30\% fuel penalty. At $1000 \mathrm{rpm}$, a 7-11 kW increase in exhaust energy required a 30-75\% fuel penalty. Engine out NOx increased as well for the 800 and 1000 rpm loads (Morris and McCarthy, 2020). VGT was not optimized during the study and the authors note how this could help air flow deficiencies. Additionally, further refining of the get hot calibration could reduce fuel penalties while still providing increased exhaust energy.

\subsection{Regulatory History}

The Clean Air Act of 1963 authorized research into monitoring and controlling air pollution in the U.S. In 1970, the EPA was formed and the Clean Air Act of 1970 was passed (United States Environmental Protection Agency, 1990). There was to be a $90 \%$ reduction in emissions from new vehicles by the year 1975. The EPA emissions standards were set for hydrocarbons ( $\mathrm{HC})$, carbon monoxide (CO), and NOx. The act also set baseline "National 
Ambient Air Quality Standards". In 1975, the Energy Policy Conservation Act was passed which was the first act to focus on fuel economy of automobiles. Catalytic converters were modified and implemented on cars, which resulted in the use of unleaded since lead had harmful effects on the catalyst system (Purdy, 2014).

In 1985, the first regulations for heavy-duty engines was introduced which set limits on NOx and PM production, at $10.5 \mathrm{~g} / \mathrm{bhp}-\mathrm{hr}$ and $0.6 \mathrm{~g} / \mathrm{bhp}-\mathrm{hr}$, respectively. New sulfur limits in diesel fuel were set in 1990, NOx emissions are also lowered to $6 \mathrm{~g} / \mathrm{bhp}-\mathrm{hr}$. In 2002, NOx emissions were lowered to $2.4 \mathrm{~g} / \mathrm{bhp}-\mathrm{hr}$ and $0.1 \mathrm{~g} / \mathrm{bhp}$-hr for PM standards (U.S. Environmental Protection Agency, 2021). Commercial use of EGR for NOx control was used for the first time in heavy-duty engines. DPF technologies were also introduced to meet the new PM standards. This was the first step to using new technology to meet emissions regulation requirements (Jääskeläinen \& Majewski, 2018).

The most recent standards for emissions were debuted in 2010 which imposed emissions regulations of $0.2 \mathrm{~g} / \mathrm{bhp}-\mathrm{hr}$ of NOx and $0.01 \mathrm{~g} / \mathrm{bhp}-\mathrm{hr}$ of PM (United States Enviromental Protection Agency, 2013b). The success of the 2004 standard and technological developments led to the development of the 2010 standard. To meet the 2010 standards, diesel manufactures introduced the SCR for the new NOx standard (Jääskeläinen \& Majewski, 2018). In 2017, the GHG standard established $\mathrm{CO}_{2}$ limits of $460 \mathrm{~g} / \mathrm{bhp}$-hr for long haul and vocational trucks during the FTP cycle (Office of the Federal Register, 2011). The emissions reduction equipment has an inherent decrease of BTE due to increased fuel consumption to 
enable these systems. Figure 4 shows a visual representation of how HDD engines NOx and PM emission standards have evolved.

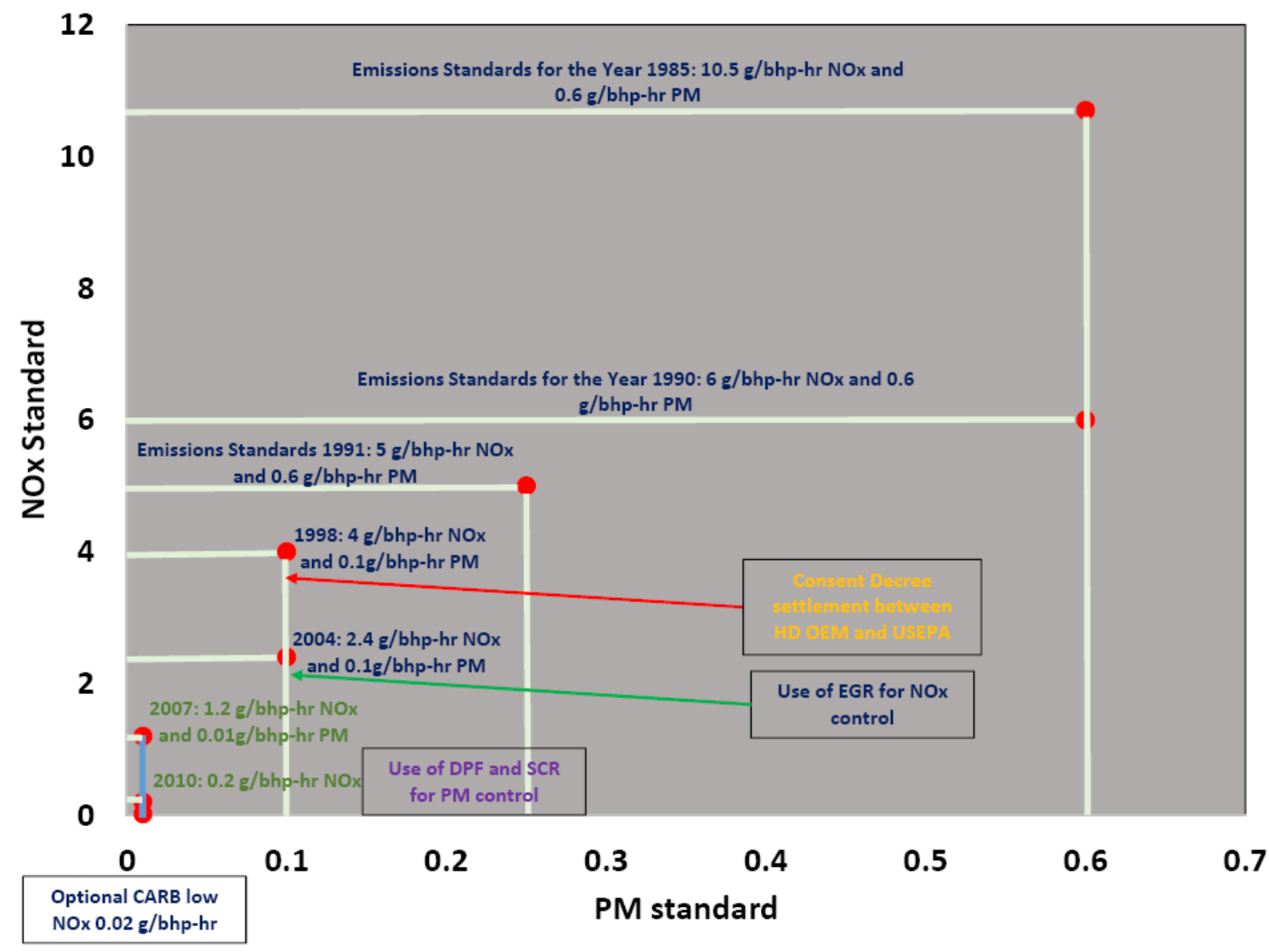

Figure 4: U.S. EPA Emission Standard Evolution (Thiruvengadam, 2018)

\subsection{Engine Certification Cycles}

\subsubsection{Federal Test Procedure}

The EPA has mandated that engine manufacturers must certify their engine on an engine dynamometer using standard test cycles. Procedures and calculations have been laid out to have set methods to perform tests at any location and have nearly identical data collection. The U.S. EPA developed a standardized certification cycle to simulate real world driving conditions for a dynamometer (United States Environmental Protection Agency, 2013b). 
The heavy-duty Federal Test Procedure (FTP) contains four sections, 300 seconds each, which are specific to traffic in and around cities and highways. The first segment is the New York NonFreeway portion which captures light traffic with frequent stop and starts. The second section is the Los Angeles Non-Freeway which has few tops but typical crowded urban traffic. Third is the Los Angeles Freeway portion which simulated crowded expressway traffic in Los Angeles. Finally, the New York Non-Freeway is repeated (Emission Test Cycles; Heavy-Duty FTP Transient Cycle, 2021). The normalized speed and torque plots of the FTP are presented in Figure 5.
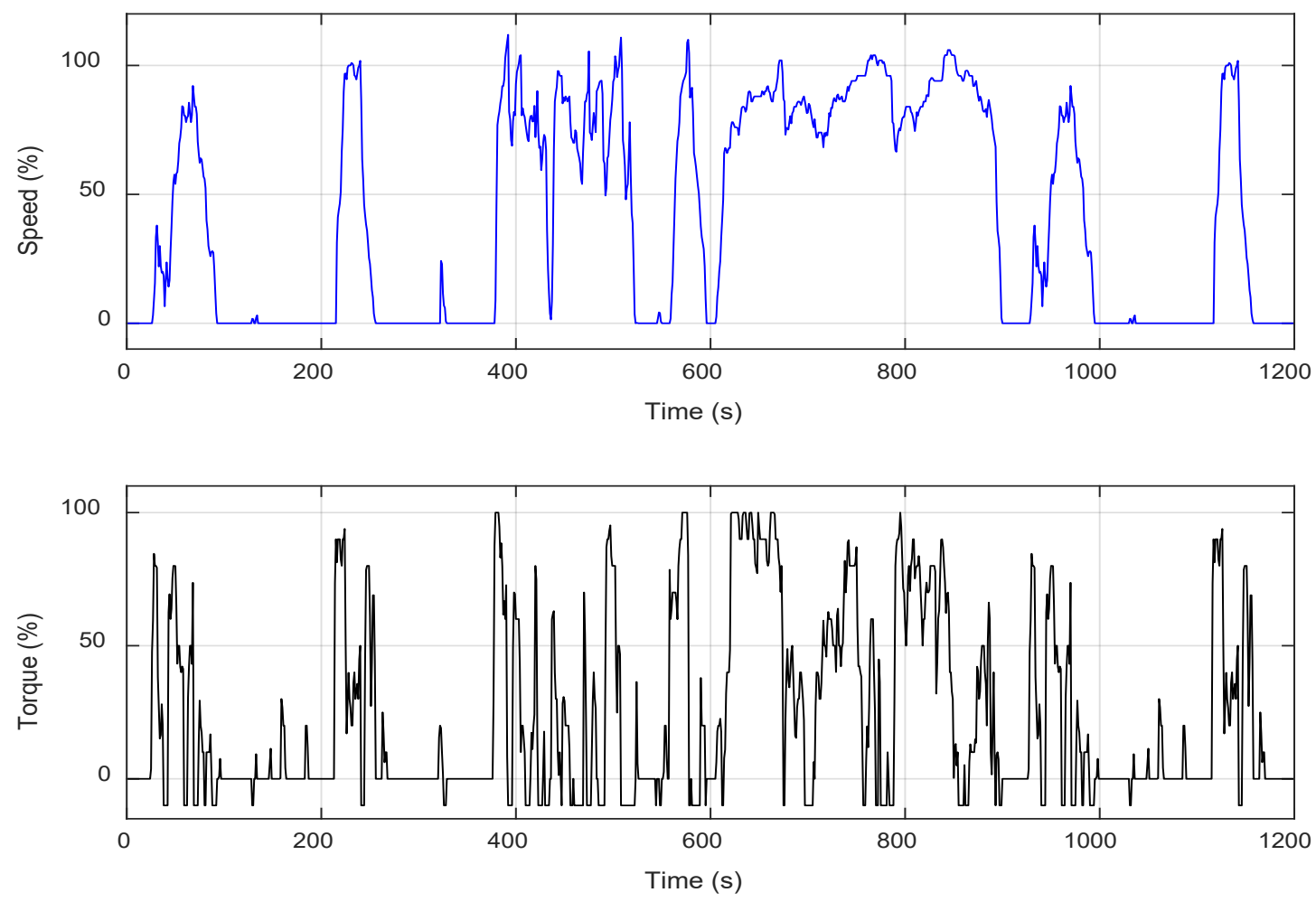

Figure 5: Normalized FTP Speed and Torque Points (Emission Test Cycles; Heavy-Duty FTP Transient Cycle, 2021)

The FTP was generated with normalized speed and torque set points. The lug curve is used to denormalize the set points to create the cycle for each specific engine. Generally, exhaust temperatures will be between $250^{\circ} \mathrm{C}$ and $350^{\circ} \mathrm{C}$. During the freeway portion, exhaust 
temperatures can reach as much as $450{ }^{\circ} \mathrm{C}$ (Emission Test Cycles; Heavy-Duty FTP Transient

Cycle, 2021). For certification, the cycle has both cold and hot starts. An overnight engine soak is typical to have the engine reach ambient room temperature. The cold start is followed by a hot start with a twenty-minute soak in between the tests. Certification values are based off of a weighted average approach, $1 / 7^{\text {th }}$ and $6 / 7^{\text {th }}$ of the cold start and hot start emissions values, respectively, are used to calculate the composite results. The composite brake specific results are obtained by dividing emissions weights and fuel consumption by weighted mechanical work (United States Environmental Protection Agency, 2013c). Equation 1 is used to determine the weighted averages and is specified in the Code of Federal Regulations (CFR). Cold start is defined as the engines oil, coolant, and aftertreatment components are all between 20 and 30 ${ }^{\circ} \mathrm{C}$ (United States Environmental Protection Agency, 2013a).

$$
A_{W M}=\frac{(1 / 7) *\left(g_{c}\right)+(6 / 7) *\left(g_{h}\right)}{(1 / 7) *\left(B H P-h r_{c}\right)+(1 / 7) *\left(B H P-h r_{h}\right)}
$$

Equation 1: Weight Average (United States Environmental Protection Agency, 2013a)

\subsubsection{CARB Low-Load Cycle}

Regions of low-load dominate exhaust emissions due to aftertreatment inactivity. This issue is not captured in the FTP test cycle. CARB has developed a low-load cycle with Southwest Research Institute to account for sustained low-load and allow for sufficient time to demonstrate thermal management strategies. Data from 751 different HDD trucks with various applications were used to develop the LLC. The LLC captures three main challenges for thermal management; high load to low-load transition, sustained low-load, and low-load to high-load transition (Heroy-Rogalski et al., 2019). Five primary events were observed from the real-world 
data. Sustained low-load, extended idle, motoring/short idle cooling, post-cooling high load, and mid-speed cruise motoring. The LLC had to have an example of each primary events which lead to poor aftertreatment performance. To perform the LLC, at least one hot FTP with a twenty-minute soak is required (Heroy-Rogalski et al., 2019). The LLC certification emissions standards will vary from FTP standards due to decreased aftertreatment activity by design.

The LLC is a ninety-minute test which has a thirty-minute sustained low-load segment. During the LLC, $93.5 \%$ of the total test cycle is below $30 \%$ full load, which is in the CDA target region for the study. Idling the engine is 2171 seconds of the total 5505. Of that idle time, there is a ten-minute continuous segment of idling (Heroy-Rogalski et al., 2019). Figure 6 presents the normalized engine speed and torque for the LLC.
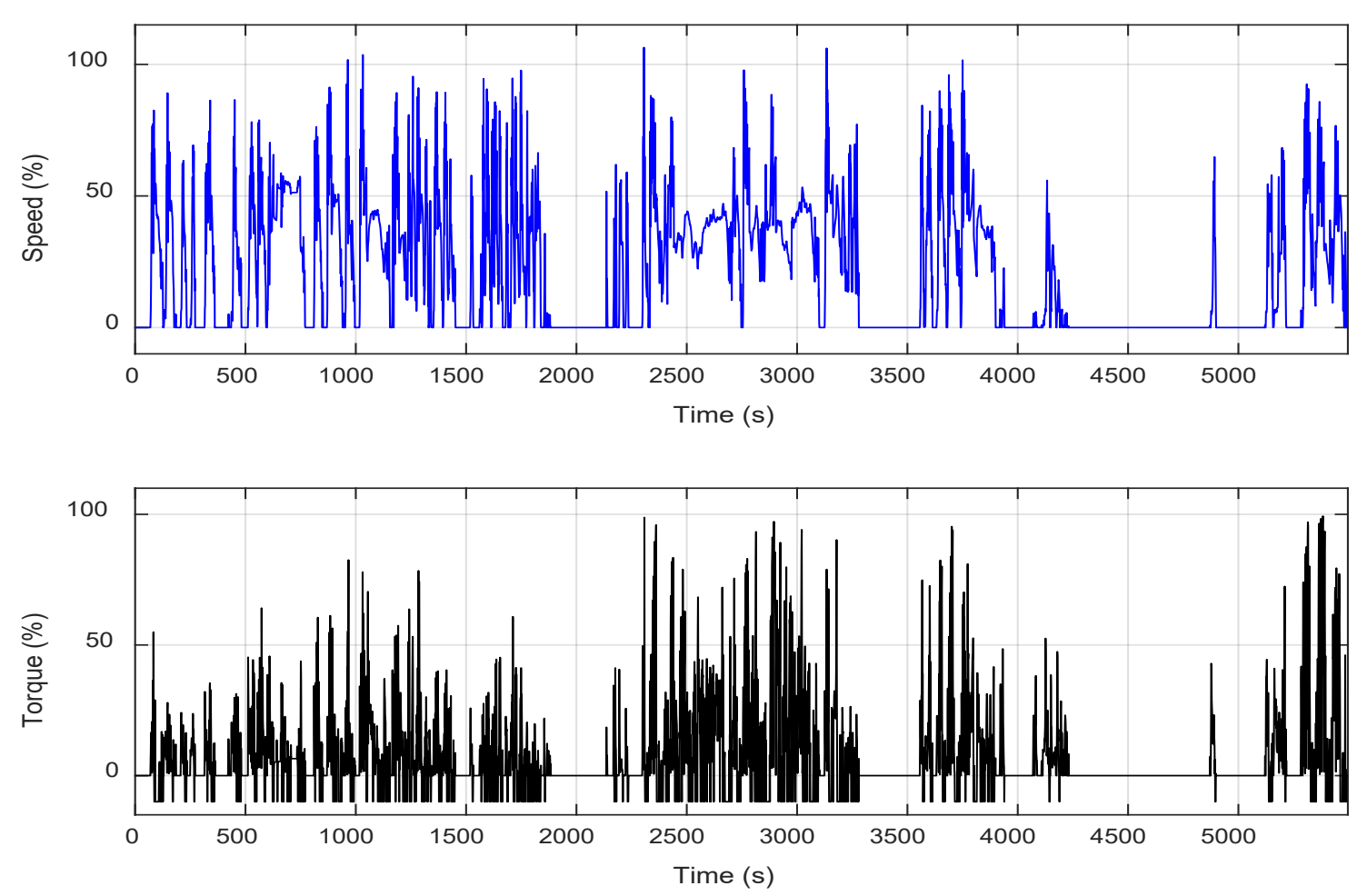

Figure 6: Normalized LLC Speed and Torque Points (Emission Test Cycle; Low Laod Cycle (LLC), 2021) 


\subsection{Future Regulations}

CARB published the Staff White Paper in April of 2019 to address future low NOx standards. CARB has been planning on using the LLC starting for model year (MY) 2024-2026 depending on agreement dates of when to start and end the phase. NOx and PM standards are also able to be lowered around that same time period due to forthcoming advancements being made by OEM to reduce NOx. MY 2027 and later have not been determined of what values CARB will use for the standards then (California Air Resources Board, 2019). Historically, the U.S. EPA and CARB follow the same emissions regulations when they have been updated previously. This makes it easier to keep track of emissions credits since EPA is only responsible for such credits. CARB has noted that if the U.S. EPA does not follow suit, they will need to develop their own emissions credits for OEMs. Figure 7 shows the proposed 2024-2026 standards and requirements.

\begin{tabular}{|l|l|}
\hline \multicolumn{2}{|c|}{ 2024 through 2026 MY Engines Assessment } \\
(Heavy-Duty and Medium-Duty Engines for > 10,000 pounds GVWR)
\end{tabular}

Figure 7: 2024-26 MY Feasible Standards and Requirements (California Air Resources Board, 2019) 
Emission standards are forcing GHG emissions down which is a challenge for engine manufacturers (Enviromental and Energy Study Institute, 2015). Thermal management technologies/strategies typically cause fuel penalties. CARB has noted that the above potential standards are feasible without major engine and aftertreatment hardware changes. CDA, SCR coated DPF, passive NOx absorber, and close coupled light-off catalysts are promising pathways for the reduced NOx emissions (California Air Resources Board, 2019). Current engine PM emissions are already able to meet the 2024 proposed certification values. Current engine PM certification values are not as low as they could be to reduce backpressure on the exhaust by having more porous DPFs. CARBs two engine projects running the LLC had $0.8 \mathrm{~g} / \mathrm{bhp}-\mathrm{hr}$ and 1.5 g/bhp-hr for tailpipe NOx. They believe these numbers can be decreased with further calibration changes (California Air Resources Board, 2019). 


\section{Chapter 3: Experimental Setup and Methodology}

The study was conducted at the Engine and Emissions Research Laboratory (EERL) at West Virginia University's Evansdale campus. The EERL is a lab associated with West Virginia University's Center for Alternative Fuels, Engines and Emissions (CAFEE).

\subsection{Experimental Setup}

\subsubsection{Test Engine Specifications}

A 2017 Cummins X15 Efficiency series was the test platform. The X15 is a $15 \mathrm{~L}$ inline 6 cylinder engine rated for class 8 on-road heavy-duty vehicles. The engine is rated for $500 \mathrm{hp}$ and a peak torque of $1850 \mathrm{lb} .-\mathrm{ft}$. It is equipped with a VGT, air-to-water charged air cooler (CAC), and a high-pressure common rail fuel injection system. The high-pressure fuel system allows for multiple injection events per combustion cycle. The engine has specially designed pistons which allow for a reduction in heat transfer to the engine oil. The engine calibration is designed to improve fuel consumption. To further improve fuel efficiency, low friction systems are used on the engine to reduce losses associated with internal friction of the engine (Cummins Inc., 2017). An OEM aftertreatment system is connected to the engine but urea is not being injected into the SCR. The aftertreatment system was a traditional DOC, DPF, and SCR configuration. The water and fuel pump are the only component linked to the drive shaft, no other accessory units are equipped on the engine. Figure 8 shows a schematic of the general set up in used in the test cell. 


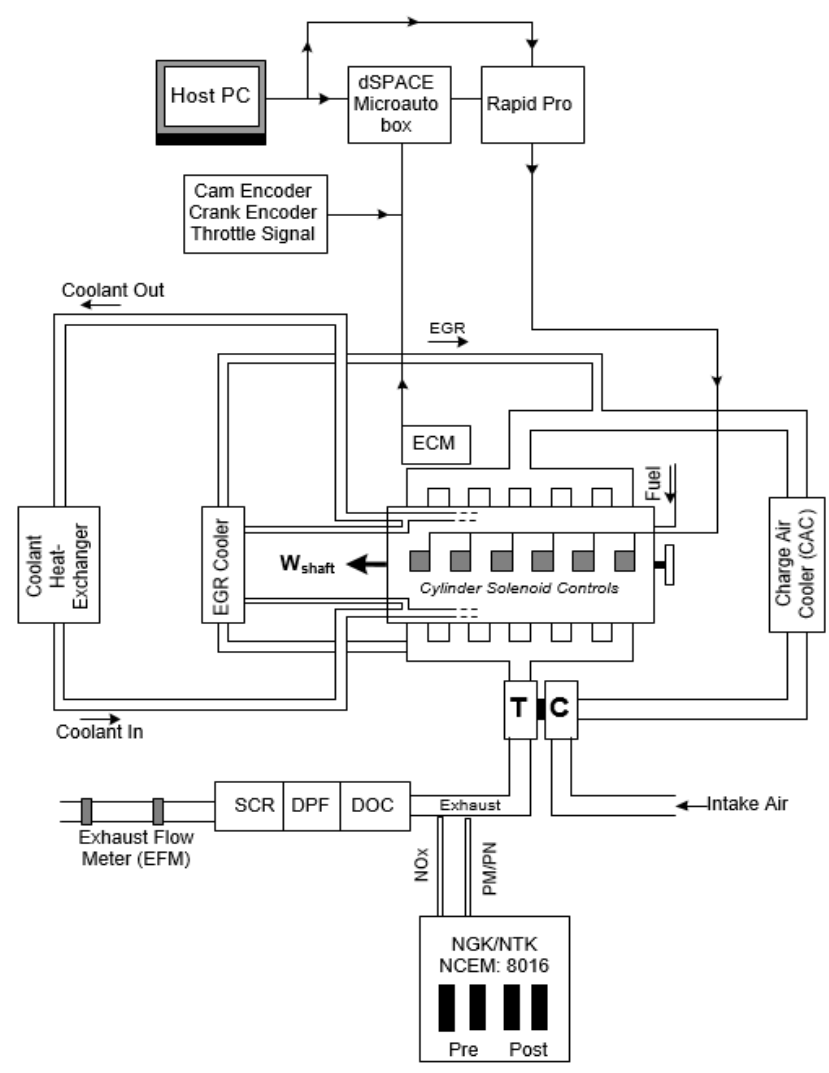

Figure 8: Engine Instrumentation Schematic

Jacobs Vehicle Systems' (JVS) cylinder deactivation system uses the engines oil hydraulic system to disable individual cylinder valves with minimal hardware changes to the OEM engine. The JVS system uses a modified rocker shaft as well as rocker arms and valve bridges to achieve this. Rerouting of oil gallery's is accomplished by activating a solenoid to allow oil passage through the rocker shaft and into the rocker arms. The modified valve bridges, when hydraulically activated, cancels the valve motion by detaching a piston inside of the valve bridge from the body which is rests on the valve stems. Figure 9 below shows a cross sectional drawing of JVS's CDA valve bridge. The lost motion system is patented by JVS. 


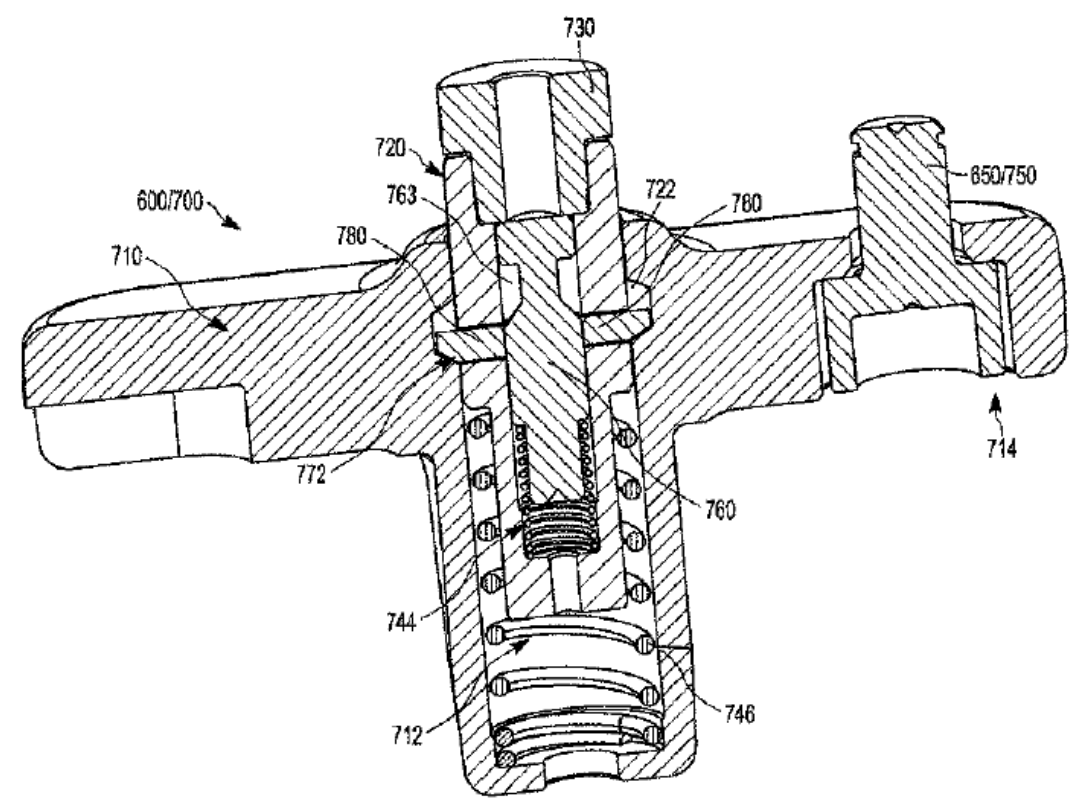

Figure 9: CDA Valve Bridge Cross Section Drawing (Baltrucki et al., 2017)

Due to little additional hardware needs, the technology has the ability to be cost effective compared to variable valve actuation systems. A relatively simple control strategy can be used for CDA with JVS's technology. There is potential for more in-depth control algorithms based off of engine needs and ability to develop such systems. A cost-effective system is critical to OEM due to already high cost of developing HDD engines. JVS has demonstrated full operation within engine operating ranges as well as outside extremes of the engines operating range. The system has shown that ability to properly sequence valve cancelation events while trapping air in the cylinder. The system needs to be "burped" regularly to ensure CDA does not contribute to an increase in oil consumption due to piston blow by. After too many canceled events, the combustion chamber will be in vacuum and start to pull oil up into the combustion chamber. The hydraulic actuators are JVS solenoids which are identical to the ones used for their engine brake. Limited testing has been performed at near freezing operating conditions due to limitations at JVS and WVU laboratories. 


\subsubsection{Engine Dynamometer and Test Cell}

A General Electric 500hp direct current heavy-duty platform dynamometer, capable of absorbing and delivering power at engine speeds up to $2500 \mathrm{rpm}$, was used for the testing. The engine was coupled with the dynamometer by a VULKAN VULKARDAN L shaft coupling and a universal joint drive shaft. The throttle input and speed control were provided using WVU CAFFE's in-house test cell software. Charge air cooler (CAC) and engine coolant loops are all cooled using CAFEE's in house coolant loop for the engine test cell. Monitoring of ECU fault codes was made capable by using the OEMs proprietary calibration software. The OEMs calibration software was also used for fuel measurement. The OEM calibration software was also used for developing new calibration maps and running steady state testing points. Steady state points were selected by examining the FTP and LLC operation points plotted on the lug curve. The points that were selected were all $30 \%$ or under rated torque of the engine, while three engine speeds were picked for developing the new calibration maps.

\subsubsection{External Engine Sensors}

To monitor all engine parameters needed, additional external sensors were implemented. Intake air, exhaust, coolant, and oil were all instrumented with fully sheathed ungrounded Omega K-type thermocouples for temperature measurements. K-type thermocouples are capable of temperature measurements between -200 and $1250{ }^{\circ} \mathrm{C}$. With a measurement uncertainty of $2.2^{\circ} \mathrm{C}$ or $0.75 \%$ above $0{ }^{\circ} \mathrm{C}$. Thermocouples were checked for linearity verification according to 40 CFR Part 1065 Subpart D. Thermocouple's were checked using a FLUKE thermocouple calibrator and verified against measured values by the data acquisition system. 
In-cylinder pressure measurements were needed to analyze how calibration changes altered combustion within the cylinder. The OEM provided a custom cylinder head which had pressure ports machined into the original casting. The cross tubes, which go from inside of the valve cover to the top of the combustion chamber, were bored through the coolant gallery's to provide cooling to the pressure transducer. Kistler $6125 \mathrm{C}$ high-speed pressure transducer was used for in-cylinder pressure measurements. Kistler designed custom cross tubes to fit their $6125 \mathrm{C}$ model into the OEMs cross tubes. The $6125 \mathrm{C}$ model is ground isolated that does not require an external cooling source. The sensor has a maximum pressure reading of 300 bar and has a resolution of $37 \mathrm{pC} /$ bar. The pressure sensor was connected to an in-house developed software for in-cylinder pressure data acquisition which uses National Instruments hardware. A 720-pulse encoder is connected to the crank shaft for speed and position measurement. The encoder used has an index pulse to indicate when one full revolution has been made in case a pulse is missed. The encoder is up sampled to 1440 for a resolution of 0.25 crank angle degrees per pulse.

To measure exhaust flow, Sensors Semtech-Exhaust Flow Meter (EFM) system was used after the OEM aftertreatment system. The EFM used Sensor Tech-EFM software for data acquisition. The EFM is capable of measuring up to 1800 SCFM. Bernoulli's equation of pressure and fluid flow are the basis for the EFMs measurement. Multiple pressure measurements allow for an average pressure reading along the cross-section of the EFM to account for variable velocity profiles. The EFM was verified using a laminar flow element (LFE) to measure air at a specified temperature. The LFE was within date of certification and allowed for the EFM to be validated against it. 
Additionally, on the exhaust was the NGK NCEM-8016, shown in Figure 10. The NGK system is used to measure particulate matter (PM), particle number (PN), oxygen content $\left(\mathrm{O}_{2}\right)$, and NOx for engine outlet concentrations. Both the PM/PN and NOx sensor are placed between the turbine outlet and the aftertreatment inlet. The following are the units of measurement for each species; PM $\left(\mathrm{mg} / \mathrm{m}^{3}\right), \mathrm{PN}\left(\# / \mathrm{cm}^{3}\right)$, NOx $(\mathrm{ppm})$, and $\mathrm{O}_{2}(\%)$. The PM/PN sensor requires daily maintenance of cleaning the sensor to ensure that PM does not accumulate inside of the sensor.

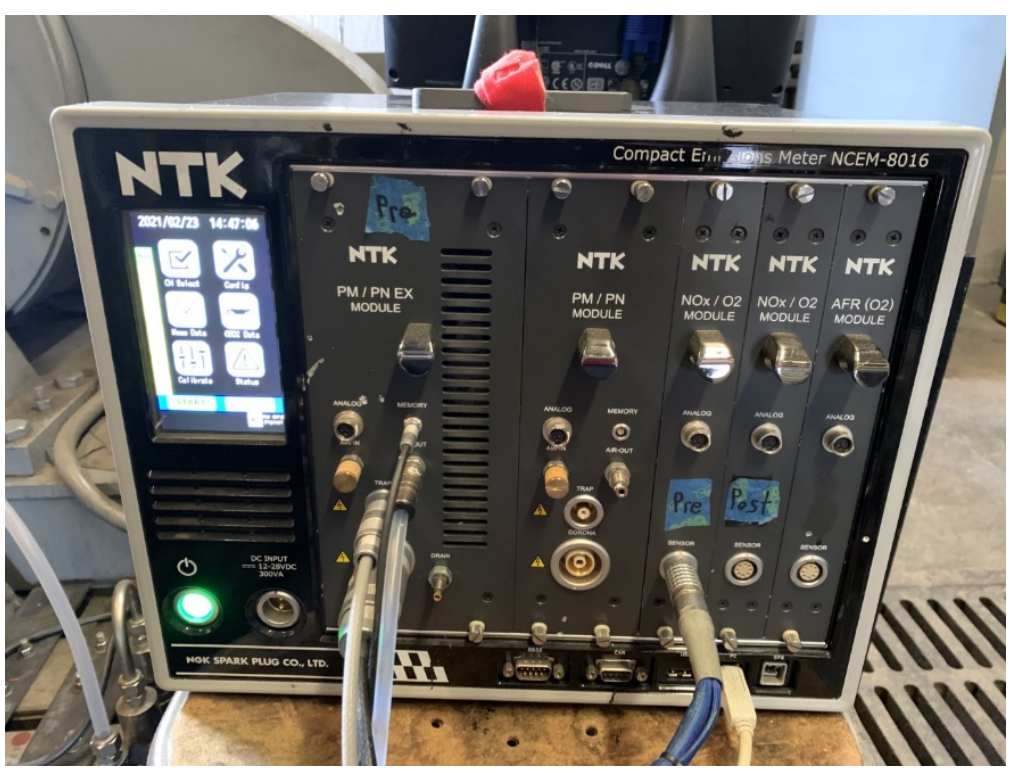

Figure 10: NGK NCEM in Test Cell

\subsection{4 dSPACE Hardware}

Valve control algorithms were developed in MATLAB's Simulink environment. Engine speed and position were based off of the engine's camshaft and crankshaft sensor, which were spliced into the dSPACE hardware. To determine speed, rising edges on the crankshaft encoder were counted within a fixed period of time. The engine crankshaft encoder is a sixty minus two configuration where each tooth is six degrees of rotation. The minus two denotes where top 
dead center (TDC) is of cylinder one or six, depending on where each cylinder is within the 4stroke cycle. The camshaft tone wheel has seven missing teeth where six of the teeth are equally spaced sixty degrees apart. The seventh missing tooth is spaced 30 degrees from another tooth which indicates TDC for cylinder one. Within the first two rotations of the engine, the algorithm aligns the missing teeth on the crank encoder with the two closely spaced missing teeth on the cam encoder wheel. After the first two revolutions, a function is built in to always reset engine position to zero after the two missing teeth on the crank have been seen and the crank completing one revolution already. This ensures that if a tooth is missed, it will not compound in the next engine cycle. In Figure 11, the analog inputs into dSPACE are seen along with signal processing blocks.

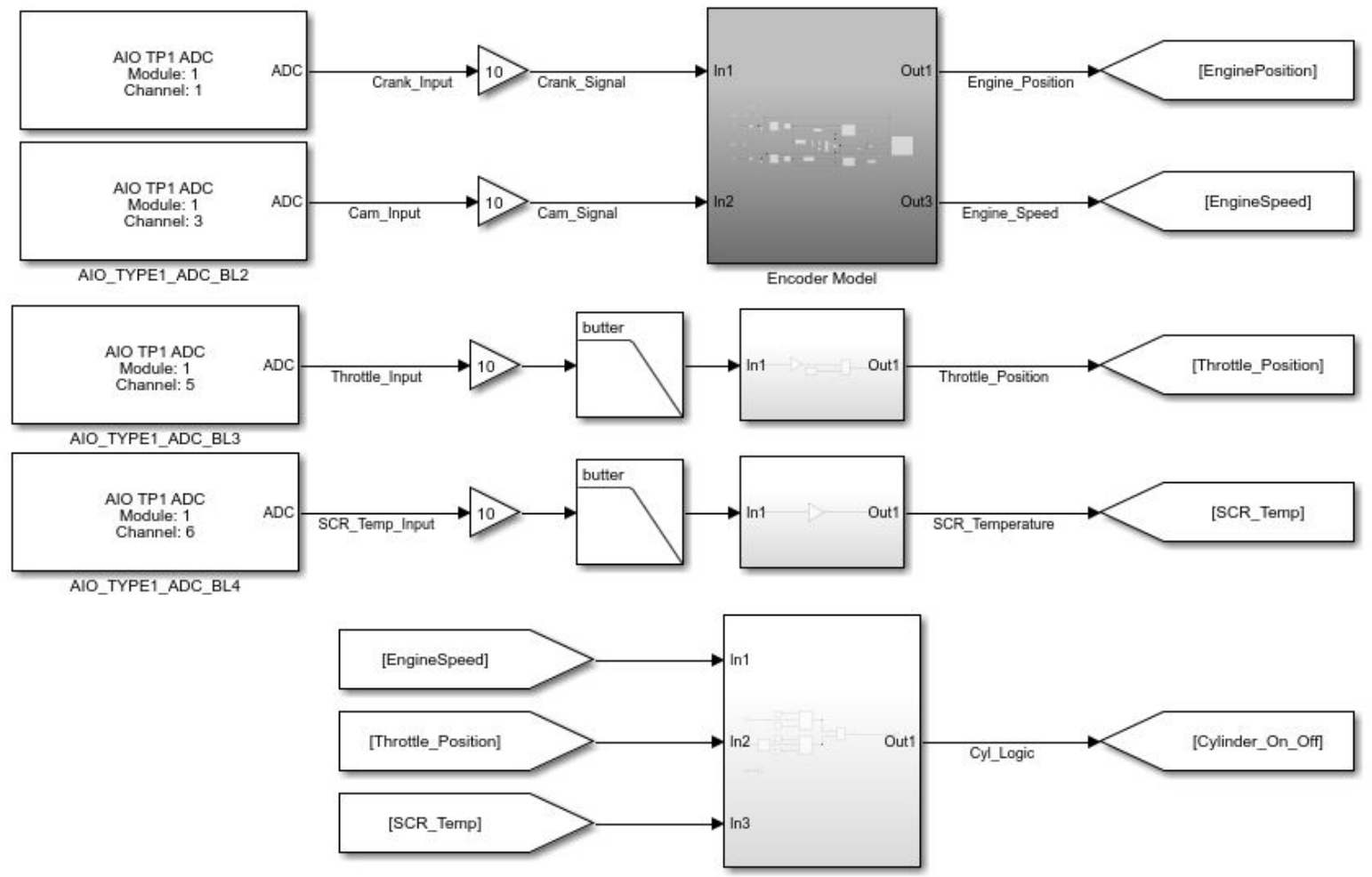

Figure 11: dSPACE External Signals and Logic Model 
The dSPACE MicroAutoBox and RapidPro are used as the control module and actuation hardware for the hardware in the loop (HIL) system. System control was designed to meet JVS's control needs for the CDA hardware. The RapidPro is the low side driver to controller when the CDA solenoids need to turn on/off. Current control is only capable of steady state testing and CDA during motoring of transient test cycles. The current transient control is to turn on CDA while the engine is motoring. WVU's transient cycles are based off of dynamometer speed and engine throttle to achieve desired torque. For initial transient testing, engine speed and throttle position were used to determine when the CDA hardware was allowed to function. When zero throttle was measured and the engine was above $800 \mathrm{rpm}$, the CDA solenoids would be actuated. Figure 12 shows the dSPACE specific "low side driver" blocks which is what triggers the drivers for power to be turned on and off for the valve solenoids. When the respective cylinder was to turn on/off and the engine position was correct, the logic signal would pass to the low side driver blocks and trigger the solenoids.

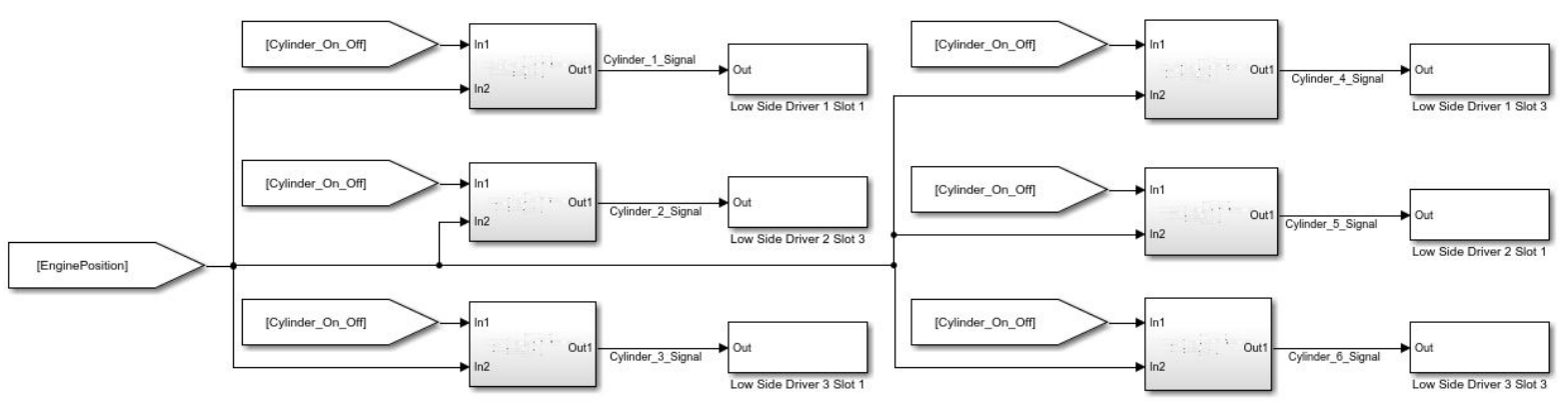

Figure 12: dSPACE Low Side Driver Triggers Model 


\subsection{Methodology}

\subsubsection{Steady State Calibration}

For steady-state testing, the majority of LLC operation is inside of the engine speeds of $800 \mathrm{rpm}$ up to $1300 \mathrm{rpm}$. To reduce the number of needed tests; $800 \mathrm{rpm}, 1000 \mathrm{rpm}$ and 1200 rpm were selected. Loading points under $30 \%$ rated torque were evaluated due to SCR inlet temperatures being near or under $250^{\circ} \mathrm{C}$. The baseline analysis was performed with normal six-cylinder operation. In Figure 13, the torque curve for the engine is shown as the solid black line. The highlighted light green area shows where $30 \%$ rated torque is. The green diamonds show steady-state test points are located. Finally, the blue astricts show where every speed and torque setpoint for the LLC falls underneath the torque curve.

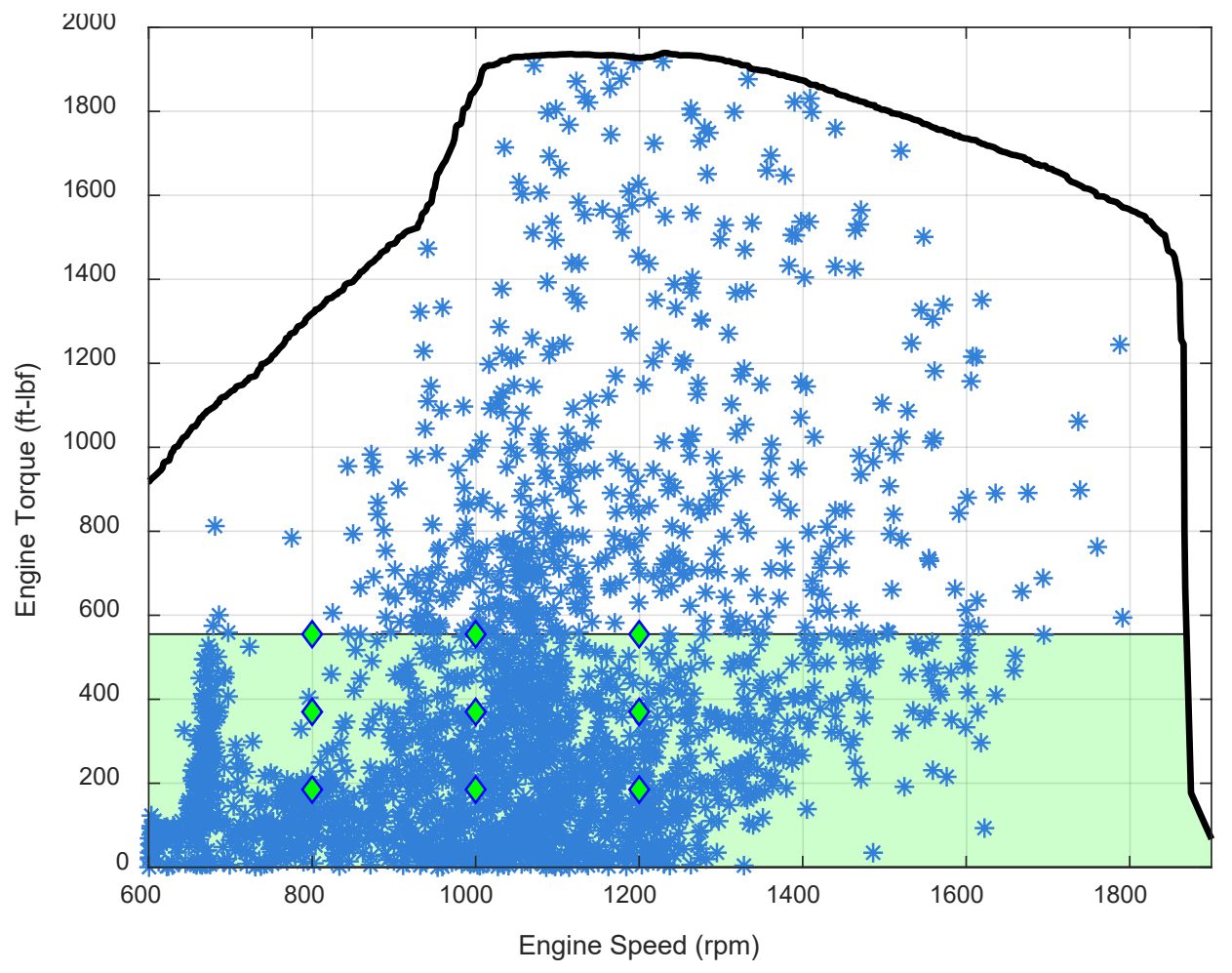

Figure 13: Torque Curve with LLC Points and CDA Test Points 
The use of the specific engine speeds $800 \mathrm{rpm}, 1000 \mathrm{rpm}$, and $1200 \mathrm{rpm}$ were selected to build a calibration map that would enclose most of the operation points. Specifically, 800 rpm was selected to identify how the engine would perform with an elevated idle at $800 \mathrm{rpm}$ while in CDA. A portion of points fall around the $650 \mathrm{rpm}$ range. With an elevated idle using CDA, those points would be shifted above $800 \mathrm{rpm}$. Load points of $10 \%, 20 \%$ and $30 \%$ were selected to map out how different loads changed engine calibration set points. Interpolation between set points would be used in transient operation. This would allow for calibration time to be reduced initially. After transient CDA operation, further optimization of calibration points could be performed for new targeted performance.

The OEM calibration software allowed the following parameters to be mapped; VGT position, EGR valve position, start of injection (SOI), intake air throttle (IAT) position, and total fueling. Due to limited access to calibration parameters, no other parameters were able to be manipulated for calibration development. Stopping the fuel injection of the deactivated cylinders was accomplished by unwiring those injectors from the wiring harness. The dynamometers measured torque was used to quantify the brake thermal efficiency. The measured torque was also used to ensure that the new calibration points were within $15 \mathrm{ft}-\mathrm{lb}$ of the actual loading point. The NCEM was used to observe NOx and PM to use best judgement on whether or not the NOx or PM increase was reasonable.

Three calibration maps were developed after the initial mapping of engine parameters. The first map developed was a thermal management calibration for 6-cylinder operation. This map could be used in cold start applications as well as extended idle operation. This calibration 
was useful to show what was the possible best temperature gains for the base engine. Modified 6-clyinder map development focused on no more than a $5 \%$ fueling penalty and using intake throttling to raise exhaust temperatures. SOI was typically advanced but stayed within 5 degrees to avoid the engine derating power. EGR valve position was typically $5 \%$ open since higher rates of EGR cooled exhaust temperatures. Certification cycle's would need to use EGR but for this study's focus, that is not necessary. The VGT position was highly sensitive to changes and would derate the engine if the modified calibration moved to far away from the engines desired set point. Typically, the VGT would not be moved more than $\pm 10 \%$ the engines desired set position. Each set point was unique to which parameter caused derate issues. Once the calibration map was created, smoothing of the new set points was performed to ensure stability for transient operation.

The second and third calibration maps were for CDA operation. Testing at the time was limited to three cylinders firing and three cylinders being deactivated $(3 \times 3)$. Either the front cylinder bank, cylinders 1, 2 and 3, were off or the back cylinder bank was deactivated. This was the optimum firing pattern to ensure the smoothest torque output was delivered by the engine. Torque delivery was every 240 degrees crank angle with $3 \times 3$ configuration with either cylinder bank deactivated. Typical torque delivery is 120 degrees crank angle for a 6 -cylinder engine. With any other combination of static cylinders deactivated, there would not be evenly spaced torque delivery for $3 \times 3 \mathrm{CDA}$. Any other configuration would have meant torque delivery would be unevenly spaced around the 720 degree cycle. The first of the two CDA maps was a fuel neutral (FN) strategy which used the baseline fueling quantity for total fueling. The fuel neutral calibration focused on generating the highest aftertreatment temperatures as possible. 
This calibration would typically still have a fuel benefit where attainable. If not, the fueling for CDA would be demanded as close to the baseline fuel demand as possible, while still delivering torque inside the allowable threshold. The third map was a fuel economy (FE) calibration map, where decreasing fueling while still raising aftertreatment temperature is possible. This calibration was designed to use as little fuel as possible while still meeting torque threshold requirements. Both a fuel neutral and a fuel economy calibration were developed for CDA operations.

Each load point had a warming up and cooling off protocol which allowed for consistency between all test points. The $10 \%, 20 \%$, and $30 \%$ rated torque had SCR inlet temperature thresholds of $130^{\circ} \mathrm{C}, 160^{\circ} \mathrm{C}$, and $190^{\circ} \mathrm{C}$ for data collection triggers. These temperatures were selected by analysis of baseline engine SCR temperatures. Specifically allowing for the rate of heating transfer to the SCR to slow toward a steady state temperature. To begin, the engine would be warmed up until the coolant thermostat opened, indicating the engine was hot. Once the engine was hot, the specific speed and load point would be set for the engine. Data collection would start once the SCR inlet met its threshold temperature for each load point. After three minutes, data collection would be stopped and the engine would be motored to cool the exhaust system down before testing the next point. Motoring of the engine would stop once the SCR inlet met its next threshold temperature. The next loading point would be set and the data collection process would start over again. If the next temperature threshold was not met during the previous test, the next point would be ran twice ensure the same warming up and cooling off protocol was accomplished. 
The aftertreatment system used as a thermal inertia system. Cooling due to urea injection is not a part of this study due to how the aftertreatment was used. The SCR inlet results will differ for various aftertreatment configurations that could be used by the OEM. Turbine outlet temperatures are best to analyze since the aftertreatment configuration will be unique for each application. A thermocouple at the inlet of the aftertreatment system was also analyzed to ensure that the temperature drop from the turbo outlet was not outside of acceptable limits. The temperature drop expected was to be within $20^{\circ} \mathrm{C}$ to $30{ }^{\circ} \mathrm{C}$, which was provided by the OEM.

\subsubsection{Motoring Cool Down}

Motoring coast down, or cool-down, curves were developed with the baseline 6 cylinders and then various amounts of cylinders deactivated. Each test point was taken up to a steady-state temperature with specific engine speed and loading to ensure consistent heating of the aftertreatment system. The loading of $1100 \mathrm{rpm}$ and $670 \mathrm{ft}-\mathrm{lbf}$ was selected due to the point having a steady state temperature near $250{ }^{\circ} \mathrm{C}$. The temperature was chosen since the SCR has optimum performance above $250^{\circ} \mathrm{C}$. When that temperature was met, the throttle to the engine would be cut and then the speed for the testing point would be set. If CDA was active, it would be turned on when the speed test point was set. The baseline was normal motoring with no CDA then 1-, 2-, and 3-cylinders were cut. The engine speeds of $800 \mathrm{rpm}$, $1200 \mathrm{rpm}$ and $1500 \mathrm{rpm}$ were used for the motoring tests. Once each test configuration reached an SCR inlet of $170^{\circ} \mathrm{C}$, the test would be concluded. The lower threshold of $170^{\circ} \mathrm{C}$ was selected because the peak rate of cooling was reached and started to decrease. Additionally, 
the SCR would have less than $20 \%$ NOx conversion efficiency below $170{ }^{\circ} \mathrm{C}$ (Cavataio et al., 2007).

\subsubsection{Transient CDA Motoring}

Transient test cycles were conducted following recommendations of CFR 1065

regulations. Each test configuration would start with a cold start and hot start FTP proceeded by CARB's LLC. The baseline was ran to collect temperature profiles for each cycle, this was performed with normal 6-cylinder operation. Exhaust mass flow rate and engine out emissions were also all collected during each cycle. In addition, two other operating conditions were tested. Due to not having ECU access using dSPACE at the time, CDA was only active while the engine was motoring. A model was developed to use engine speed and throttle to know when the engine was motoring. A minimum engine speed was used to ensure CDA would not be triggered during idle. Test cell throttle signal was mapped to throttle position given in OEM calibration software. The CDA tests consisted of 3-cylinders and 6-cylinders deactivated during motoring to evaluate the cooling effect during transient test cycles. Histograms of motoring points in both of the FTP and LLC can be found in Appendix B: Motoring Occurrences During Transient Cycles. Specific areas of emphasis were determined by examining the thermal profiles and refencing to the motoring histograms. 


\section{Chapter 4: Results}

\subsection{Introduction}

Chapter Four presents the data collected during the study. This chapter is split into different sections based on what data was collected. Initial data analysis was performed to ensure all of the data was consistent. If a data points did not have consistent results with other points, another test would be performed to recollect data until a consistent values was measured. Each section has various procedures that were followed and discussed in Chapter Three. Analysis and discussion of the data collected are provided below.

\subsection{Steady State}

Steady state testing was conducted such that there was uniform time for warming up and cooling off protocol for each point, which is discussed in Chapter Three. All exhaust measurements were based off of a thirty second average during the test once calibration parameters were fixed. Four calibration points were analyzed for each test point. Baseline is the engine ECU commanded set points for the specified load and speed. Modified is 6 cylinder operation with a focus on increasing exhaust temperature with minimal fuel penalty. Fuel neutral ( $F N)$ is $3 \times 3$ CDA where fueling was as close to baseline as needed to reach the specified load at the given speed. Fuel economy (FE) is also $3 \times 3 \mathrm{CDA}$ which used the least fuel possible to attain the load within $15 \mathrm{ft}$-lbf of engine out torque. In-cylinder pressure measurements were collected to initially analyze how each calibration parameter altered combustion. All numerical results are presented in Appendix A: Steady State Results. 
The rate of energy input into the engine for steady state testing was given by the OEM calibration software. The fuel energy used was calculated by the mass flow rate of fuel, $\dot{m}_{\text {fuel }}$ and the assumed lower heating value (LHV) of diesel fuel which is $42.6 \mathrm{MJ} / \mathrm{kg}$ (Alternative Fuels Data Center, 2021).

$$
Q_{\text {fuel }}=\dot{\mathrm{m}}_{\text {fuel }} * L H V
$$

Equation 2: Fuel Energy Formula

Brake thermal efficiency is a measure of how much power is being generated by an engine with the given amount of fuel input. Typically at full load, on-road diesel engines have an approximate efficiency of $42 \%$. Roughly $28 \%$ of energy is lost in the exhaust, $28 \%$ is lost to heat losses in the engine and $2 \%$ to miscellaneous sources (Folkson, 2014). Brake power was directly measured from the test cell software and fuel energy were calculated in Equation 2.

$$
\eta_{b t}=\frac{\text { brake power }}{\text { fuel engergy }}
$$

\section{Equation 3: Brake Thermal Efficiency}

Normalized fueling and BTE is where a test point is divided by the baseline for that specific load and speed. Thus, baseline will always have a value of 1 . Air fuel ratio was calculated from measuring the oxygen content of the exhaust and shown below in Equation 4. $\mathrm{O}_{2}$ is measured in percentage and 14.5 is used as the stoichiometric ratio for diesel (Air-Fuel Ratio, Lambda and Engine Performance, 2018).

$$
A F R_{\text {diesel }}=14.5 * \frac{21}{\left(21-O_{2}\right)}
$$


NOx mass emissions rates were calculated using NOx concentration in PPM and the exhaust flow rate $(\mathrm{kg} / \mathrm{hr})$ from the EFM. Equation 5 below uses a correction factor which transforms NOx ppm to $\mathrm{mol} / \mathrm{mol}$ and flow rate from $\mathrm{kg} / \mathrm{hr}$ to $\mathrm{mol} / \mathrm{sec}$. Density is also included to convert to a mass (Pondicherry, 2020).

$$
\operatorname{NOx}\left(\frac{g}{S}\right)=0.001588 * \text { Exhaust Flow }\left(\frac{\mathrm{kg}}{\mathrm{hr}}\right) * \operatorname{NOx}(\mathrm{ppm}) * \frac{1}{3600}
$$

Equation 5: NOx Mass Flow Rate

NOx measurements occurred wet, thus intake humidity corrections are necessary. Calculations for NOx correction followed CFR 1065 guidelines. Vapor pressure of water at saturation temperature, $\mathrm{P}_{\mathrm{H} 2 \mathrm{O}}$, is calculated in Equation 6. Saturation temperature, $\mathrm{T}_{\text {sat, }}$ is the intake air temperature of the engine (United States Enviromental Protection Agency, 2013a).

$$
\begin{aligned}
\log _{10}\left(P_{H_{2} O}\right)= & 10.795874 *\left(1-\frac{273.16}{T_{\text {sat }}}\right)-5.028 * \log _{10}\left(\frac{T_{\text {sat }}}{273.16}\right)+1.05475 * 10^{-4} \\
& *\left(1-10^{-8.297 *\left(\frac{T_{\text {sat }}}{273.16}-1\right)}\right)+0.42873 * 10^{-3}\left(10^{4.76955\left(1-\frac{27.16}{T_{\text {sat }}}\right)}-1\right)-0.2138602
\end{aligned}
$$

\section{Equation 6: Vapor Pressure of Water}

Relative humidity, shown in Equation 7, accounts for the amount of water in an ideal gas, $\mathrm{X}_{\mathrm{H} 2 \mathrm{O}}$. Relative humidity, $\mathrm{RH} \%$, is measured directly from the test cell. Absolute pressure, $\mathrm{P}_{\mathrm{abs}}$, is located at the relatively humidity measurement location (United States Enviromental Protection Agency, 2013a).

$$
X_{\mathrm{H}_{2} \mathrm{O}}=\frac{R H \% * P_{\mathrm{H}_{2} \mathrm{O}}}{P_{a b s}}
$$


The NOx correction factor for compression ignition engines is presented in Equation 8 (United States Enviromental Protection Agency, 2013a). Baseline and Modified calibration NOx correction factor was 0.894 for each calibrations test points. The fuel economy and fuel neutral calibration NOx correction factor was 0.896 .

$$
\begin{gathered}
K_{h}=\left(9.953 * X_{\mathrm{H}_{2} \mathrm{O}}+0.832\right) \\
\text { Equation 8: NOx Correction Factor }
\end{gathered}
$$

Brake specific NOx (BsNOx), shown in Equation 9, is the measure of NOx emissions with respect to the brake horsepower (bhp) being produced by the given engine.

$$
\operatorname{BSNOx}\left(\frac{g}{b h p * h r}\right)=\operatorname{NOx}\left(\frac{g}{s}\right) * K_{h} * \frac{3600}{b h p}
$$

Equation 9: Brake Specific NOx

Exhaust energy was calculated using basic thermodynamic principles. The specific heat $c_{p}$ was assumed as standard air to simplify analysis since diesel exhaust composition is directly related to air to fuel ratio. In a study conducted by Thiruvengadam et al., the group found that there was an $R^{2}$ of 0.99 between specific heat of air versus the specific heat of the exhaust while calculating exhaust energy (Thiruvengadam et al., 2020). They also noted that accounting for exhaust species would give more accurate results for some specific operating conditions. Exhaust flow rate, $\dot{m}_{\text {exhaust, }}$ was measured using the EFM. Exhaust temperature had three locations of measurement and each location will be specified which location is used. A 
reference temperature of $0{ }^{\circ} \mathrm{C}$ was used to be able to compare rate of heat being delivered at each exhaust location across all operating conditions tested.

$$
\begin{gathered}
Q_{\text {exhaust }}=\dot{\mathrm{m}}_{\text {exhaust }} * c_{\text {pair }} * T_{\text {exhaust }} \\
\text { Equation 10: Rate of Heat Delivery }
\end{gathered}
$$

\subsubsection{RPM Results}

Since $30 \%$ rated torque was unable to be reached in CDA with three active cylinders, $10 \%$ and $20 \%$ rated torque points are analyzed in this section. In Figure 14 , results for 800 rpm steady state testing can be observed. At $10 \%$ and $800 \mathrm{rpm}$, CDA had the greatest fuel economy benefit and thus BTE increase over the baseline. With a $10.7 \%$ and $1.6 \%$ reduction in fuel for $10 \%$ and $20 \%$ rated torque, the fuel economy calibration developed a $55^{\circ} \mathrm{C}$ and $111^{\circ} \mathrm{C}$ increase for turbine outlet temperature over the baseline, respectively. The fuel neutral calibration, which had a $4.8 \%$ reduction and $0.4 \%$ increase in fuel, demonstrated a $103^{\circ} \mathrm{C}$ and $117^{\circ} \mathrm{C}$ increase, respectively, over the baseline TOT. For the $10 \%$ rated torque and using the FN calibration, the SCR inlet increased by $23^{\circ} \mathrm{C}$. The FE calibration had an SCR inlet increase of 16

${ }^{\circ} \mathrm{C}$. At $20 \%$ rated torque, the $\mathrm{FN}$ and $\mathrm{FE}$ calibration performed virtually the same with roughly a $34{ }^{\circ} \mathrm{C}$ increase for the SCR inlet.

The differential in TOT versus SCR inlet temperature difference can be captured by examining exhaust flowrate and the energy of the system. The fuel neutral calibration had a $40 \%$ and $34 \%$ reduction in exhaust flow rate for $10 \%$ and $20 \%$ rated torque, respectively. The fuel economy calibration had a $30 \%$ and $45 \%$ reduction in exhaust flow for $10 \%$ and $20 \%$, respectively. The FE calibration resulted in a SCR inlet energy at the end of the test to be an 8.3 
$\mathrm{kW}$ reduction for $10 \%$ and $20.6 \mathrm{~kW}$ reduction for $20 \%$ rated torque. Those equate to $27.1 \%$ and 41.1\% less energy transfer for CDA operation compared to the baseline. The FN calibration had $11.1 \mathrm{~kW}$ and $13.9 \mathrm{~kW}$ less of heat energy in the SCR at the end of the test. Equating to a $36.2 \%$ and $27.7 \%$ less heat energy transfer for CDA versus the baseline. Due to CDA having up to 117 ${ }^{\circ} \mathrm{C}$ higher exhaust temperature, the mass flow reduction was able to be overcome while heating the aftertreatment for all test points at $800 \mathrm{rpm}$.
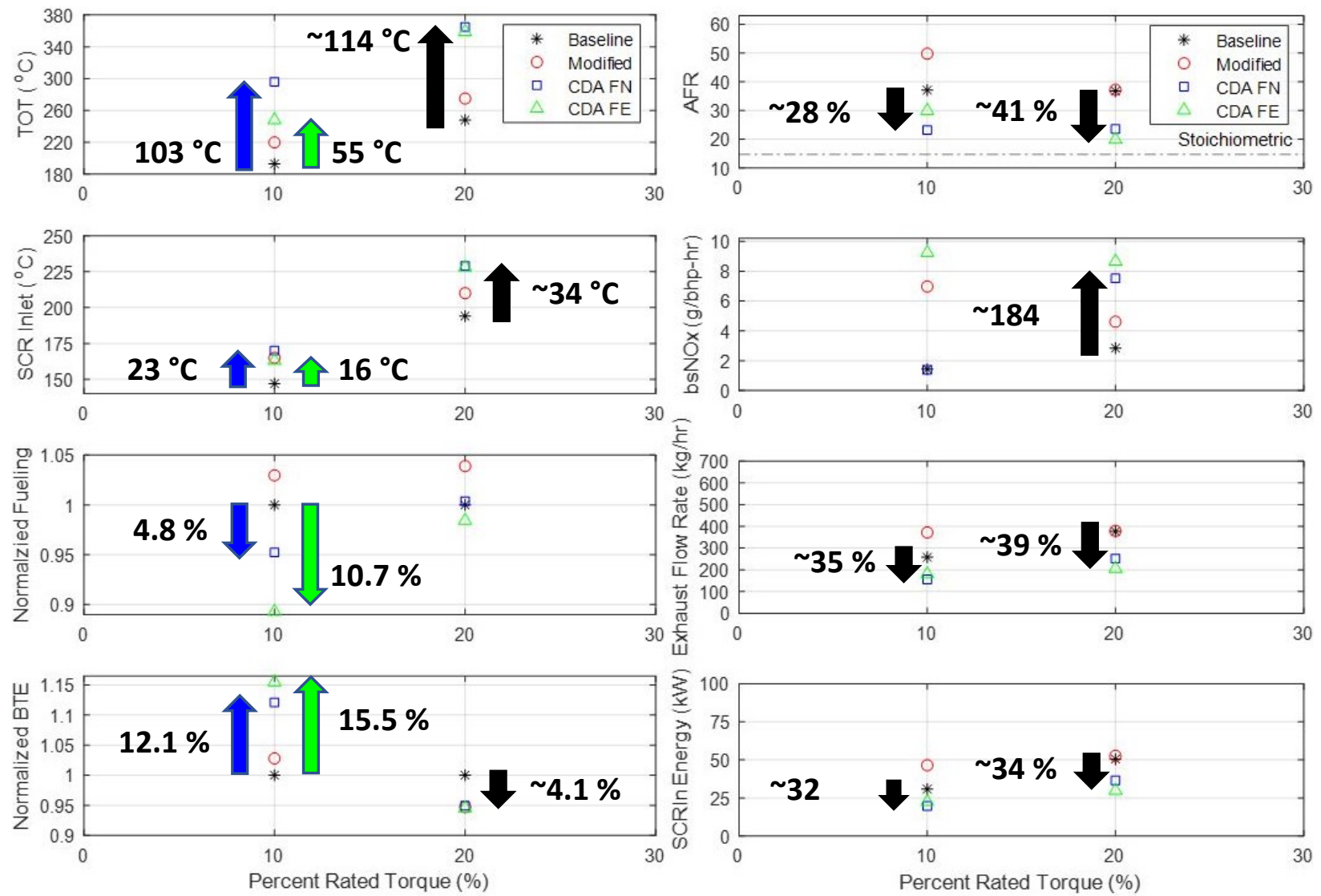

Figure 14: 800 RPM Steady State Data

Due to the nature of the calibrations developed, EGR was used as little as possible as EGR decreases exhaust temperatures. This is due to the fact that the exhaust has water vapor which will absorb heat in the compression stroke, thus decreasing the in cylinder temperature 
before combustion occurs. Adversely, due to the lower combustion temperature particulate matter formation will increase while NOx emissions will decrease (Agrawal et al., 2004). Injection timing is also a critical parameter on controlling the combustion process. Ignition advancing is moving the fuel injection further away from TDC which results in more power generation but also increased NOx with reduced exhaust temperatures. Retarding ignition is moving injection close to TDC or after. This requires more fuel for the same power output but has less NOx created and increased exhaust temperatures.

Since EGR was used as little as possible to demonstrate maximum temperatures possible, engine out NOx emissions could be up to six times the baseline engine. At $10 \%$ rated torque, the FE calibration increased NOx from $1.44 \mathrm{~g} / \mathrm{bhp}-\mathrm{hr}$ for the baseline to $9.24 \mathrm{~g} / \mathrm{bhp}-\mathrm{hr}$. The FN calibration had engine out NOx of $1.39 \mathrm{~g} / \mathrm{bhp}-\mathrm{hr}$. The $20 \%$ rated torque point resulted in the FE and FN calibration NOx output to be $8.66 \mathrm{~g} / \mathrm{bhp}-\mathrm{hr}$ and $7.53 \mathrm{~g} / \mathrm{bhp}-\mathrm{hr}$, respectively. While the baseline engine had a NOx output of $2.85 \mathrm{~g} / \mathrm{bhp}-\mathrm{hr}$.

To further analyze the comparison of exhaust energy, turbine outlet and SCR inlet are compared as well as with respect to the fuel used. Figure 15 shows the exhaust energy results as well as the comparison when normalized by fuel used. Baseline $10 \%$ rated torque turbine outlet exhaust energy was $34.2 \mathrm{~kW}$ while FN and FE were $25.7 \mathrm{~kW}$ and $27.1 \mathrm{~kW}$. At $20 \%$ rated torque, the baseline engine turbine out energy was $56.5 \mathrm{~kW}$. The FN outlet was $47.4 \mathrm{~kW}$ and FE was $38.3 \mathrm{~kW}$. Traditionally, an OEM's wants as little fuel energy to be lost in the exhaust since that is a loss in potential power output. For CDA, this trait is desirable since it is being used as a method to increase aftertreatment temperatures with little to no fuel penalty, as well as the 
possibility for a fuel benefit. The comparison is not directly related to fuel energy since mass flowrate is a contributing factor of exhaust energy transfer rates.

It was unexpected that the $20 \%$ rated torque had a higher exhaust energy per fuel compared to the $10 \%$ rated torque. This was unexpected since the engine becomes more efficient as load increases, which would mean more fuel is converted to useful work instead of being lost in the exhaust. The baseline engine converted $0.48 \mathrm{~kW}$ for $10 \%$ rated torque and 0.52 kW $20 \%$ rated torque of energy to the exhaust for every $1 \mathrm{~kW}$ of fuel at the turbine outlet. Fuel neutral calibration was able to convert $0.38 \mathrm{~kW}$ and $0.43 \mathrm{~kW}$ for $10 \%$ and $20 \%$ rated torque, respectively. While the fuel economy calibration converted $0.42 \mathrm{~kW}$ for $10 \%$ and $0.36 \mathrm{~kW}$ for $20 \%$ rated torque. For the $10 \%$ rated torque, the $\mathrm{FN}$ had a reduction in $20.8 \%$ where the $\mathrm{FE}$ reduction was $12.5 \%$. This is compared to the $24.9 \%$ and $20.7 \%$ for $\mathrm{FN}$ and FE reduction, respectively, in turbine outlet energy. This comparison helps to show how mass flow dominated the absolute temperature gain when examining the effects of heat transfer in the exhaust for these calibration points. 

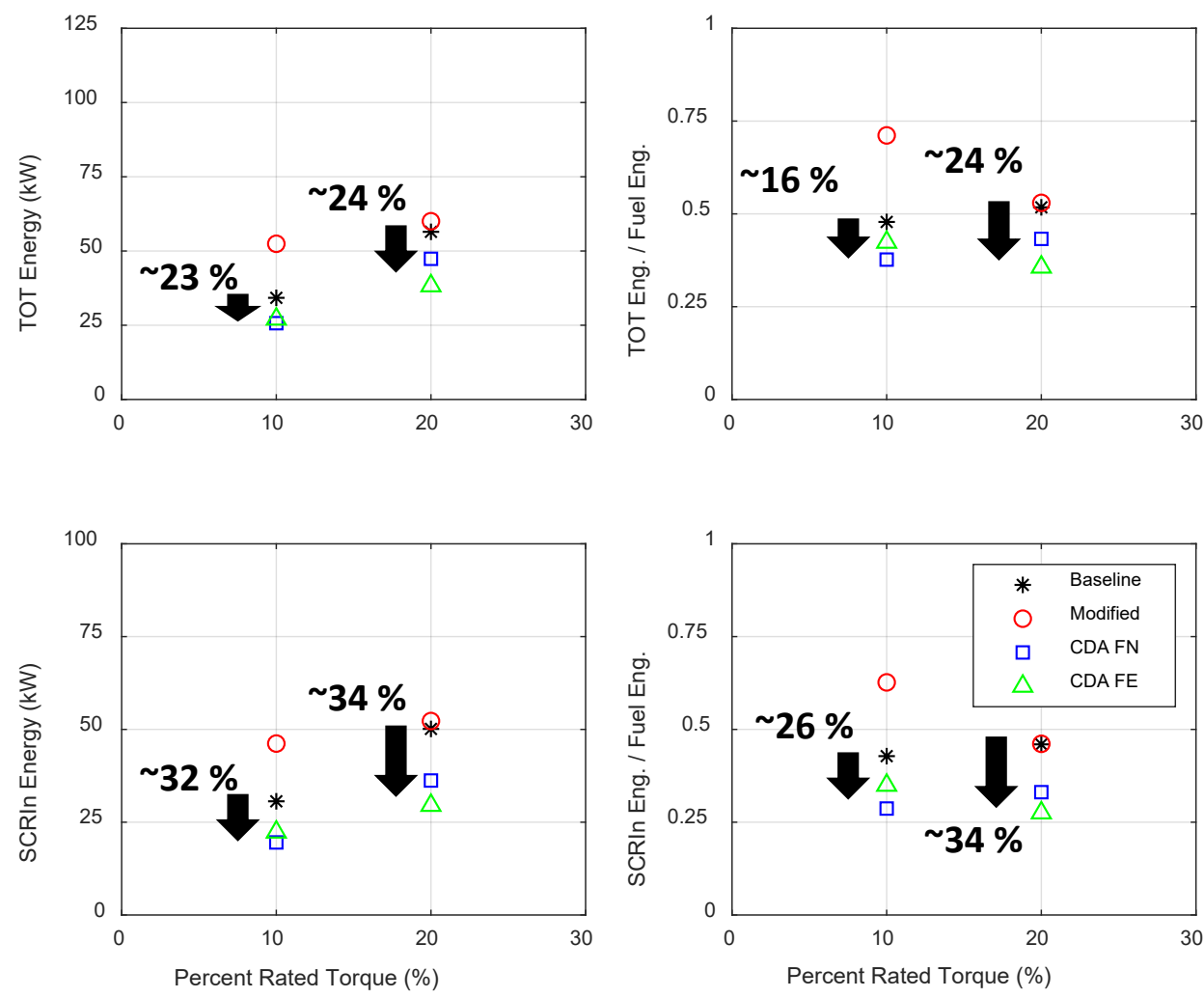

Figure 15: 800 RPM Exhaust Energy

The SCR energy per fuel energy showed similar results to the turbine outlet comparison but had lower conversion to heat due to the lower temperatures in the SCR. Baseline exhaust energy to fuel was $0.43 \mathrm{~kW}$ and 0.46 for $10 \%$ and $20 \%$ rated torque, respectively. Fuel neutral calibration resulted in $0.29 \mathrm{~kW}$ and $0.33 \mathrm{~kW}$ for $10 \%$ and $20 \%$ rated torque, respectively. Where the fuel economy calibration was $0.35 \mathrm{~kW}$ for $10 \%$ and $0.28 \mathrm{~kW}$ for $20 \%$ rated torque.

\subsubsection{RPM Results}

Again, 30\% rated torque was unable to be achieved with $3 \times 3$ CDA. The $1000 \mathrm{rpm}$ testing points proved to be the most difficult to create calibration points. With the access given for developing calibrations, moving engine parameters from where the engine should have been resulted in derate codes. The calibration parameters were unable to be moved into regions 
that would be best due to derate codes. Though these issues caused limitations, CDA was still able to be used for the 1000 rpm tests. Figure 16 shows the results collected.

Like the 800 rpm tests, $10 \%$ rated torque saw the best fuel economy and BTE benefit for $3 \times 3$ CDA. The fuel economy calibration had a $7.9 \%$ increase in BTE with a $10.3 \%$ reduction in fuel. Even with the reduction in fuel, TOT increased by $44^{\circ} \mathrm{C}$ and SCR inlet increased by $18^{\circ} \mathrm{C}$. The fuel neutral calibration resulted in a $4.2 \%$ reduction in fuel with a $5.2 \%$ increase in BTE. With the increased fueling versus the FE calibration, SCR inlet increased by $33^{\circ} \mathrm{C}$ and TOT increased by $83{ }^{\circ} \mathrm{C}$ over the baseline. Again, the $20 \%$ rated torque followed a similar trend as the 800 rpm results. Both the FN and FE decreased the BTE of the engine with a $4.6 \%$ and $3.8 \%$ decrease, respectively. Unlike the $800 \mathrm{rpm}$ test, both the FE and FN calibration had a fueling decrease. The fuel neutral calibration used $2.5 \%$ less fuel and the fuel economy calibration used 3.3\% less fuel. The fuel neutral calibration resulted in a TOT increase of $112{ }^{\circ} \mathrm{C}$ and an SCR inlet increase of $40{ }^{\circ} \mathrm{C}$. SCR inlet increased by $35^{\circ} \mathrm{C}$ while TOT increased by $101^{\circ} \mathrm{C}$ for the fuel economy calibration. 

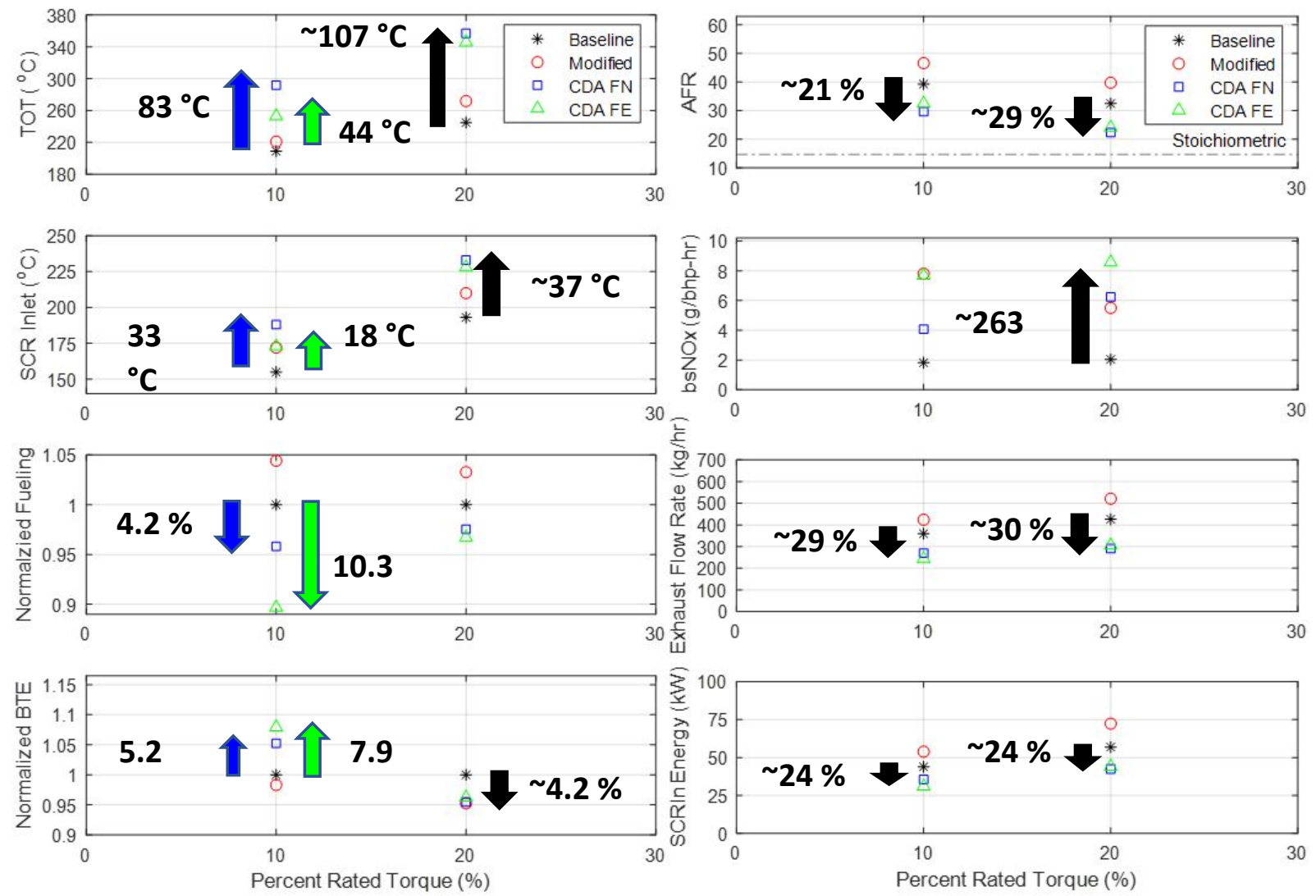

Figure 16: 1000 RPM Steady State Data

All of the $10 \%$ rated torque points for $1000 \mathrm{rpm}$ had reasonable AFR but the $20 \%$ CDA points started to become rich for optimum diesel combustion. The goal was to maintain AFR above 24 to 1 , the FN calibration point was 22 to 1 . As the AFR approached stoichiometric conditions, PM production increase while engine out torque stayed stagnant. Both CDA calibrations did not perform well with NOx since the focus was to maximize exhaust temperatures. Engine out NOx for $10 \%$ was $4.1 \mathrm{~g} / \mathrm{bhp}$-hr for the FN calibration and $7.7 \mathrm{~g} / \mathrm{bhp}-\mathrm{hr}$ for the FE calibration, where the baseline engine was $1.8 \mathrm{~g} / \mathrm{bhp}-\mathrm{hr}$. Testing the $20 \%$ rated torque, the baseline engine produced $2.0 \mathrm{~g} / \mathrm{bhp}-\mathrm{hr}$ engine out. FE calibration and FN calibration resulted in $8.6 \mathrm{~g} / \mathrm{bhp}-\mathrm{hr}$ and $6.2 \mathrm{~g} / \mathrm{bhp}-\mathrm{hr}$, respectively. 
Exhaust flow rate recovery performed better at $1000 \mathrm{rpm}$ test points than the $800 \mathrm{rpm}$. The baseline engine flowrates were $360 \mathrm{~kg} / \mathrm{hr}$ for $10 \%$ and $426 \mathrm{~kg} / \mathrm{hr}$ for $20 \%$. Fuel economy calibration was able to produce $244 \mathrm{~kg} / \mathrm{hr}$ and $306 \mathrm{~kg} / \mathrm{hr}$ for $10 \%$ and $20 \%$ rated torque, respectively. This resulted in a $32.2 \%$ reduction in flow for $10 \%$ and a $28.2 \%$ reduction for $20 \%$ rated torque. The fuel neutral calibration resulted in $269 \mathrm{~kg} / \mathrm{hr}$ for $10 \%$ rated torque and 290.4 for $20 \%$ and results in a $25.3 \%$ decrease for $10 \%$ rated torque and $31.8 \%$ decrease for the $20 \%$ rated torque test. For $3 \times 3$ CDA at $1000 \mathrm{rpm}, 18.2 \%$ to $24.7 \%$ of the mass flow was able to be recovered. The recovery in mass flow was due to optimization of VGT position to increase fresh air intake. Even with the reduction in mass flow through the exhaust, the SCR inlet temperature increased during steady state testing. The absolute temperature gain with CDA was able to overcome the mass flow deficit, like what was able to be accomplished for $800 \mathrm{rpm}$ CDA results.

Baseline engine SCR inlet energy was $43.6 \mathrm{~kW}$ for $10 \%$ and $56.5 \mathrm{~kW}$ for $20 \%$ rated torque. The fuel neutral calibration, which had a fuel savings, resulted in an SCR inlet of 35.3 $\mathrm{kW}$ and $42.1 \mathrm{~kW}$ for $10 \%$ and $20 \%$ rated torque, respectively. SCR inlet energy decreased by $19.0 \%$ for $10 \%$ and $25.5 \%$ for $20 \%$ rated torque, which was less of a decrease than the flowrate. These results show that the absolute temperature gains were able to partially compensate for the reduction in mass flow due to CDA. Calibration results for the fuel economy configuration demonstrated an SCR inlet energy of $30.9 \mathrm{~kW}$ and $43.8 \mathrm{~kW}$ at $10 \%$ and $20 \%$ rated torque, respectively. The energy decrease versus the baseline engine was $29.1 \%$ for $10 \%$ rated torque and $22.5 \%$ for $20 \%$ rated torque, respectively. 
To further analyze exhaust energy, turbine outlet energy was also evaluated. Exhaust energy specific results are shown in Figure 17 below. The baseline engine produced $49.5 \mathrm{~kW}$ at $10 \%$ and $63.4 \mathrm{~kW}$ at $20 \%$ rated torque. The fuel neutral calibration generated $44.1 \mathrm{~kW}$ and 53.8 $\mathrm{kW}$ for $10 \%$ and $20 \%$ rated torque points, respectively. The fuel neutral calibration decreased turbine outlet energy was $10.9 \%$ for $10 \%$ and $15.1 \%$ for $20 \%$ rated torque compared to the baseline. Turbine outlet energy for the fuel economy calibration was $36.9 \mathrm{~kW}$ and $55.5 \mathrm{~kW}$ for $10 \%$ and $20 \%$ rated torque. Resulting in a decrease from the baseline to be $25.5 \%$ and $12.5 \%$ for $10 \%$ and $20 \%$ rated torque.
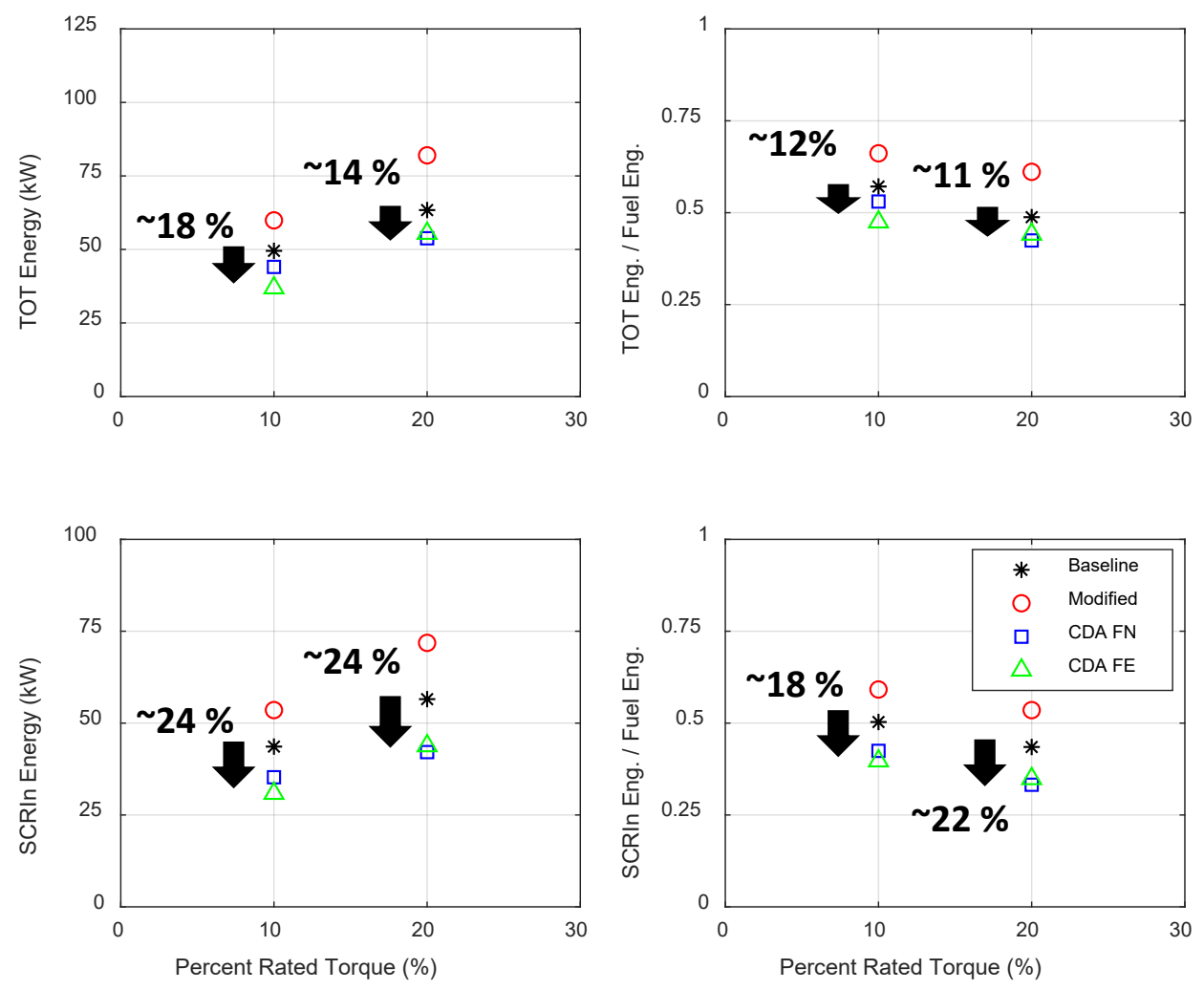

Figure 17: 1000 RPM Exhaust Energy

Again, to see how fuel energy and exhaust energy are related, both turbine outlet and SCR inlet exhaust energy were compared to energy provided by fuel. Unlike the $800 \mathrm{rpm}$ test, 
$20 \%$ rated torque was a lower conversion than the $10 \%$ rated torque for all four test configurations. The baseline engine turbine outlet produced $0.57 \mathrm{~kW}$ for every $1 \mathrm{~kW}$ of fuel for $10 \%$ and $0.49 \mathrm{~kW}$ for $20 \%$ rated torque. The SCR inlet converted $0.50 \mathrm{~kW}$ for $10 \%$ and $0.44 \mathrm{~kW}$ for $20 \%$ rated torque for every $1 \mathrm{~kW}$ of fuel used. The fuel neutral and fuel economy calibrations flipped which test point they were best at compared to the $800 \mathrm{rpm}$ results. This is due to the two points having roughly the same SCR inlet temperatures but the FE calibration had a higher exhaust flow rate. Fuel neutral demonstrated $0.53 \mathrm{~kW}$ for $10 \%$ and $0.42 \mathrm{~kW}$ for $20 \%$ rated torque per $1 \mathrm{~kW}$ of fuel for the turbine outlet. Following a similar trend, FN calibration had SCR inlet at $0.42 \mathrm{~kW}$ and $0.33 \mathrm{~kW}$ for $10 \%$ rated torque and $20 \%$ rated torque, respectively. The fuel economy turbine outlet conversion was $0.47 \mathrm{~kW}$ at $10 \%$ rated torque and $0.44 \mathrm{~kW}$ at $20 \%$ rated torque for $1 \mathrm{~kW}$ of fuel used. Likewise, the SCR inlet energy resulted in $0.40 \mathrm{~kW}$ and $0.35 \mathrm{~kW}$ for $10 \%$ and $20 \%$ rated torque, respectively.

When comparing SCR energy conversion performance for $10 \%$ rated torque, the FE calibration had a $20.0 \%$ decrease with respect to baseline. The FN calibration decreased by $16.0 \%$ versus the baseline for $10 \%$ rated torque. At $20 \%$ rated torque, the $\mathrm{FN}$ calibration decreased by $25.0 \%$ and the FE calibration decreased by $20.5 \%$. Again, since there was less fuel used for all CDA test points, this comparison is helpful to compare how the normalize exhaust energy changed. At the worst point, fuel neutral at $20 \%$ rated torque, there was a $25 \%$ reduction for exhaust energy while using CDA compared to the baseline. When in theory, the mass flowrate should have been half since only half of the cylinders are active while in $3 \times 3$ CDA. Absolute temperature gains and calibration strategies to increase intake air mass was critical in compensating for the reduction of flowrate due to CDA. The fuel neutral calibration was only a 
$16 \%$ deficit at $10 \%$ rated torque for exhaust flowrate. This point resulted in good performance of a calibration point to have a fuel benefit, while increasing exhaust temperatures even with a reduction in intake air mass flow rate.

\subsubsection{RPM Results}

The $30 \%$ rated torque was unable to be achieved with $3 \times 3$ CDA at $1200 \mathrm{rpm}$. This test speed was the least effective of the three test points for exhaust energy recovery. CDA was unable to recuperate any of the loss of mass flowrate at this engine speed with $3 \times 3$ CDA. SCR inlet temperatures were still able to be increased compared to the baseline so this point is effective for CDA. Another firing configuration with more cylinders active is believed to be able to perform well at this test point. With more cylinders active, the mass flow rate deficit will improve but the exhaust temperatures will decrease. Results of the $1200 \mathrm{rpm}$ steady state tests are presented in Figure 18.

Baseline engine testing resulted in a $185^{\circ} \mathrm{C}$ TOT and a $156{ }^{\circ} \mathrm{C} \mathrm{SCR}$ inlet for $10 \%$ rated torque. At $20 \%$ rated torque, the base engine had a $236{ }^{\circ} \mathrm{C}$ TOT and $195{ }^{\circ} \mathrm{C} \mathrm{SCR}$ inlet temperature. As expected, the FN strategy performed the best for temperature gains. The FN calibration had a TOT of $291^{\circ} \mathrm{C}$ and $353^{\circ} \mathrm{C}$, while the SCR inlet was $204{ }^{\circ} \mathrm{C}$ and $246{ }^{\circ} \mathrm{C}$. The FN calibration for $1200 \mathrm{rpm}$ is the only point at $10 \%$ rated torque which had an SCR temperature above $200{ }^{\circ} \mathrm{C}$. Fuel economy calibration turbine outlet temperatures were $262{ }^{\circ} \mathrm{C}$ for $10 \%$ rated torque and $352{ }^{\circ} \mathrm{C}$ for $20 \%$ rated torque. SCR inlet temperature rose to $186{ }^{\circ} \mathrm{C}$ and $243{ }^{\circ} \mathrm{C}$ for the $10 \%$ and $20 \%$ rated torque, respectively. 
The $1200 \mathrm{rpm}$ test point was the first time there was a fueling increase to reach the rated torque demand. Fuel neutral at $20 \%$ rated torque had a $0.8 \%$ increase in fuel while the $10 \%$ rated torque had a $1.0 \%$ decrease in fuel. The fuel economy calibration decreased its fuel usage by $5.5 \%$ at $10 \%$ rated torque and $1.2 \%$ at $20 \%$ rated torque. The BTE benefits were lowest of the three test speeds at $10 \%$ rated torque. Fuel neutral calibration had a $0.2 \%$ increase in BTE where the fuel economy calibration had a $1.5 \%$ increase. Like the other $20 \%$ rated torque points, both CDA calibrations had a decrease in BTE. The fuel neutral calibration decreased by $7.5 \%$ and an $8.4 \%$ decrease for the FE calibration.

All four CDA test points for 1200 rpm were above 24:1 AFR which was the lowest desirable for this experiment. Baseline engine produced $6.7 \mathrm{~g} / \mathrm{bhp}$-hr of NOx for $10 \%$ rated torque and $3.9 \mathrm{~g} / \mathrm{bhp}-\mathrm{hr}$ at $20 \%$ rated torque. The FN calibration was $4.7 \mathrm{~g} / \mathrm{bhp}-\mathrm{hr}$ at $10 \%$ rated torque but, the $20 \%$ rated torque engine out NOx was $7.1 \mathrm{~g} / \mathrm{bhp}-\mathrm{hr}$. The FE calibration was 7.1 $\mathrm{g} / \mathrm{bhp}-\mathrm{hr}$ of NOx at $10 \%$ rated torque and $5.8 \mathrm{~g} / \mathrm{bhp}-\mathrm{hr}$ at $20 \%$ rated torque. The base engine had its worst NOx output at this speed. Combined with low SCR temperatures and high NOx, the baseline engine would have low NOx conversion. This is the best point when evaluating temperatures and engine out NOx for CDA to show improvements. 

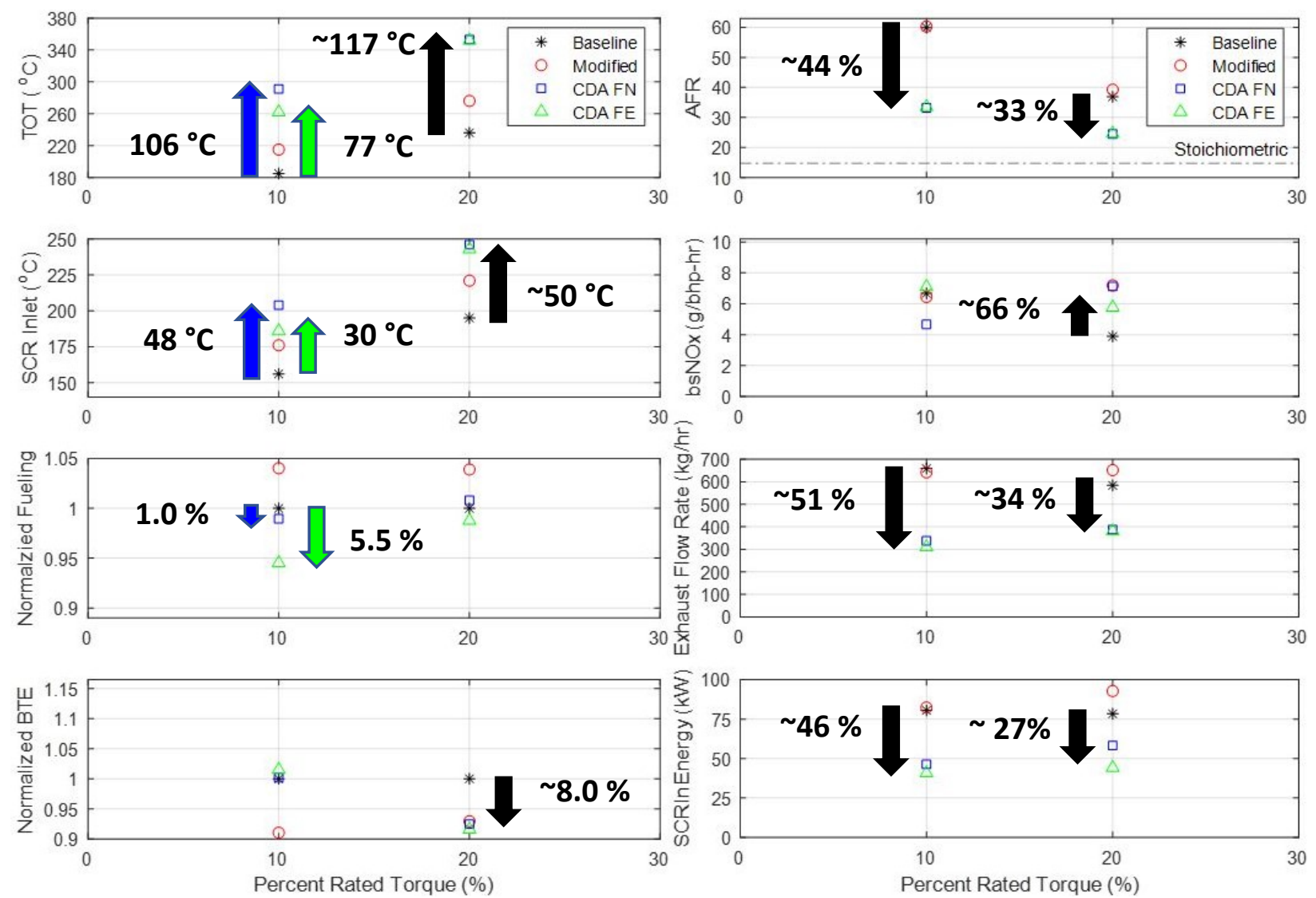

Figure 18: 1200 RPM Steady State Data

Like mentioned in the beginning of this section, CDA had the worst exhaust flow rate performance for both tested loads. The base engine had an exhaust flow rate of $659 \mathrm{~kg} / \mathrm{hr}$ for $10 \%$ rated torque and $584 \mathrm{~kg} / \mathrm{hr}$ for $20 \%$ rated torque. The fuel neutral calibration performed slightly better than the fuel economy calibration. The FN exhaust flow rate was $338 \mathrm{~kg} / \mathrm{hr}$ and $388 \mathrm{~kg} / \mathrm{hr}$ for $10 \%$ and $20 \%$ rated torque, respectively. Whereas the FE calibration had an exhaust flow rate of $311 \mathrm{~kg} / \mathrm{hr}$ at $10 \%$ and $381 \mathrm{~kg} / \mathrm{hr}$ at $20 \%$. At $10 \%$ rated torque, the flow reduction was $48.7 \%$ for the FN calibration and $52.9 \%$ for the FE calibration. This was the worst performance of flowrate recovery for all CDA points. For the $20 \%$ rated torque, the FN calibration reduction was $33.6 \%$, where the fuel economy calibration reduction was $34.8 \%$. 
Due to the poor performance recovery of exhaust flow rate, exhaust energy suffered compared to the other two engine speed test configurations. Figure 19 below shows aftertreatment energy characteristics for the steady state test. The turbine outlet baseline energy was $85.8 \mathrm{~kW}$ and $85.2 \mathrm{~kW}$ for $10 \%$ and $20 \%$ rated torque, respectively. While the SCR inlet energy for the baseline was $80.0 \mathrm{~kW}$ for $10 \%$ and $77.8 \mathrm{~kW}$ for $20 \%$ rated torque. Due to having a higher flow rate, the fuel neutral calibration had a higher exhaust energy performance compared to the fuel economy calibration. The FN calibration had a turbine outlet energy of $55.3 \mathrm{~kW}$ at $10 \%$ rated torque and $71.3 \mathrm{~kW}$ at $20 \%$ rated torque. The SCR inlet exhaust energy for the FN calibration was $46.0 \mathrm{~kW}$ at $10 \%$ rated torque and $57.8 \mathrm{~kW}$ at $20 \%$ rated torque. Whereas the fuel economy calibration resulted in $47.9 \mathrm{~kW}$ for $10 \%$ and $69.9 \mathrm{~kW}$ for $20 \%$ rated torque for turbine outlet. SCR inlet exhaust energy was $40.5 \mathrm{~kW}$ for $10 \%$ rated torque and 56.4 $\mathrm{kW}$ at $20 \%$ rated torque for the fuel economy calibration.

While analyzing the efficiency of converting fuel energy to exhaust energy, the baseline $10 \%$ rated torque for $1200 \mathrm{rpm}$ had the highest value. Typically, as little energy wants to be left in the exhaust as possible but for a thermal management strategy, this is a desirable characteristic. The baseline engine had a turbine outlet conversion of $0.85 \mathrm{~kW}$ at $10 \%$ rated torque and $0.54 \mathrm{~kW}$ at $20 \%$ rated torque for every $1 \mathrm{~kW}$ of fuel used. The baseline SCR conversion was similar at $0.79 \mathrm{~kW}$ and $0.50 \mathrm{~kW}$ for $10 \%$ and $20 \%$ rated torque, respectively. Again, due to higher exhaust flowrate, the FN calibration performed better as a thermal management strategy than the FE calibration because of higher exhaust energy results. This was as expected since the FN calibration was developed to produce higher exhaust temperatures. The FN calibration had a turbine outlet energy conversion of $0.55 \mathrm{~kW}$ at $10 \%$ and 
$0.45 \mathrm{~kW}$ at $20 \%$ rated torque per $1 \mathrm{~kW}$ of fuel. Its SCR inlet energy conversion was $0.46 \mathrm{~kW}$ at $10 \%$ rated torque and $0.36 \mathrm{~kW}$ at $20 \%$ rated torque. For the fuel economy calibration, the $20 \%$ rated torque points had identical performance compared to the fuel neutral calibration. At $10 \%$ rated torque, the turbine outlet conversion was $0.50 \mathrm{~kW}$ and SCR inlet was $0.43 \mathrm{~kW}$ for every 1 kW of fuel used.
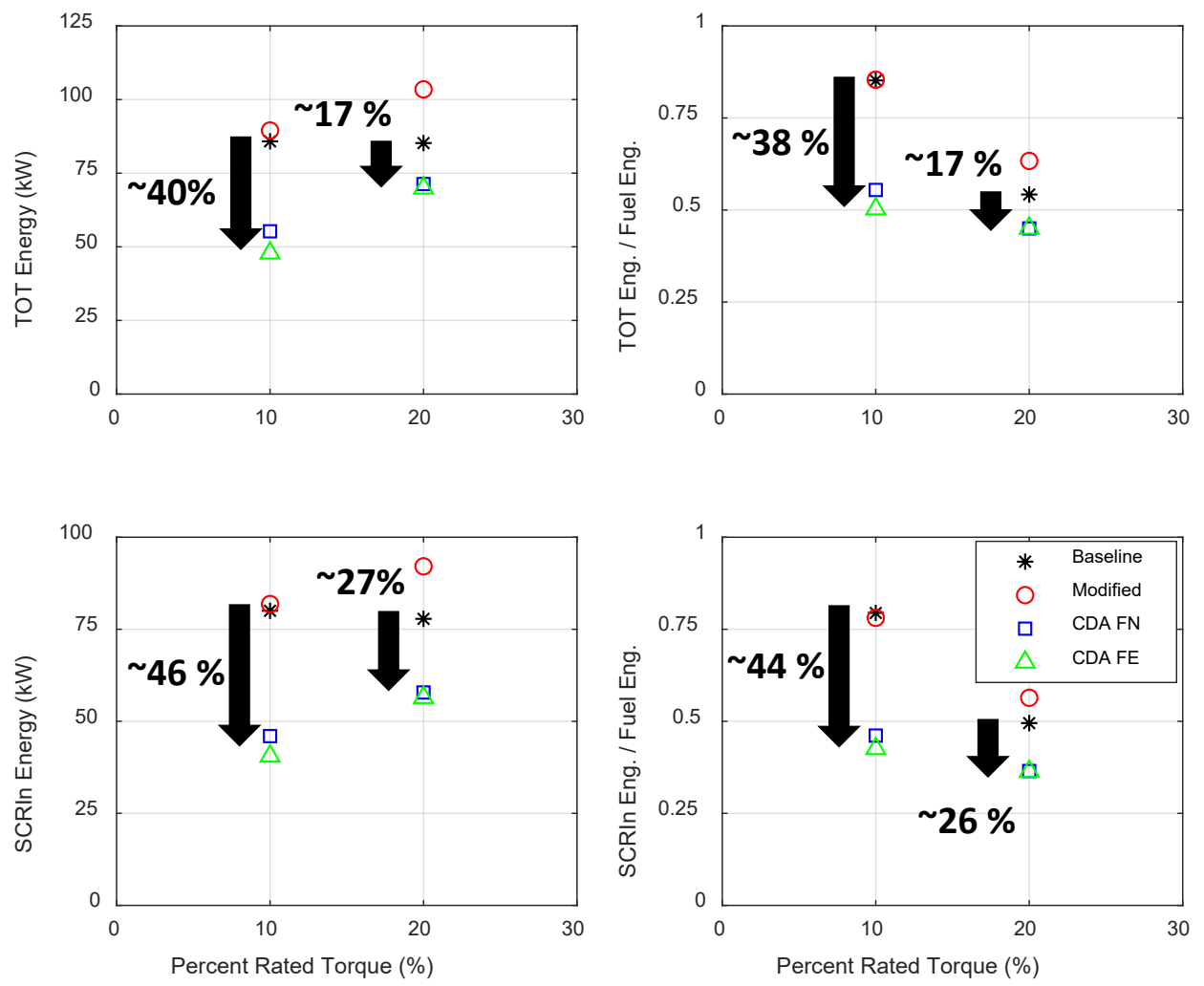

Figure 19: 1200 RPM Exhaust Energy

\subsection{Motoring Cool Down Curves}

Motoring of the engine results in the intake air being cycled through the engine with no fuel injected. This cold air causes adverse cooling of the aftertreatment components. Motoring is typical for when a diesel powered vehicle is either coasting or coming to a stop. Both the FTP and LLC contain sections where the engine will be motoring and thus removing heat from the 
aftertreatment. The FTP has 177 seconds of the 1200 second cycle where the engine would be motoring. During the LLC, 826 of the 5496 seconds of the cycle is spent with the engine motoring. Both cycles spend roughly $15 \%$ of the total time motoring the engine. The rate of cooling due to motoring is directly related to the mass flowrate of air moving through the engine. CDA allows for the displacement of the engine to be reduced, thus decreasing the amount of air able to move through the engine. Engine speed is the largest factor since the faster an engine spins, the more air will move through due to more cycles occurring. This means that cooling rates will be highest near high idle and lowest near curb idle speeds.

Figure 20 below shows temperature traces once the throttle was set to zero till the SCR reached $170^{\circ} \mathrm{C}$. Due to the inability to exactly replicate each test, there are differences in the peak temperature. Baseline motoring took 89 seconds to reach $260^{\circ} \mathrm{C}$ from fuel cut off. It then took 167 seconds to reach the $170^{\circ} \mathrm{C}$ threshold, for a total time of 256 seconds. With three cylinder cut, the time to $260^{\circ} \mathrm{C} \mathrm{SCR}$ inlet was 203 seconds. The SCR inlet for three cylinders cut took 233 seconds to then reach the $170^{\circ} \mathrm{C}$ threshold. 


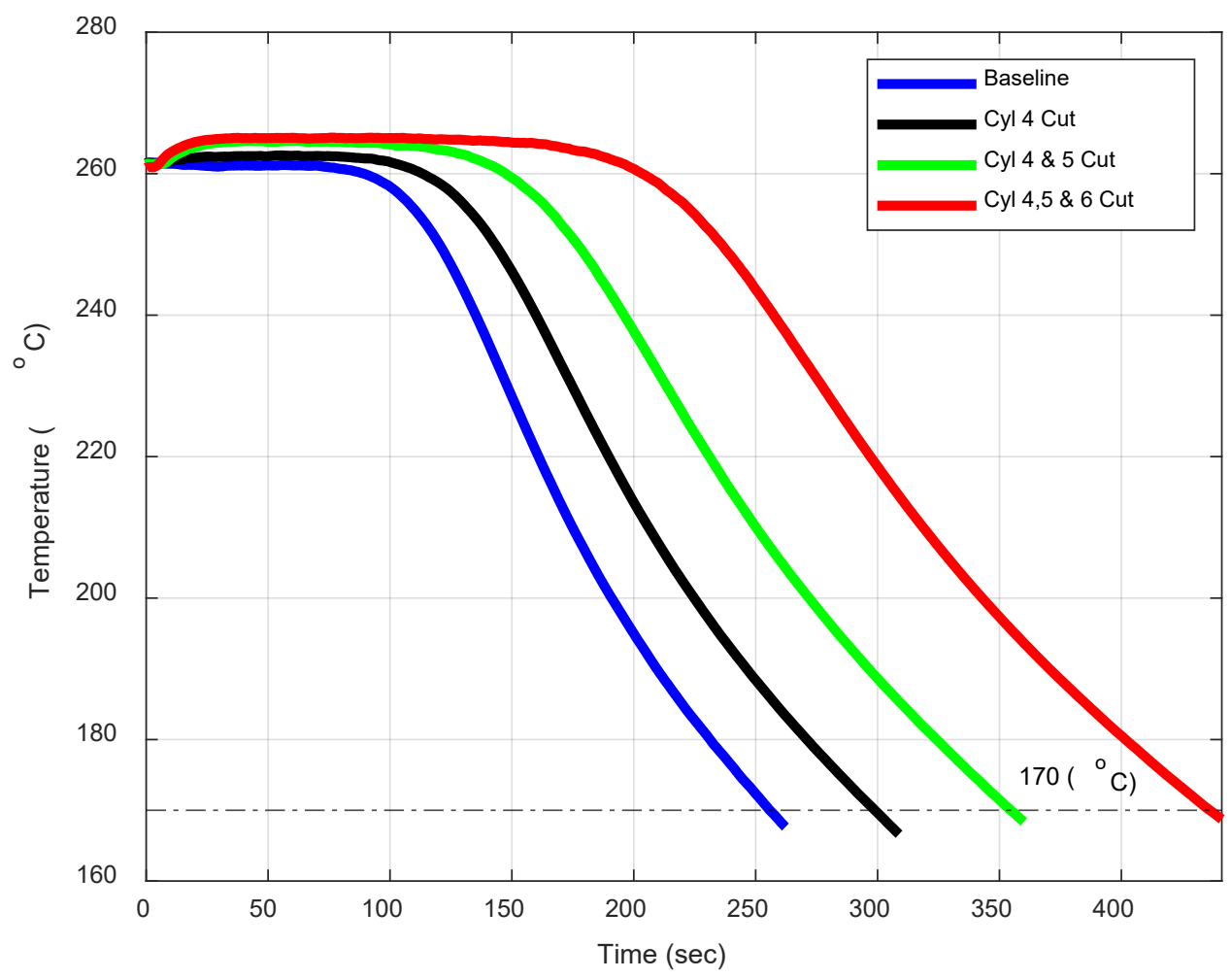

Figure 20: 800 RPM SCR Inlet Motoring Cool Down

In Figure 21, the temperature traces for the 1200 rpm test are shown. Again, due to the nature of engine testing perfect recreation of tests is unable to be met. During the baseline test, the elapsed time to reach $260^{\circ} \mathrm{C}$ was 56 seconds. The baseline then took 99 seconds to cool off to the $170{ }^{\circ} \mathrm{C}$ threshold. With the three cylinders deactivated during motoring, time to $260^{\circ} \mathrm{C}$ SCR inlet was 129 seconds. An additional 179 seconds was needed to reach $170{ }^{\circ} \mathrm{C}$. 


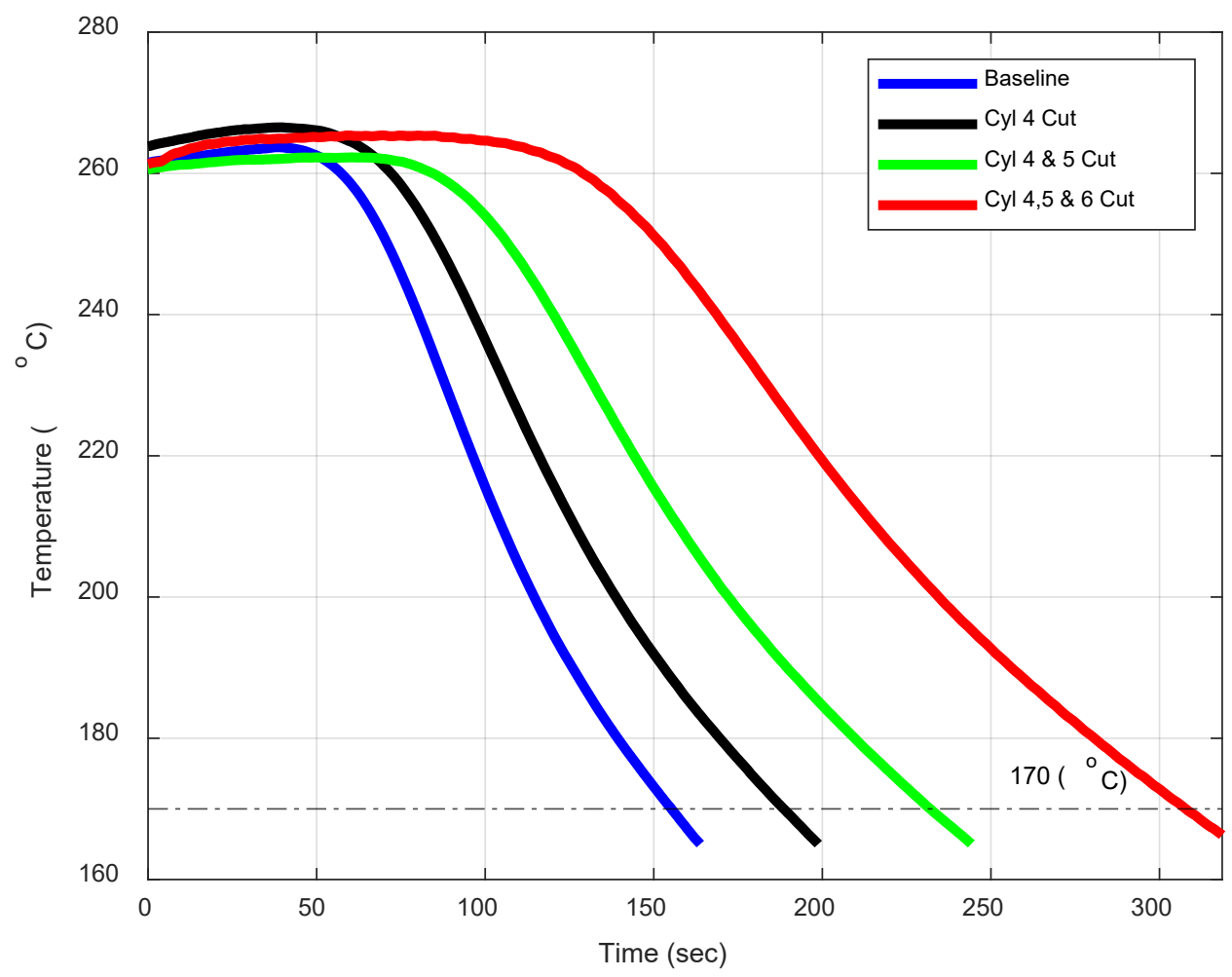

Figure 21: 1200 RPM SCR Inlet Motoring Cool Down

Finally, Figure 22 presents the results from the $1500 \mathrm{rpm}$ motoring cool down test. The baseline test, where all cylinders are operational, took 45 seconds to reach $260{ }^{\circ} \mathrm{C}$. Then an additional 80 seconds was needed for SCR inlet to reach $170{ }^{\circ} \mathrm{C}$. For three cylinders cut, 84 seconds and 164 seconds were needed to reach the two respective temperature thresholds. 


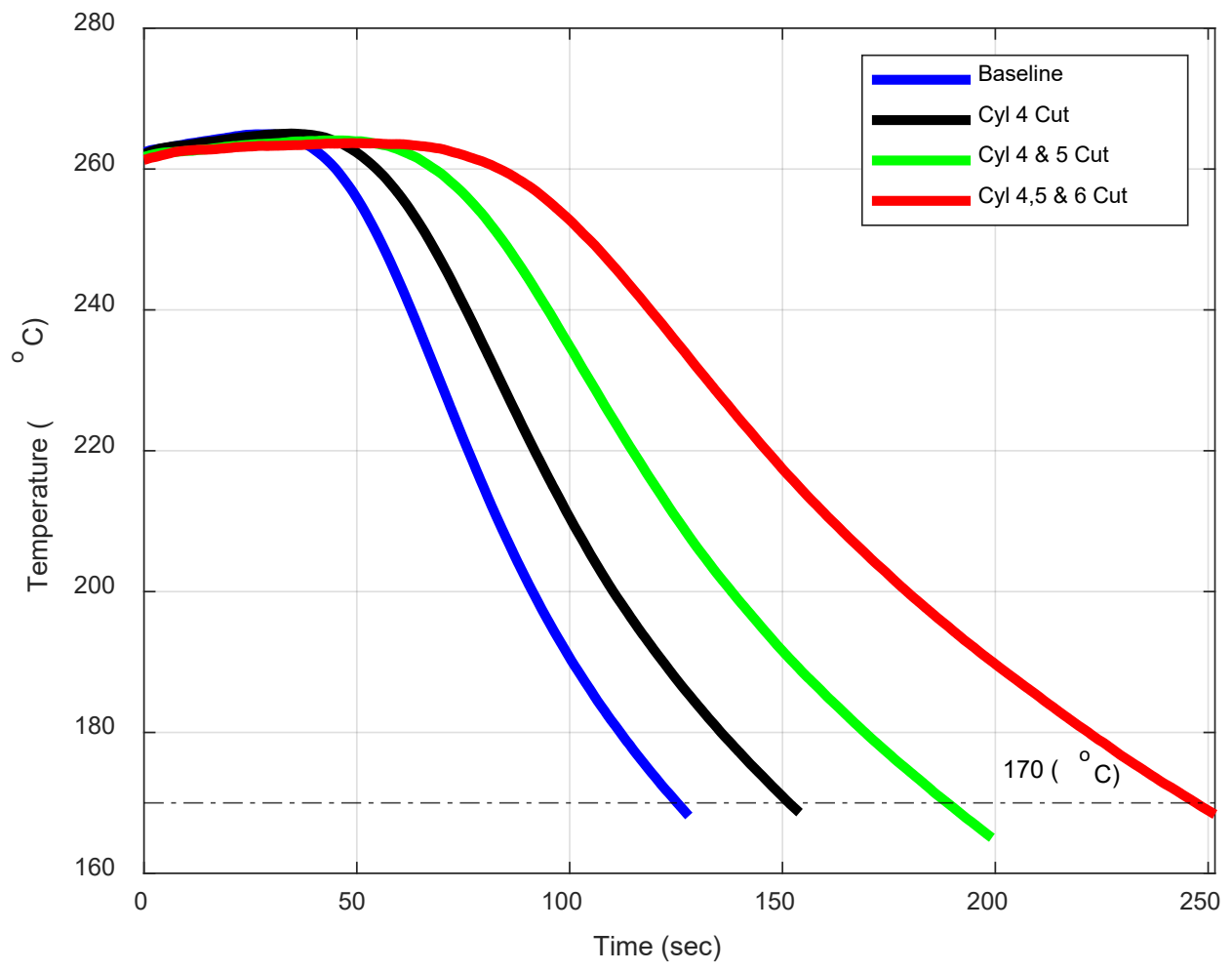

Figure 22: 1500 RPM SCR Inlet Motoring Cool Down

The average total time increase for each test point was calculated to see if cooling would follow a trend. For one cylinder deactivated, the average total time to cool off increased by $19.8 \%$ versus the baseline. Two and three cylinders deactivated resulted in a total time increase of $46.3 \%$ and $88.7 \%$ compared to the baseline. Approximation of the inflection point of the cool down curves were performed to examine how long each combination spent in a "rapid" cooling phase. The average time spent in the rapid cooling phase for each configuration increased by $19.2 \%, 38.5 \%$ and $73.7 \%$ for 1 cylinder, 2 cylinders, and 3 cylinders deactivated, respectively. As expected, cooling rates decreased with deactivating cylinders. Deactivation of half the cylinders resulted in retaining temperature for $89 \%$ longer than all cylinders active. CDA has been validated as a strategy to decrease the displacement of the engine and slow the rate of heat loss in the aftertreatment for HDD engines. 


\subsection{Transient CDA Temperature}

After motoring results, transient CDA during the FTP and LLC was the next step in testing. Both hot and cold start FTP test cycles were analyzed. Due to the lack of access provided at the time, CDA was only able to be active when the engine was motoring. This was achieved by a logic that was based on engine speed and throttle signal to the engine. This control logic allowed for the ability to understand the influence of thermal heat transfer losses during transient engine operation. Thermal losses due to convective cooling while motoring is highlighted in the following section. A combination of 3 and 6 cylinders deactivated while motoring were compared to baseline runs.

The three measured temperatures in this section are the turbine outlet, aftertreatment inlet and SCR inlet. TOT is important to be able to analyze how the engine is performing since each OEM aftertreatment system will differ on thermal capacity and location. Aftertreatment inlet temperature was measured to ensure that the temperature drop between the turbocharger outlet and inlet to the aftertreatment was in an acceptable range. The measurement of SCR temperatures was after the DOC, DPF and crossover tube (where Urea would be injected) before the second canister which houses the SCR.

In Figure 23, the temperature profiles for the FTP cold starts for each test condition are shown. The initial SCR inlet temperature for each cold start was within $2{ }^{\circ} \mathrm{C}$. The SCR inlet final temperature was $229^{\circ} \mathrm{C}$ for the baseline, $232^{\circ} \mathrm{C}$ for three cylinders deactivated and $235^{\circ} \mathrm{C}$ for six cylinders deactivated. The peak SCR inlet temperature for the baseline was $289^{\circ} \mathrm{C}$. Both CDA configuration had the maximum SCR inlet temperature of $295^{\circ} \mathrm{C}$. The baseline average SCR 
temperature over the cycle was $191.4{ }^{\circ} \mathrm{C}$. The $3 \mathrm{CDA}$ and 6 CDA SCR average was $192.8^{\circ} \mathrm{C}$ and $195.9^{\circ} \mathrm{C}$, respectively. SCR inlet temperature time above $200{ }^{\circ} \mathrm{C}$

increased by 33.4 seconds which is a $5.6 \%$ increase for 3 CDA. The 6 CDA test increased by 42.5 seconds or $7.2 \%$.
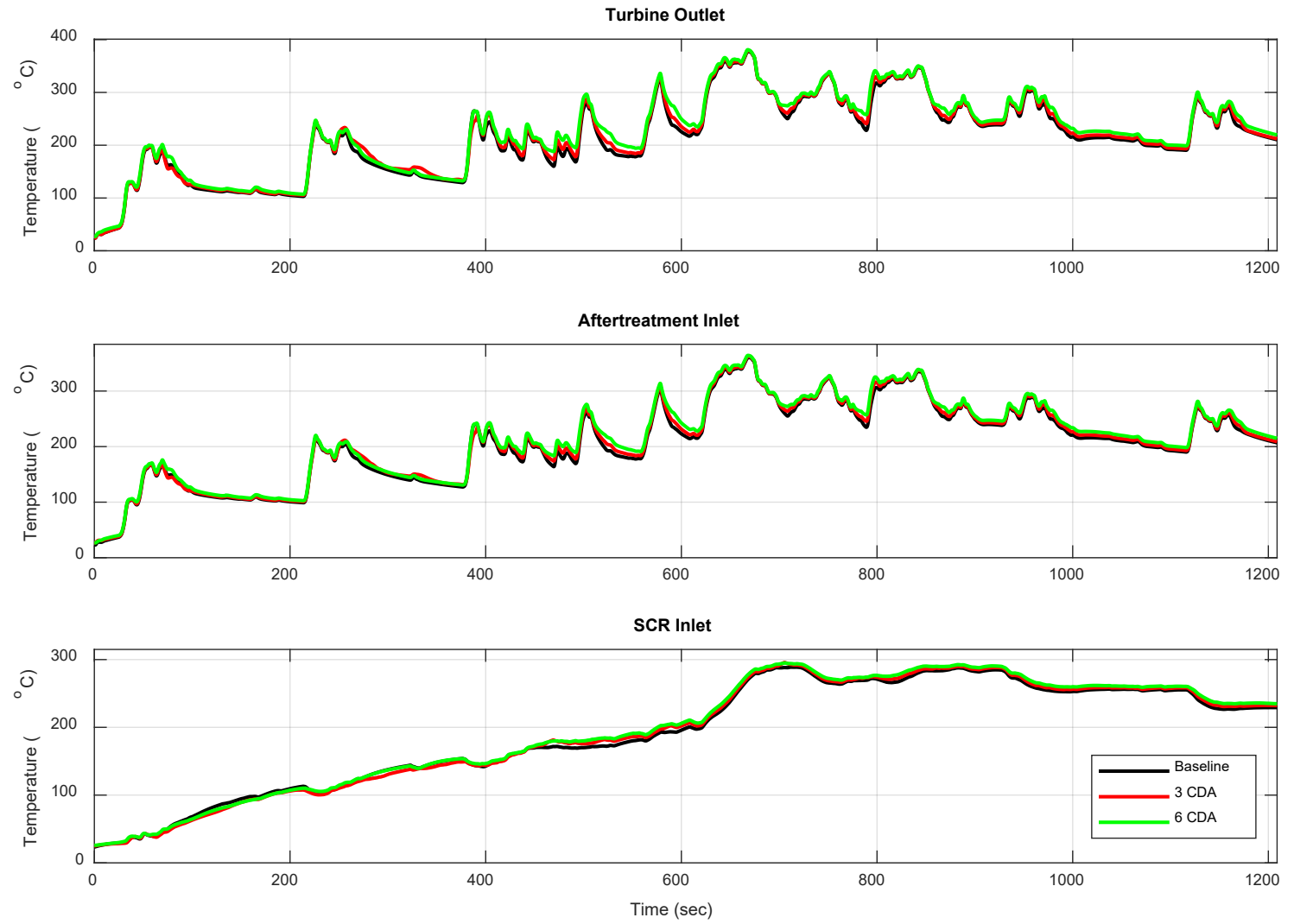

Figure 23: Cold Start FTP CDA While Motoring

During the cold start, the most interesting section to examine was the Los Angeles Non Freeway section into the Los Angeles Freeway section. Specifically, from 450 seconds to 900 seconds of the FTP cycle. In Figure 24, the blue dotted line on the bottom of the SCR inlet graph shows when the engine was motoring. During this interval, there are 99 seconds of motoring which is $22 \%$ of the total time in this segment. Inside of this interval, 3 CDA had an 
SCR inlet temperature above $200{ }^{\circ} \mathrm{C}$ for 33.4 seconds longer than the baseline. While deactivating 6 cylinders, the SCR inlet temperature above $200^{\circ} \mathrm{C}$ was 42.5 seconds more than the baseline. The baseline average TOT was $269.3^{\circ} \mathrm{C}$ and the SCR average inlet temperature was $235.7^{\circ} \mathrm{C}$. Average TOT for $3 \mathrm{CDA}$ and $6 \mathrm{CDA}$ tests were $274.4^{\circ} \mathrm{C}$ and $282.0^{\circ} \mathrm{C}$, respectively. The average SCR inlet temperature was $240.3^{\circ} \mathrm{C}$ for $3 \mathrm{CDA}$ and $243.5^{\circ} \mathrm{C}$ for 6 cylinders deactivated. Turbine outlet temperature plots show a clear distinction where motoring caused a cooling effect on the exhaust. Between 450 and 625 seconds, the average SCR inlet for 3 CDA was $6.2^{\circ} \mathrm{C}$ higher than baseline. During the same time interval, $6 \mathrm{CDA}$ averaged $9.6^{\circ} \mathrm{C}$ higher SCR inlet temperature versus the baseline.
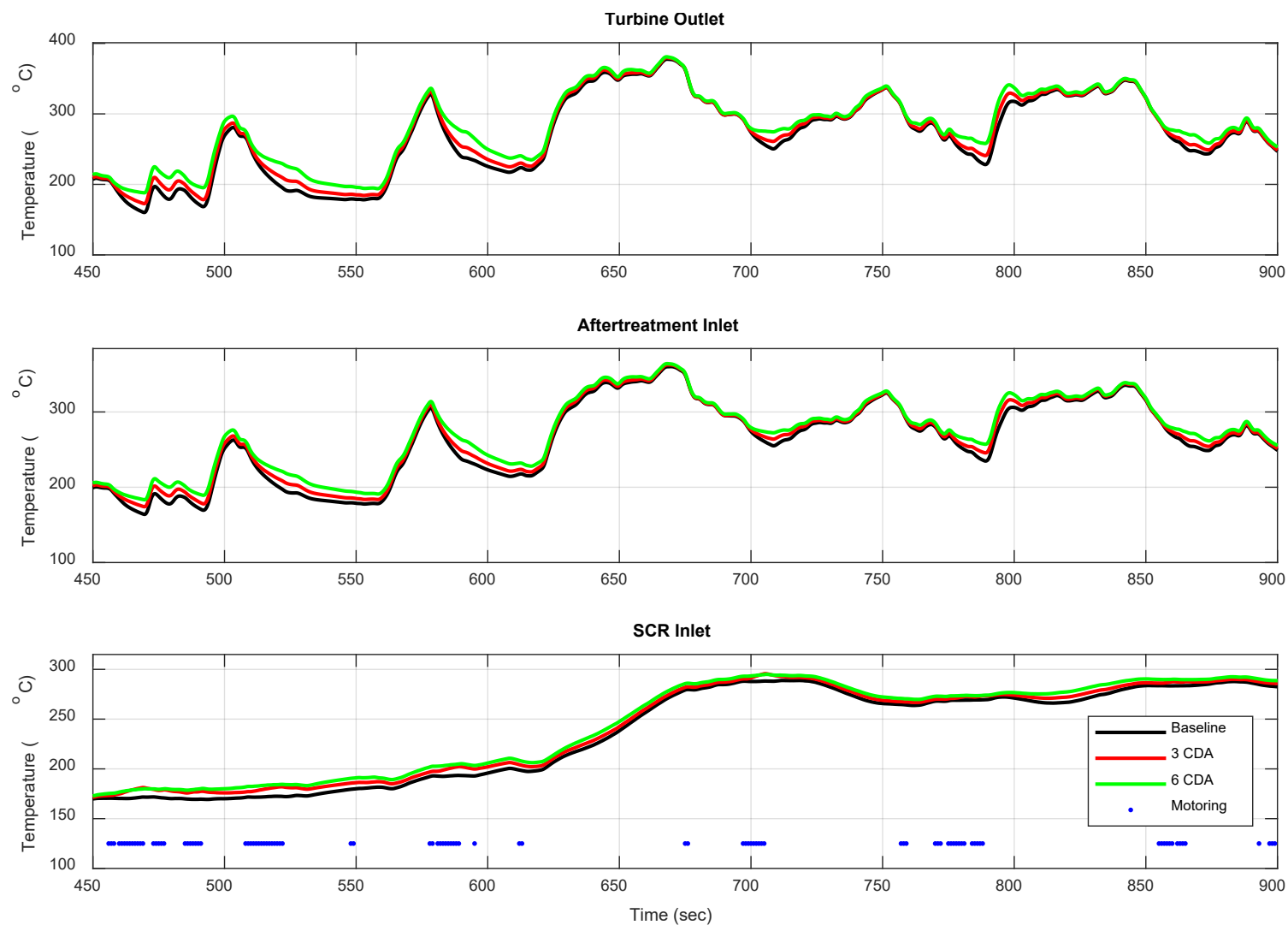

Figure 24: Cold Start FTP Motoring Segments 
Figure 25 below, shows the temperature profiles for the hot stat FTP. Both the baseline and 3 CDA tests had a starting SCR inlet temperature of $132{ }^{\circ} \mathrm{C}$. The 6 CDA SCR inlet temperature started at $135^{\circ} \mathrm{C}$. The ending SCR temperature was: $231.2^{\circ} \mathrm{C}$ for the baseline, $235.2{ }^{\circ} \mathrm{C}$ for $3 \mathrm{CDA}$ and $238.7^{\circ} \mathrm{C}$ for $6 \mathrm{CDA}$. The maximum SCR inlet for baseline was $298.6{ }^{\circ} \mathrm{C}$ and for both 3 and 6 CDA was $305.1^{\circ} \mathrm{C}$. During the 3 CDA test, the average SCR inlet temperature was 227.3 where the $6 \mathrm{CDA}$ test was $229.8^{\circ} \mathrm{C}$, the baseline was $222.0^{\circ} \mathrm{C}$. The baseline test resulted in 643.2 seconds above $200{ }^{\circ} \mathrm{C}$ for the SCR inlet. The 3 CDA and 6 CDA tests were above this threshold for 760.3 and 761.8 seconds, roughly $18.2 \%$ longer above the SCR operating temperature range. Aftertreatment cooling from urea injection was not present.
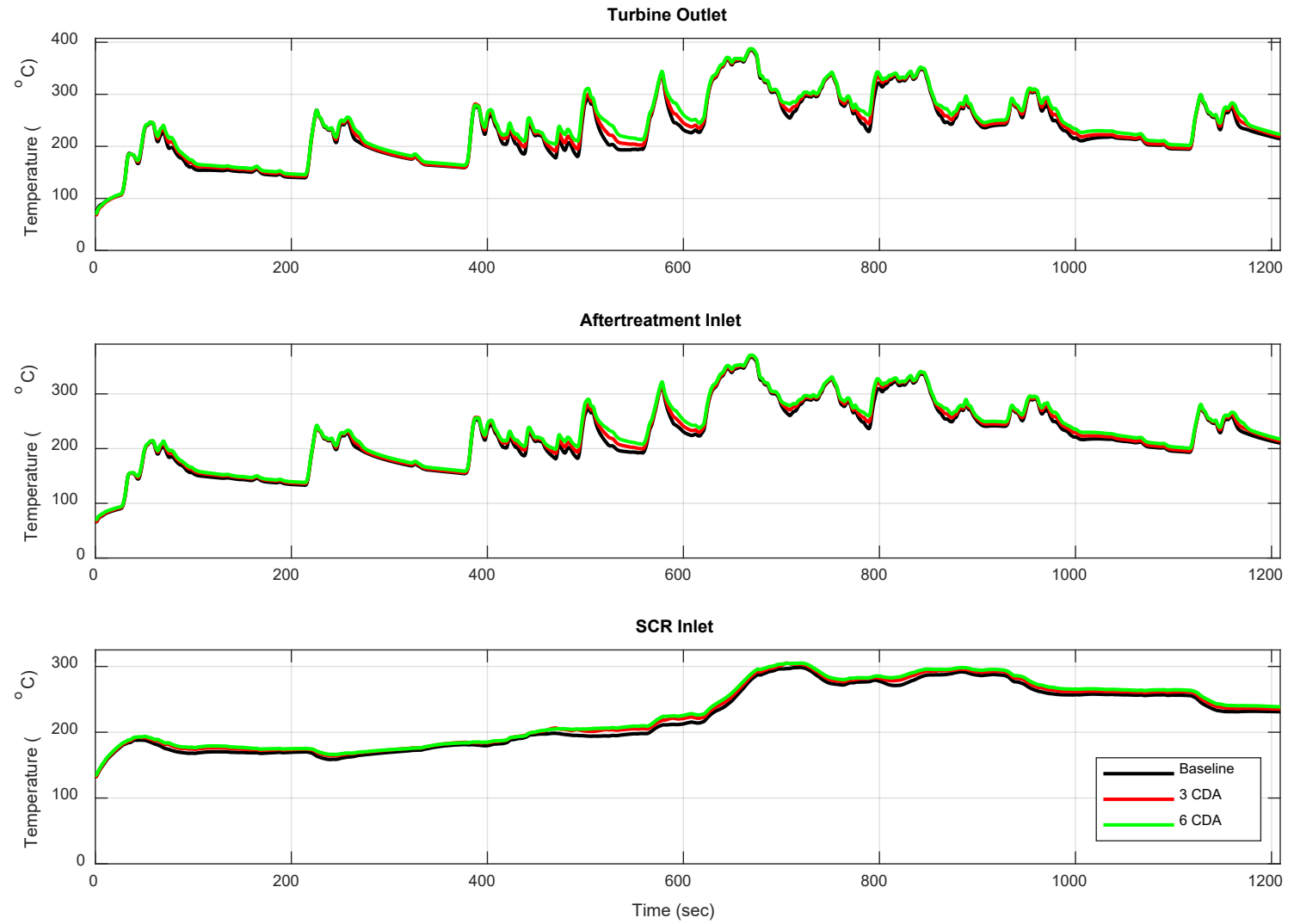

Figure 25: Hot Start FTP CDA While Motoring 
Again, a specific area of interest was the section between 450 and 900 seconds of the FTP. In Figure 26, a section of the graph is shown. Both the 3 and 6 deactivated cylinder tests were above $200^{\circ} \mathrm{C}$ for all of this section. The baseline was above the SCR $200^{\circ} \mathrm{C}$ threshold for 334.3 seconds of the 450 second window. The average SCR inlet for 3 CDA was $6.4^{\circ} \mathrm{C}$ higher than the baseline and $9.5^{\circ} \mathrm{C}$ higher than the baseline for $6 \mathrm{CDA}$. Average TOT increased by 7.0 ${ }^{\circ} \mathrm{C}$ and $14.2^{\circ} \mathrm{C}$ for $3 \mathrm{CDA}$ and $6 \mathrm{CDA}$, respectively, versus the baseline. Like the cold start, there is a clear distinction while looking at the three different tests for this section with high motoring occurrences. The first 125 seconds of this section resulted in a $7.5^{\circ} \mathrm{C}$ for $3 \mathrm{CDA}$ and $10.7^{\circ} \mathrm{C}$ for 6 CDA when compared to the baseline for the SCR inlet. Each CDA mode for the hot start was able to retain enough heat to ensure that the SCR remained above $200{ }^{\circ} \mathrm{C}$ during this specific section of the FTP, where $56 \%$ of motoring during the FTP occurs. 

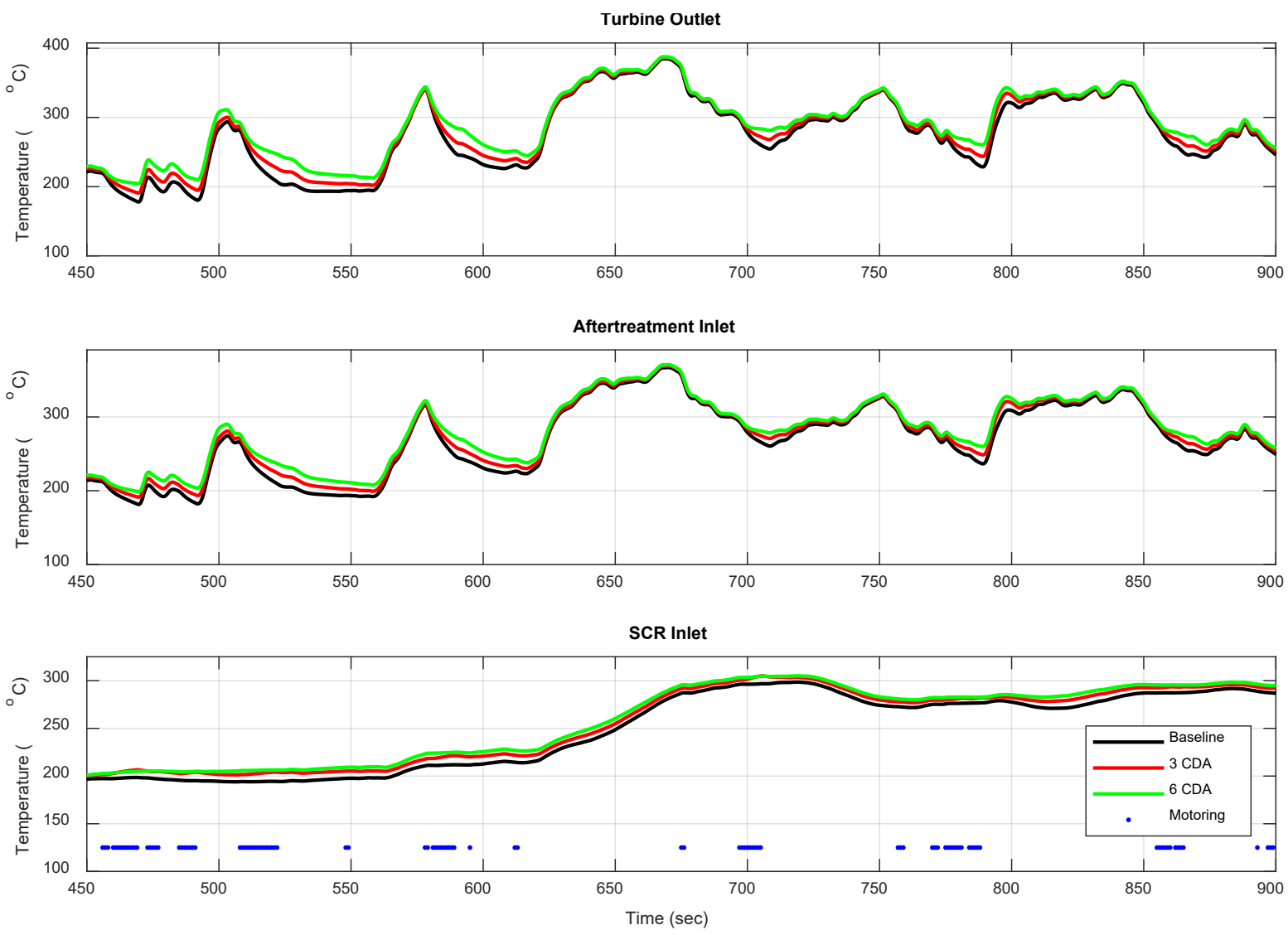

Figure 26: Hot Start FTP Motoring Segments

The last test examined was the CARB LLC which is seen in Figure 27. This was conducted after the consecutive FTP's with soaks between each test. The initial baseline SCR inlet temperature was $136.6^{\circ} \mathrm{C}, 3 \mathrm{CDA}$ was $131^{\circ} \mathrm{C}$ and $6 \mathrm{CDA}$ was $141.5^{\circ} \mathrm{C}$. End of cycle SCR inlet temperature was $204.1^{\circ} \mathrm{C}$ for the baseline, $209.8^{\circ} \mathrm{C}$ for $3 \mathrm{CDA}$ and $212.9^{\circ} \mathrm{C}$ for 6 cylinders deactivated. The maximum SCR inlet temperature for baseline test was $218.7^{\circ} \mathrm{C}, 225.4{ }^{\circ} \mathrm{C}$ for 3 CDA and 230.7 for 6 CDA. Over the whole cycle, the baseline average SCR temperature was $158.9^{\circ} \mathrm{C}$ and total time above $200^{\circ} \mathrm{C}$ was 283.7 seconds. For the $3 \mathrm{CDA}$ test, the average SCR temperature was $164.7^{\circ} \mathrm{C}$ with 706.7 seconds above $200^{\circ} \mathrm{C}$. Finally for $6 \mathrm{CDA}, 168.8$ was the average SCR temperature and 1104.3 seconds above $200^{\circ} \mathrm{C}$. Both CDA tests saw significant 
increases in time above $200^{\circ} \mathrm{C}$ where the SCR would be able to be active during the test cycle. A $149 \%$ increase in time above $200{ }^{\circ} \mathrm{C}$ for $3 \mathrm{CDA}$ and a $289 \%$ increase for $6 \mathrm{CDA}$ test. This is very promising results as the only change to the engine done during this test is reducing the effects of cooling the aftertreatment during motoring. Once full transients is possible, it can be expected that CDA while firing will further increase SCR inlet temperatures.
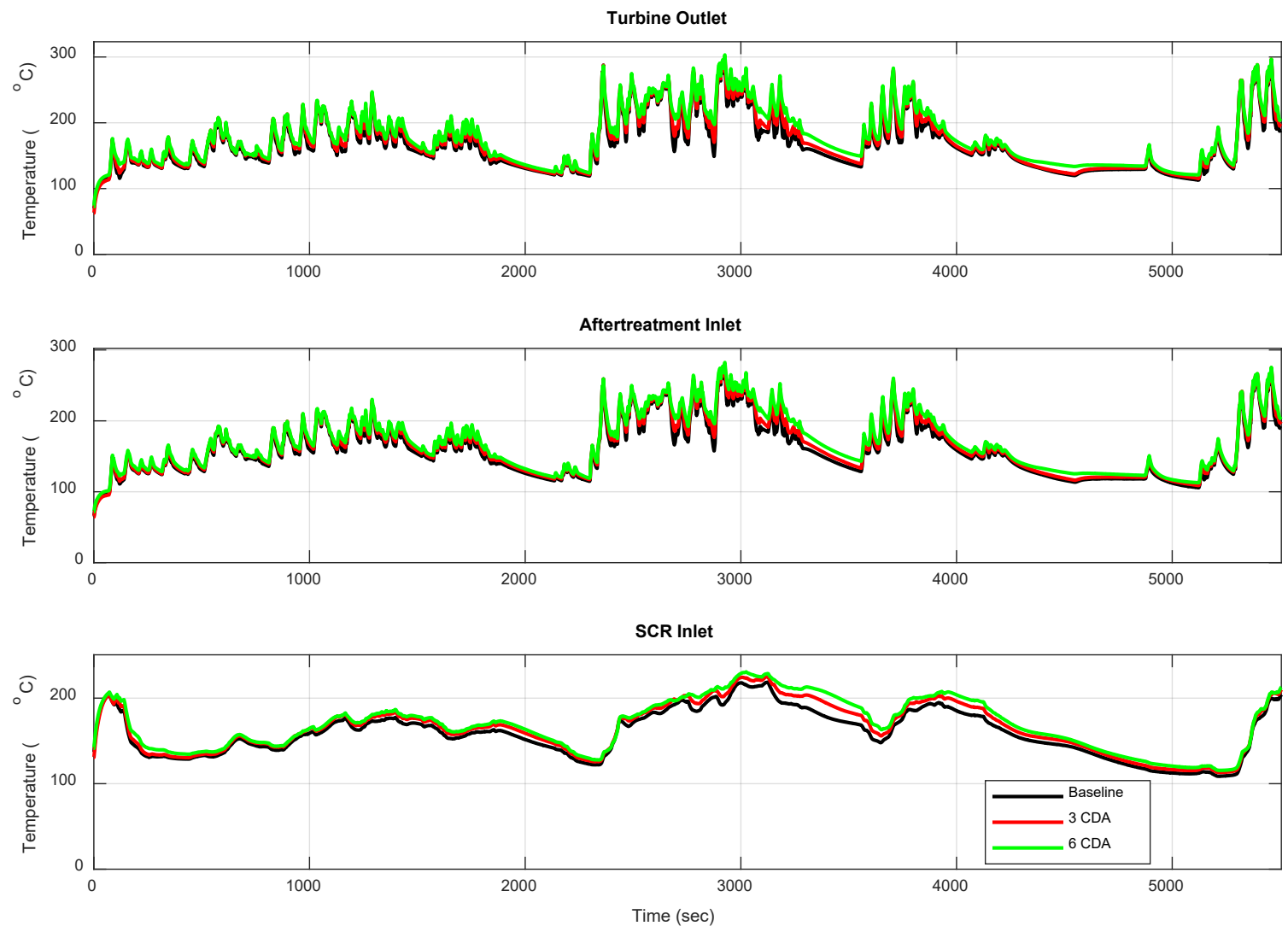

Figure 27: Hot Start LLC CDA While Motoring

The area of emphasis for the LLC was between 2300 and 3560 seconds of the LLC.

Figure 28 below, shows this section of the LLC. This section had the highest density of motoring points which can be seen in Appendix B: Motoring Occurrences During Transient Cycles. The last 320 seconds of this window is the engine idling. The baseline test had an average SCR inlet 
temperature of $184.2^{\circ} \mathrm{C}$ and an average TOT of $198.9^{\circ} \mathrm{C}$. Operation with $3 \mathrm{CDA}$ resulted in average SCR temperature of $192.5^{\circ} \mathrm{C}$ and an average TOT of $206.2^{\circ} \mathrm{C}$. The average SCR temperature for $6 \mathrm{CDA}$ was $198.1^{\circ} \mathrm{C}$ and $215.8^{\circ} \mathrm{C}$ for average TOT. It is important to note that the average SCR temperature for $6 \mathrm{CDA}$ was $0.8^{\circ} \mathrm{C}$ less than the average TOT for the baseline engine. Again, the only difference between the tests was that cylinders were deactivated during motoring to reduce cooling. This specific section demonstration the significant cooling effects of motoring HDD engines.

While examining the histogram of motoring during the LLC and the temperature profile graphs, $37.1 \%$ of motoring during the LLC is in this time segment. Idle begins after the 3240 second in the test. In this section, all tests reach the $200^{\circ} \mathrm{C}$ threshold for the SCR, where the catalyst would be active. The baseline test reached this temperature at the 2945 second mark of the test. The $3 \mathrm{CDA}$ test was able to sustain above $200^{\circ} \mathrm{C}$ at the 2837 second mark. This test reached $200{ }^{\circ} \mathrm{C}$ at 2720 seconds but dropped below after 45 seconds due to aftertreatment cooling during this period. The deactivation of 6 cylinders test reached the NOx conversion temperature threshold at 2717 seconds in the LLC till the 3455 second mark in the LLC. The 6 CDA test in this section had the longest continuous time above $200{ }^{\circ} \mathrm{C} \mathrm{SCR}$ inlet. During this section, 3 CDA averaged 9.9 degrees warmer than the baseline and $6 \mathrm{CDA}$ average $17^{\circ} \mathrm{C}$ higher for the SCR inlet compared to the baseline. For the TOT, 3 CDA averaged being 8.4 degrees hotter than the baseline and $6 \mathrm{CDA}$ averaged a $20^{\circ} \mathrm{C}$ increase. 

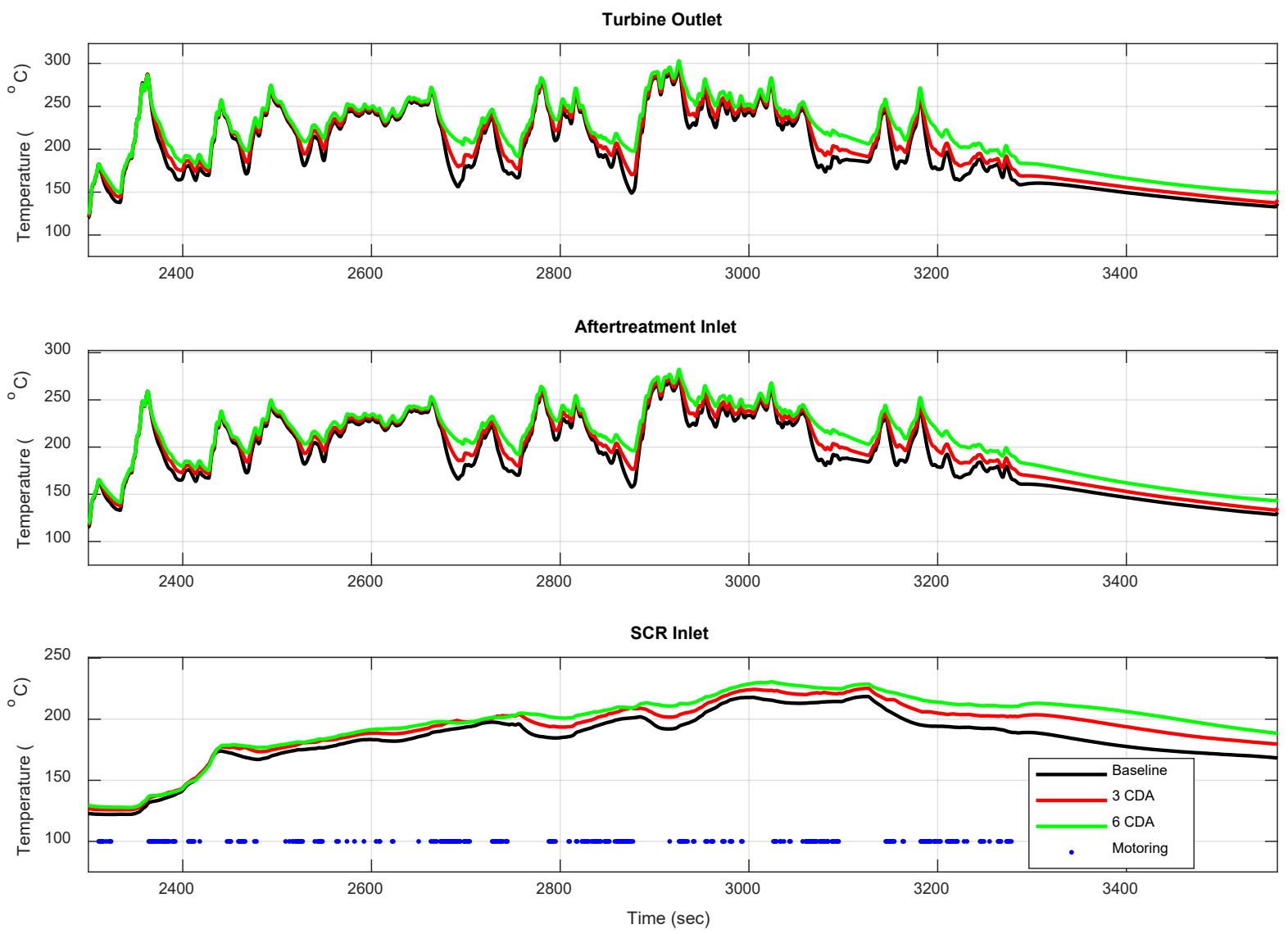

Figure 28: Hot Start LLC Motoring Segments 


\section{Chapter 5: Conclusions and Recommendations for Future Work}

\subsection{Conclusions}

In this study, the investigation of cylinder deactivation performance for exhaust thermal management was achieved on a HDD engine. The engine used was a 2017 Cummins X-15 Efficiency series. Two calibrations were developed from steady state testing that targeted maximizing fueling benefits or exhaust temperatures. Both turbine outlet and SCR inlet temperatures are beneficial to examine for various aftertreatment configurations. More advanced aftertreatment systems will be needed for future regulations, specifically close coupled SCR catalysts which will be placed near the turbine outlet (Manufacturers of Emission Controls Association, 2020). Cooling affects due to motoring the engine were measured. Validation of cooling effects due to motoring were completed by analyzing performance on transient test cycles.

Both calibrations for CDA showed TOT and SCR inlet temperatures gains over the baseline engine. Additionally, all CDA calibration points but one had a fuel benefit compared to the baseline. Even with the reduction in exhaust energy due to CDA, every SCR inlet temperature was increased by at least $23^{\circ} \mathrm{C}$. One of the CDA points at $10 \%$ rated torque was able to exceed the $200^{\circ} \mathrm{C}$ threshold for SCR activity. All of the $20 \%$ rated torque CDA test points met or exceed $228^{\circ} \mathrm{C}$ for SCR inlet, whereas baseline SCR inlet temperature was never above $195^{\circ} \mathrm{C}$. At $10 \%$ rated torque, BTE increases were achieved for all test points utilizing CDA. Decreases in BTE were observed for all $20 \%$ rated torque points. 
Cooling effects due to motoring of the test engine was analyzed and reduced using cylinder deactivation. Coast down curves demonstrated how cooling effects can be controlled by varying the number of cylinders being deactivated. The effect of motoring during transient test cycles was also evaluated and mitigated using CDA. During an FTP cold start, time above $200^{\circ} \mathrm{C} \mathrm{SCR}$ inlet was increased by $7.2 \%$ over the baseline with only deactivating all six cylinders while motoring. During a hot start FTP, $18.2 \%$ more time was spent above $200{ }^{\circ} \mathrm{C} \mathrm{SCR}$ inlet over the baseline with the same CDA strategy as the cold start. Finally, during the LLC, deactivation of all six cylinders resulted in a $289 \%$ increase in time above $200{ }^{\circ} \mathrm{C} \mathrm{SCR}$ inlet.

This study realized the ability to use cylinder deactivation has a plausible strategy for exhaust thermal management. Only two CDA test points accrued a fuel penalty, which was a maximum of $0.8 \%$. Both a fuel neutral and fuel economy were developed to achieve needs dependent on what specific operating conditions are present for the engine. Steady state testing showed the ability to achieve the same speed and load while raising aftertreatment temperatures. The TOT for all CDA points increased by at least $44{ }^{\circ} \mathrm{C}$ up to $117^{\circ} \mathrm{C}$. All TOT $10 \%$ rated torque $\mathrm{CDA}$ points exceeded $250^{\circ} \mathrm{C}$, while the baseline ranged from $185^{\circ} \mathrm{C}$ to $209^{\circ} \mathrm{C}$. Motoring was also shown to have a dominate effect on cooling of the aftertreatment and reduction can occur using CDA. Cold start FTP tests resulted in an additional 42 seconds above $200^{\circ} \mathrm{C} \mathrm{SCR}$ inlet compared to the baseline. During a high motoring segment of the LLC, average SCR inlet temperatures increased from $184^{\circ} \mathrm{C}$ for the baseline to $198^{\circ} \mathrm{C}$ with $6 \mathrm{CDA}$ during motoring. 
This study has a short coming of not achieving transient verification. This was due to not having the necessary software support to control transient operation with the alternative calibrations developed during this work.

\subsection{Future Work}

1. Develop idle strategies employing CDA for cold start and maintaining exhaust temperatures while the aftertreatment is at its operating temperature.

2. Research alternative firing patterns, as speed and load changes resulted in some unwanted operating conditions for 3x3 CDA.

3. Once real-time ECU interfacing is resolved, validate steady state maps developed on the FTP and CARB LLC with an operational SCR system. 


\section{References}

Agrawal, A. K., Singh, S. K., Sinha, S., \& Shukla, M. K. (2004). Effect of EGR on the exhaust gas temperature and exhaust opacity in compression ignition engines. Sadhana - Academy Proceedings in Engineering Sciences, 29(3), 275-284. https://doi.org/10.1007/BF02703777

Air-fuel ratio, lambda and engine performance. (2018). 1. https://x-engineer.org/automotiveengineering/internal-combustion-engines/performance/air-fuel-ratio-lambda-engineperformance/

Alternative Fuels Data Center. (2021). Fuel Properties Comparison. https://afdc.energy.gov/files/u/publication/fuel_comparison_chart.pdf

Baltrucki, J., Gron Jr, G. M., Audibert, K., \& Fuchs, N. (2017). Lost Motion Valve Actuation Systems with Locking Elements Including Wedge Locking Elements (Patent No. US 9 , 790 , 824 B2).

Boriboonsomsin, K., Durbin, T., Scora, G., Johnson, K., Sandez, D., Vu, A., Jiang, Y., Burnette, A., Yoon, S., Collins, J., Dai, Z., Fulper, C., Kishan, S., Sabisch, M., \& Jackson, D. (2018). Realworld exhaust temperature profiles of on-road heavy-duty diesel vehicles equipped with selective catalytic reduction. Science of the Total Environment, 634, 909-921. https://doi.org/10.1016/j.scitotenv.2018.03.362

California Air Resources Board. (2019). Staff White Paper. https://ww3.arb.ca.gov/msprog/hdlownox/white_paper_04182019a.pdf

Cavataio, G., Girard, J., Patterson, J. E., Montreuil, C., Cheng, Y., \& Lambert, C. K. (2007). Laboratory testing of urea-SCR formulations to meet tier 2 bin 5 emissions. SAE Technical Papers. https://doi.org/10.4271/2007-01-1575

Cummins Inc. (2017). X15 Efficiency Series (2017). https://www.cummins.com/engines/x15efficiency-series-2017

Emission Standards; GHG Emissions \& Fuel Economy. (2021). https://dieselnet.com/standards/us/fe_ghg.php\#: :text=The EPA GHG standards were,before CAFE credits and flexibilities)

Emission Test Cycle; Low Laod Cycle (LLC). (2021). https://dieselnet.com/standards/cycles/llc.php

Emission Test Cycles; Heavy-Duty FTP Transient Cycle. (2021). https://dieselnet.com/standards/cycles/ftp_trans.php\#: :text=The FTP (Federal Test Procedure,UDDS chassis dynamometer driving cycle

Enviromental and Energy Study Institute. (2015). Fact Sheet / Vehicle Efficiency and Emissions Standards. https://www.eesi.org/papers/view/fact-sheet-vehicle-efficiency-andemissions-standards

Farrell, L., Frazier, T., Younkins, M., \& Fuerst, J. (2020). Diesel Dynamic Skip Fire ( dDSF ${ }^{T M}$ ) 


\section{Simultaneous CO 2 and NO x Reduction.}

Folkson, R. (2014). Alternative fuels and advanced vehicle technologies for improved environmental performance: Towards zero carbon transportation. In Alternative Fuels and Advanced Vehicle Technologies for Improved Environmental Performance: Towards Zero Carbon Transportation. Woodhead Publishing. https://doi.org/10.1533/9780857097422

Harris, T. (2020). Simulation of Aftertreatment Thermal Management Strategies for Low-Load Operation. SAE Technical Papers, 2020-April(April), 1-12. https://doi.org/10.4271/202001-0359

Heroy-Rogalski, K., Lemieux, S., \& Wang, L. (2019). Low Load Cycle Development.

Jääskeläinen, H. (2020). Cylinder Deactivation for Diesel Engines. https://dieselnet.com/tech/engine_thermal-management_cda.php

Jääskeläinen, H., \& Majewski, W. A. (2018). Heavy - Duty Diesel Engines with Aftertreatment. https://dieselnet.com/tech/engine_heavy-duty_aftertreatment.php

Körfer, T., Busch, H., Kolbeck, A., Severin, C., Schnorbus, T., \& Honardar, S. (2012). Advanced thermal management for modern diesel engines-optimized synergy between engine hardware and software intelligence. Proceedings of the Spring Technical Conference of the ASME Internal Combustion Engine Division, 415-430. https://doi.org/10.1115/ICES201281003

Leone, T. G., \& Pozar, M. (2001). Fuel economy benefit of cylinder deactivation-sensitivity to vehicle application and operating constraints. SAE Technical Papers, 724. https://doi.org/10.4271/2001-01-3591

Lu, X., Ding, C., Ramesh, A. K., Shaver, G. M., Holloway, E., McCarthy, J., Ruth, M., Koeberlein, E., \& Nielsen, D. (2015). Impact of Cylinder Deactivation on Active Diesel Particulate Filter Regeneration at Highway Cruise Conditions. Frontiers in Mechanical Engineering, 1(August), 1-8. https://doi.org/10.3389/fmech.2015.00009

Magee, M. E. (2014). Exhaust Thermal Management Using Cylinder Deactivation and Late Intake Valve Closing.60. https://docs.lib.purdue.edu/open_access_theses/214/

Manufacturers of Emission Controls Association. (2020). Technology Feasibility for Heavy-Duty Diesel Trucks in Achieving 90\% Lower NOx Standards in 2027 (Issue X). http://www.meca.org/resources/MECA_2027_Low_NOx_White_Paper_FINAL.pdf

Matheaus, A., Singh, J., Sanchez, L., Evans, D., \& Janak, R. (2020). Evaluation of Cylinder Deactivation on a Class 8 Truck over Light Load Cycles. SAE Technical Papers, 2020April(April), 1-14. https://doi.org/10.4271/2020-01-0800

Morris, A., \& McCarthy, J. (2020). The Effect of Heavy-Duty Diesel Cylinder Deactivation on Exhaust Temperature, Fuel Consumption, and Turbocharger Performance up to 3 bar BMEP. SAE Technical Papers, 2020-April(April), 1-16. https://doi.org/10.4271/2020-011407 
Office of the Federal Register, N. A. and R. A. (2011). Federal Register Volume 76, Issue 179.

Pondicherry, R. (2020). Development of an Activity-based Windowing Approach to Evaluate Real-World NOx Emissions from Modern Medium and Heavy-Duty Diesel Trucks [West Virginia University]. In West Virginia University.

https://researchrepository.wvu.edu/etd/7682

Purdy, E. R. (2014). Energy Policy and Conservation Act of 1975. Encyclopedia of Transportation: Social Science and Policy. https://doi.org/10.4135/9781483346526.n190

Roberts, L. E. (2014). Analysis of the Impact of Early Exhaust Valve Opening and Cylinder Deactivation on Aftertreatment Thermal Management and Efficiency for Compression Ignition Engines. Purdue University.

Southwest Research Institute. (2019). SwRI'S New Low-Load Cycle Targets Heavy-Duty Diesel Engine Emissions. https://www.swri.org/press-release/low-load-cycle-llc-heavy-dutydiesel-engine-emissions

Thiruvengadam, A. (2018). MAE 525 Heavy Duty Emissions.

Thiruvengadam, A., Pradhan, S., Thiruvengadam, P., Padmanaban, V., Besch, M., Delgado, O., \& Lutsey, N. (2020). Characterization of Energy Distribution and Efficiency in a Modern Heavy-Duty Diesel Engine. SAE International Journal of Engines, 13(4). https://doi.org/10.4271/03-13-04-0037

U.S. Environmental Protection Agency. (2021). Timeline of Major Accomplishments in Transportation, Air Pollution, and Climate Change / Transportation, Air Pollution, and Climate Change / US EPA. https://www.epa.gov/transportation-air-pollution-and-climatechange/timeline-major-accomplishments-transportation-air\#1970

United States Enviromental Protection Agency. (2013a). Code of Federal Regulations, Title 40 Part 1065.645-670.

United States Enviromental Protection Agency. (2013b). Code of Federal Regulations, Title 40 Part 86.007-11.

United States Environmental Protection Agency. (1979). Health and Environmental Effects of Particulate Pollutants. Fine Particulate Pollution. https://doi.org/10.1016/b978-0-08023399-4.50008-9

United States Environmental Protection Agency. (1990). 1990 Clean Air Act Overview. United States Environmental Protection Agency. https://www.epa.gov/clean-air-actoverview/1990-clean-air-act-amendment-summary

United States Environmental Protection Agency. (2013a). Code of Federal Regulations, Title 40, Part 1065.530.

United States Environmental Protection Agency. (2013b). Code of Federal Regulations, Title 40, Part 86.1333-2010. 
United States Environmental Protection Agency. (2013c). Code of Federal Regulations, Title 40 Part 86.1342-90. 


\section{Appendix A: Steady State Results}

Table 1: 800 RPM Steady State Data

\begin{tabular}{|c|c|c|c|c|c|c|c|c|}
\hline & \multicolumn{4}{|c|}{$10 \%$ Rated Torque } & \multicolumn{4}{c|}{ 20\% Rated Torque } \\
\cline { 2 - 9 } & Baseline & Modified & CDA FN & CDA FE & Baseline & Modified & CDA FN & CDA FE \\
\hline TOT $\left({ }^{\circ} \mathrm{C}\right)$ & 193 & 220 & 296 & 248 & 248 & 275 & 365 & 359 \\
\hline SCR Inlet $\left({ }^{\circ} \mathrm{C}\right)$ & 147 & 165 & 170 & 163 & 194 & 210 & 229 & 228 \\
\hline Normalized Fueling & 1 & 1.030 & 0.952 & 0.893 & 1 & 1.039 & 1.004 & 0.984 \\
\hline Normalized BTE & 1 & 1.028 & 1.155 & 1.121 & 1 & 0.947 & 0.949 & 0.945 \\
\hline AFR & 37.1 & 49.8 & 23.2 & 30.0 & 36.7 & 37.2 & 23.6 & 19.9 \\
\hline bsNOx (g/bhp-hr) & 1.44 & 6.98 & 1.39 & 9.24 & 2.85 & 4.62 & 7.53 & 8.66 \\
\hline $\begin{array}{c}\text { Exhaust Flowrate } \\
\text { (kg/hr) }\end{array}$ & 258.0 & 372.0 & 155.6 & 180.7 & 377.0 & 379.0 & 252.0 & 206.0 \\
\hline SCR In Energy (kW) & 30.6 & 46.2 & 19.6 & 22.3 & 50.1 & 52.3 & 36.2 & 29.5 \\
\hline TOT Energy (kW) & 34.2 & 52.4 & 25.7 & 27.1 & 56.5 & 60.0 & 47.4 & 38.3 \\
\hline TOT Eng. / Fuel Eng. & 0.478 & 0.711 & 0.377 & 0.424 & 0.518 & 0.530 & 0.433 & 0.357 \\
\hline SCRIn Eng. / Fuel Eng. & 0.428 & 0.627 & 0.287 & 0.349 & 0.460 & 0.461 & 0.331 & 0.275 \\
\hline
\end{tabular}

Table 2: 1000 RPM Steady State Data

\begin{tabular}{|c|c|c|c|c|c|c|c|c|}
\hline & \multicolumn{4}{|c|}{$10 \%$ Rated Torque } & \multicolumn{4}{c|}{$20 \%$ Rated Torque } \\
\cline { 2 - 9 } & Baseline & Modified & CDA FN & CDA FE & Baseline & Modified & CDA FN & CDA FE \\
\hline TOT ( ${ }^{\circ} \mathrm{C}$ ) & 209 & 221 & 292 & 253 & 245 & 272 & 357 & 346 \\
\hline SCR Inlet ( $\left.{ }^{\circ} \mathrm{C}\right)$ & 155 & 172 & 188 & 173 & 193 & 210 & 233 & 228 \\
\hline Normalized Fueling & 1 & 1.044 & 0.958 & 0.897 & 1 & 1.033 & 0.975 & 0.967 \\
\hline Normalized BTE & 1 & 0.983 & 1.052 & 1.079 & 1 & 0.953 & 0.954 & 0.962 \\
\hline AFR & 39.3 & 46.6 & 29.7 & 32.5 & 32.5 & 39.8 & 22.4 & 24.1 \\
\hline bsNOx (g/bhp-hr) & 1.82 & 7.81 & 4.07 & 7.69 & 2.04 & 5.50 & 6.24 & 8.58 \\
\hline $\begin{array}{c}\text { Exhaust Flowrate } \\
\text { (kg/hr) }\end{array}$ & 360.0 & 424.0 & 269.0 & 244.0 & 426.0 & 521.0 & 290.4 & 305.5 \\
\hline SCR In Energy (kW) & 43.6 & 53.5 & 35.3 & 30.9 & 56.5 & 71.8 & 42.1 & 43.8 \\
\hline TOT Energy (kW) & 49.5 & 59.9 & 44.1 & 36.9 & 63.4 & 82.0 & 53.8 & 55.5 \\
\hline TOT Eng. / Fuel Eng. & 0.571 & 0.662 & 0.530 & 0.475 & 0.488 & 0.611 & 0.424 & 0.441 \\
\hline SCRIn Eng. / Fuel Eng. & 0.503 & 0.591 & 0.425 & 0.397 & 0.435 & 0.535 & 0.332 & 0.349 \\
\hline
\end{tabular}


Table 3: 1200 RPM Steady State Data

\begin{tabular}{|c|c|c|c|c|c|c|c|c|}
\hline & \multicolumn{4}{|c|}{$10 \%$ Rated Torque } & \multicolumn{5}{c|}{ 20\% Rated Torque } \\
\cline { 2 - 10 } & Baseline & Modified & CDA FN & CDA FE & Baseline & Modified & CDA FN & CDA FE \\
\hline TOT $\left({ }^{\circ} \mathrm{C}\right)$ & 185 & 215 & 291 & 262 & 236 & 276 & 353 & 352 \\
\hline SCR Inlet $\left({ }^{\circ} \mathrm{C}\right)$ & 156 & 176 & 204 & 186 & 195 & 221 & 246 & 243 \\
\hline Normalized Fueling & 1 & 1.040 & 0.990 & 0.945 & 1 & 1.039 & 1.008 & 0.988 \\
\hline Normalized BTE & 1 & 0.910 & 1.002 & 1.015 & 1 & 0.929 & 0.925 & 0.916 \\
\hline AFR & 59.9 & 60.3 & 33.2 & 33.6 & 36.9 & 39.3 & 24.5 & 24.7 \\
\hline bsNOx (g/bhp-hr) & 6.67 & 6.44 & 4.67 & 7.10 & 3.89 & 7.19 & 7.12 & 5.77 \\
\hline $\begin{array}{c}\text { Exhaust Flowrate } \\
\text { (kg/hr) }\end{array}$ & 659.0 & 642.0 & 338.0 & 310.5 & 584.0 & 652.0 & 388.0 & 381.0 \\
\hline SCR In Energy (kW) & 80.0 & 81.9 & 46.0 & 40.5 & 77.8 & 92.1 & 57.8 & 56.4 \\
\hline TOT Energy (kW) & 85.8 & 89.5 & 55.3 & 47.9 & 85.2 & 103.5 & 71.3 & 69.9 \\
\hline TOT Eng. / Fuel Eng. & 0.852 & 0.854 & 0.555 & 0.503 & 0.542 & 0.634 & 0.450 & 0.450 \\
\hline SCRIn Eng. / Fuel Eng. & 0.794 & 0.781 & 0.461 & 0.426 & 0.495 & 0.564 & 0.365 & 0.364 \\
\hline
\end{tabular}


Appendix B: Motoring Occurrences During Transient Cycles

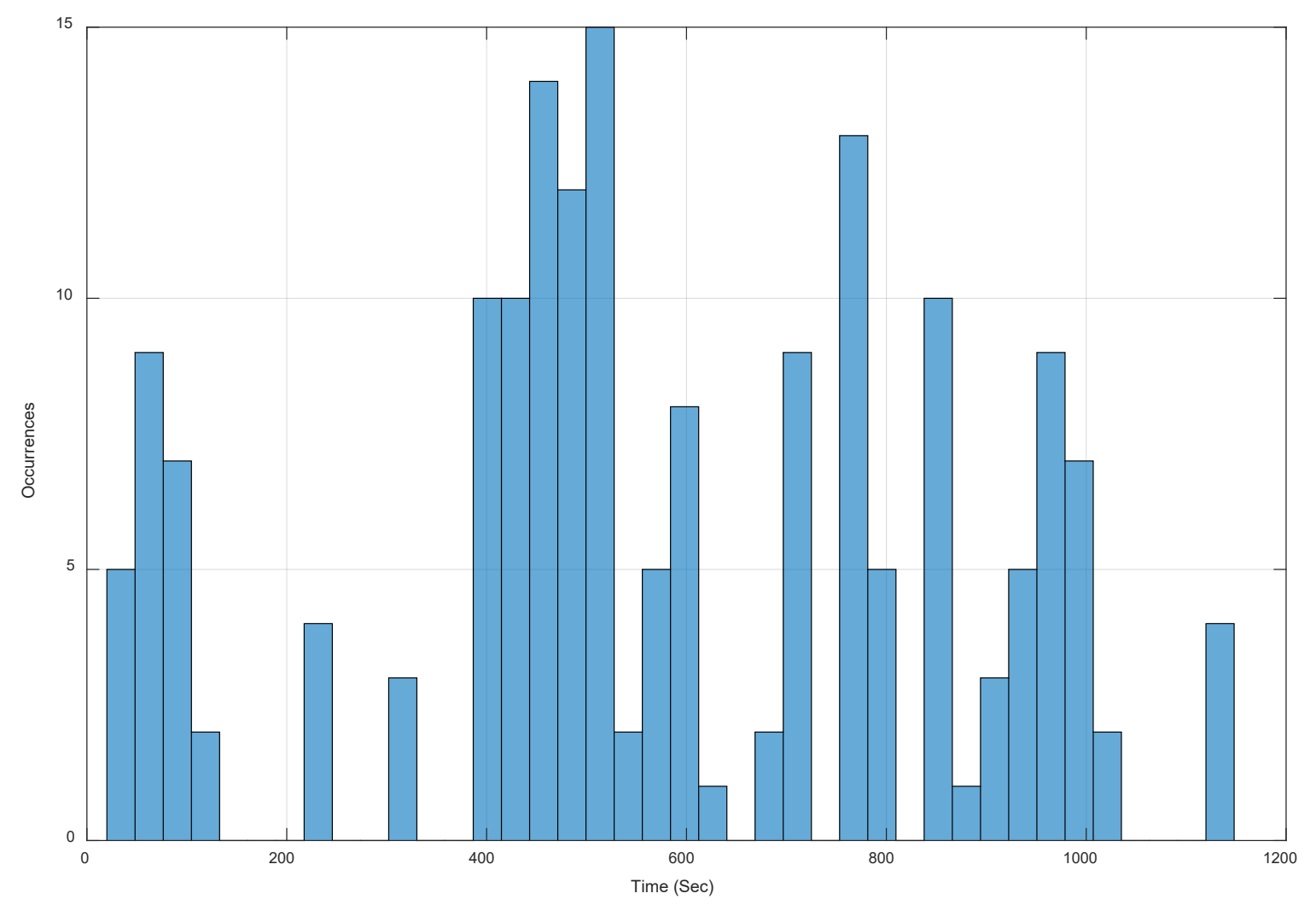

Figure 29: Histogram of FTP Motoring Events 


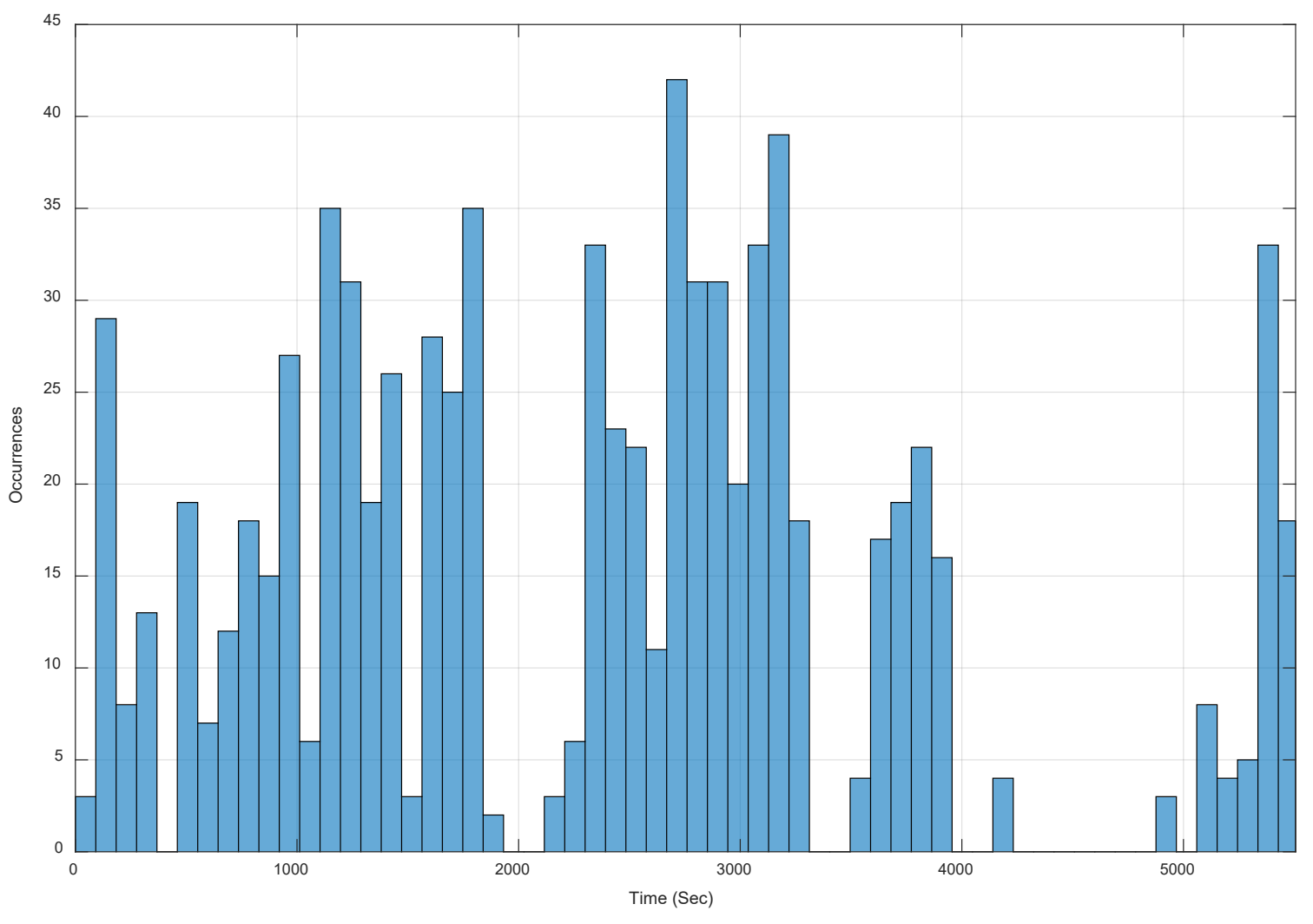

Figure 30: Histogram of LLC Motoring Events 